CONSTRUCTION OF A THERMAL DEMAGNETIZATION

OVEN, AND INVESTIGATIONS ON

THE MATAHINA IGNIMBRITE

by

RAYMOND ATTAN HOARE

SUBMITMED FOR THE DEGREE OF

MASTER OF SCIENCE

IN PHYSICS

AT VICTORIA UNIVERSITY OF WELIINGTON

NEW ZEAIAND

AUGUST, 1964 
ABSTRACT

A non-magnetic oven, and its ancillary equipment have been constructed and used to study magnetic properties of the Natahina ignimbrite, for which the following results have been established:

1. The directions of magnetization do not alter on heating in the oven.

2. The ignimbrite may be divided into sheets on the basis of magnetic properties.

3. Geological faulting has been revealed by divergent magnetization directions.

4. The T.R.M. acquired in the present earth's field is much greater than the N.R.M. This is possibly due to changes in minerals in the rock, either in the field since the rock was deposited, or on heating in the laborstory. 
CHAPTER 1 INTRODUCTION

CHAPTER 2 MAGNETIZATION OF ROCKS

2.1 SOURCE OF MAGNETISM 4

2.2 MAGNETIC MINERALS 5

$2.2 .1 \quad 5$

2.2.2 Magnetite-Ulvospinel Series 6

2.2.3 Hematite - Ilmenite Series 6

2.2.4 Pyrrhotite 7

$\begin{array}{ll}2.2 .5 & 7\end{array}$

2.3 THERMOREMANENT MAGNETIZATION 7

2.3.1 Definition $\quad 7$

2.3.2 Partial T.R.M. 8

2.3.3 The Addition Law of P.T.R.M. 8

2.3.4 Time Dependence of T.R.M. 10

$\begin{array}{lll}\text { CHAPTER } 3 & \text { THEORY OF ROCK MAGNETISM } & 11\end{array}$

3.1 DOMAINS

3.2 SINGLE DOMAIN GRAIN THEORY 12

3.2.1 Hysteresis of a Single Domain Grain 12

3.2.2 T.R.M. and Isothermal Remanent Magnetization 13

3.2.3 Blocking Temperature 14

3.2.4 Comparison with Experiment 16

$\begin{array}{ll}3.3 & 17\end{array}$

3.3.1 General Principles of Multidomain Theory 17

3.3.2 Magnetic Viscosity 18

3.3.3 Temperature and Viscous Nagnetization 21 
4.1 ALTERNATING FIEID DEMAGNETIZATION

4.2 THERMAL DEMAGNETIZATION

4.3 COMPARISON OF ALTERNATING FIELD AND THERMAL DEMAGNETIZATION

CHAPTER 5 DESIGN AND CONSTRUCTION OF AN OVEN FOR THERMAI DEMAGNETIZATION

5.1 INTRODUCTION

5.2 GENERAT DESCRIPTION OF OVEN 30

5.3 SIZE OF OVEN

5.4 HEATING ELEMENT

$\begin{array}{lll}5.5 & 3\end{array}$

5.6 SAMPIE HOIDER

5.7 INERT ATMOSPHERE

5.8 POWER SUPPLY

5.9 TEMPERATURE MEASUREMENT 36

5.10 UNIFORMITY OF TEMPERATURES IN OVEN 37

CHAPTER $6 \quad$ FIEID CANCETIATION COILS

6.1 GENERAI 43

6.2 FIETD OF PARRY COII SET 44

6.2.1 Introduction 44

6.2.2 Parry Spacing 44

6.2.3 Field at off-Centre Points 45

6.2.4 Effect of Construction Accuracy 47 
$\begin{array}{lll}\text { CHAPTER } & 6.3 \text { CONSTRUCTION OF COIIS } & 49\end{array}$

6.4 THE EAST-WEST CONPONENT COILS 50

6.5 INSTALIATION OF THE COIIS 50

6.6 FIELD CANCELIAATION PROCEDURE 52

6.6.1 Fluxgate Nagnetometer 52

6.6.2 Alignment of Coil Axes 53

6.6.3 Cancellation 54

$\begin{array}{lll}\text { CHAPTER } 7 & \text { CONSTANT CURRENT POWER SUPPLY } & 57\end{array}$

$\begin{array}{lll}7.1 & \text { SPECIFICATIONS } & 57\end{array}$

$\begin{array}{lll}7.2 & \text { SIMPLE REGULATOR }\end{array}$

7.3 SATISFACTORY REGULATOR 59

7.3.1 Basic Circuit 59

7.3.2 Temperature Regulation 59

7.3.3 Final Design 61

7.4 TESTING AND MODIFICATION OT REGULATOR 62

7.4.1 Effect of Load Changes 62

7.4.2 Ambient Temperature Effects 62

7.4.3 Supply Voltage Variation 65

7,5 IOAD IMPEDANCE RESTRICTIONS 65

7.5.1 Open Circuit Conditions 65

7.5.2 Short Circlit 66

$\begin{array}{lll}7.6 & 67\end{array}$

$\begin{array}{lll}7.7 & \text { FINAL CIRCUIT } & 67\end{array}$

$\begin{array}{lll}\text { CHAPTIR } 8 & \text { THE MAGNETOMETER } & 75\end{array}$

8.1 GENERAI DESCRIPTION

$\begin{array}{lll}\text { 8.2 CENTRING AND LEVELLING } & 76\end{array}$ 
$\underline{\text { Page }}$

CHAPTER 8.3 CANCEITATION OF EARTH'S MAGNETIC FIEID 78

$\begin{array}{lll}\text { CHAPTER } 9 & \text { IGNIMBRITIS } & 81\end{array}$

9.1 GENERAI GEOLOGICAT DESCRIPTION 81

9.2 PREVIOUS PALAEOMAGNETIC WORK 82

9.3 THE MATAHINA IGNIMBRITE 84

CHAPTER 10 SOME MAGNETIC PROPERTIES OF THE

MATAHINA IGNIMBRITE 86

10.1 SAMPLE COLLECPION 86

10.1.1 Collection Iocality 86

10.1.2 Sample Altitudes 87

10.1.3 Orientation Method 88

10.1.4 Preparation of Specimens 89

10.2 DENSITY OF SPECIMENS 89

10.3 NATURAI REMANENT MAGNETIZATION 90

10.3.1 Notation 90

10.3.2 Measurements of Direction 91

10.3.3 Intensity \& Susceptibility of N.R.M. 92

10.4 THERNAL DEVAGNETIZATION OF N.R.M. 92

10.4.1 Choice of Specimens for Trial
Denagnetization

10.4.2 Heating and Measuring Procedure 93

10.4.3 Changes in Direction of Magnetization 93

10.4.4 Changes in Intensity 93

10.4.5 Changes in Susceptibility 95

10.5 THERMAT DEMAGNETIZATION OF T.R.M. 96

10.6 COMPARISON OF N.R.M. and T.R.M. 96 
$\underline{\text { Page }}$

CHAPTER 10.7 THERMAI WASHING AT $300^{\circ} \mathrm{C}$.

10.7.1 Experimental 96

10.7.2 Changes in Direction 97

10.7.3 Changes in Intensity of Magnetization 97

10.8 EFFECT OF EARTH'S MAGNETIC FIELD AT ZLEVATED TEMPERATURES 98

10.9 DECAY OF T.R.M. WITH TINE 98

10.10 T.R.M. OF ALI SPECIMENS 99

$\begin{array}{lll}\text { CHAPTER } 11 \text { SIGNIFICANCE OF EXPERIMENTAL RESULTS } & 130\end{array}$

11.1 DIRECTION OF N.R.M. 130

11.2 VARIATION WITH ALTITUDE OF WAGNETIC
PROPERTIES OF THE IGNIMBRITI

11.2.1 Change in Magnetization Intensity After Heating to $300^{\circ} \mathrm{C}$. 132

11.2.2 Changes in $\frac{M}{\chi}$ ) N.R.M. 134

11.3 SIGNIFICANCE OF THE VALUES OF $\frac{\mathrm{M}_{\mathrm{TRM}}}{\mathrm{M}_{\mathrm{NRN}}} \quad 134$

11.4 POSSIBIT CHANGES IN THE MAGNETIC MINERAIS

APPENDIX I MAGNETOMETER CORRECTION FACTOR FOR CYLINDRICAI SAMPLES 141

APPENDIX II CALCULATION OF SAMPLE MAGMETIZATION 152

APPENDIX III USE OF A STEREOGRAM TO TRRANSFORM COORDINATES $\quad 158$

REFERENCES 160 
CHAPTER ONE

I N T RO D U C T I O N

It has been known for a long time ( $R$. Chevallier, 1925) that igneous rocks may become strongly magnetized in the direction of the weak magnetic field in which they cool. The remanent magnetization they acquire in this way is from a lew to a hundred times as great as the magnetization induced at normal temperatures by the same field. It has also been demonstrated (Thellier \& Thellier, 1959, Graham, 1949, Shimizu, 1960) that such magnetization can be stable over very long periods of time in fields which are in different directions from the remanent magnetization. These facts form the basis of the study of palaeomagnetism, which tries to determine the variation in the earth's magnetic field during geological time by studies on the present magnetization of rocks.

It has been shown (J. Graham, 1953, Brynjolfsson, 1957) that the magnetization of some rocks may differ from their original direction of magnetization. Often the difference is due to the presence of two components of magnetization - a "hard" component residing in grains having high coercive force, and hence being resistant to changes in direction, and a "soft" component residing in grains of lower coercive force, which easily take up new directions of magnetization. The techniques of alternating field demagnetization and thermal washing rely on the removal of soft components by randomizing their directions, either by a steadily decreasing randomly changing alternating 
magnetic field, or by moderate heating followed by cooling in zero magnetic field, or a simultaneous combination of both (As \& Zijderveld, 1958, Irving, Stott \& Ward 1961, Irving, Robertson, Stott, Tarling \& Ward, 1961).

When the original magnetization of an unstably magnetized rock is not parallel to the present earth's field, it is usually found that with treatment at successively higher peak fields or temperatures, the direction of magnetization rotates away from its original direction towards a new one. If the direction reaches a constant direction which is then maintained until the sample is completely demagnetized, it is usually assumed that this final direction is that of the field which originally magnetized the rock.

The purpose of this thesis is to describe the construction and use of a furnace in which thermal demagnetization experiments may be carried out.

It is not proposed to discuss the results of the large amount of work on palaeomagnetism which has been done. A good review article has been written by Cox \& Doell (1960).

The theory of thermoremanent magnetization (T.R.M.) will be discussed in some detail, because of its relevance to some stability tests which have been devised, and its use in interpreting the results of demagnetization studies.

The design of apparatus is discussed in the main body of the thesis, while detailed instructions on its use are included as appendices.

To illustrate the purpose of the oven, a set of samples from an ignimbrite sheet has been investigated, and conclusions regarding 
the structure of the sheet, and past behaviour of the earth's magnetic field have been drawn. 
MAGNETIZATION OF ROCKS

\subsection{SOURCE OF MAGNETISM}

The remanent magnetization of rocks resides in certain ferromagnetic minerals which usually occupy a small eraction (up to, but usually much less than, 10\%) of the volume of the rock. These minerals are spontaneously magnetized at all temperatures below their Curie points, by the mutual alignment of the magnetic moments of the iron atoms in their crystal lattice. In the absence of an extermal field this alignment is along one of several "easy" directions within the lattice, which correspond to a local minimum in the graph of energy of the crystal versus magnetization direction. According to Weiss' theory of ferromagnetism, it is possible for several domains to form within a crystal, in each of which the magnetization is uniform and equal in intensity to the spontaneous magnetization, $\sigma$ per unit volume, the directions in each domain being such that they form closed or partly closed magnetic paths, and reduce the self-demagnetizing field of the crystal.

The spontaneous magnetization generally decreases with increasing temperature, in a manner which depends on the particular mineral, and reaches zero at a temperature called the Curie temperature. Above this temperature the minerals are paramagnetic. 
It is found that increasing an applied magnetic field increases the induced magnetic moment, until above a certain field no further increase is observed. This is explained by supposing that below this maximum field not all of the spontaneous moments are aligned with the applied field, so that an increased field will cause alignment of further domains, and increase the magnetic moment. The maximum moment (per unit volume) which may be induced is called the saturation magnetic moment, $J_{\mathrm{S}}$. If $\mathrm{J}_{\mathrm{S}}$ refers to a pure magnetic mineral, it is clear that $\mathrm{J}_{\mathbf{s}}=\sigma$. If $\mathrm{J}_{\mathrm{s}}$ refers to a rock, then it will be lower than $\sigma$ because the magnetic fraction is only a small part of the volume of the rock. When studies are made of the variation in $\sigma$ with temperature, it is usually $\mathrm{J}_{\mathrm{S}}$ which is measured, and the shape of the graph of $\mathrm{J}_{\mathrm{S}}$ versus temperature is the same as the shape of the $\sigma-T$ graph. Other magnetic properties of a rock depend greatly on the size and shape of the crystals of magnetic minerals, and will be referred to later.

\subsection{MAGNETIC MINERALS}

2.2.1 Detailed studies of the minerals involved in rock magnetism have been described by Akimoto (1955) and Nicholls (1955), while a large amount of work has been summarised by Nagata (1953).

Although there are only three common types of ferromagnetic minerals, and all contain iron, the situation is complicated by the various solid solution series and compositional changes which occur. 


\subsubsection{Magnetite-ulvospinel Series (Titanomagnetites)}

Magnetite $\left(\mathrm{Fe}_{3} \mathrm{O}_{4}\right)$ is the most important mineral in rock magnetism. It is a typical ferrimagnetic, and its crystal has the inverse spinel structure. It has a saturation magnetization of $92-93 \mathrm{e.m.u./gram} \mathrm{at} \mathrm{room}$ temperature, and a Curie point of about $578^{\circ} \mathrm{C}$. It is completely mutually soluble with ulvospinel ( $\left.\mathrm{TiFe}_{2} \mathrm{O}_{4}\right)$ which is not ferromagnetic. The solid solutions have Curie points which range continuously from $578^{\circ} \mathrm{C}$ to $0^{\circ} \mathrm{K}$, depending on the proportion of magnetite present.

\subsubsection{Hematite-ilmenite Series}

Hematite $\left(\mathrm{Fe}_{2} \mathrm{O}_{3}\right)$ is thought to be anti-ferromagnetic, but some workers have reported a "parasitic" ferromagnetism (Stacey 1963). It has a rhombohedral crystal structure and a low saturation magnetization (Jsabout .5 e.m.u./gram), but a high coercive force, so that it is generally stably magnetized.

$\mathrm{Fe}_{2} \mathrm{O}_{3}$ occurs also as a cubic form, maghemite $\left(\gamma \mathrm{Fe}_{2} \mathrm{O}_{3}\right)$, with the inverse spinel structure very similar to magnetite $\left(\gamma_{\mathrm{Fe}_{2} \mathrm{O}_{3}}\right.$ has a lattice defect, compared with $\left.\mathrm{Fe}_{3} \mathrm{O}_{4}\right)$. Maghemite is unstable, reverting to hematite at a temperature ranging from 300 to $800^{\circ} \mathrm{C}$, depending to some extent on impurities (especially aluminium). Its saturation magnetization is 83.5 e.m.u./gm and its Curie temperature, obtained indirectly, is $675^{\circ} \mathrm{C}$.

Hematite dissolves to a limited extent in Ilmenite ( $\mathrm{TiFeO}_{3}$ ), giving rise to ferrimagnetic mixtures at certain concentrations. Some of these solutions show the phenomenen of self-reversal of 
magnetization, that is, they become magnetized in a direction opposite to the applied field, when cooled in a field from above their Curie point.

2.2.4 Pyrrhotite $\left(F^{2} S_{1+x}\right)(x<1)$

For some values of $x$ the minerals in this series are ferrimagnetic, having a hexagonal structure. They have a fairly strong $J_{S}$ of 15 e.m.u./gm, and a Curie temperature of about $300-325^{\circ} \mathrm{C}$. They seem to be stable to thermal treatment, but in view of their low coercive force and usually metamorphic origin, should be treated with some caution. Kang (1962) has studied the usefulness of these minerals to papaeomagnetism.

2.2.5 It will usually be assumed in general discussions that the minerals have properties similar to magnetite, with possible variation in being caused by the solution of $\mathrm{TiFe}_{2} \mathrm{O}_{4}$.

\subsection{THERMOREMANENT MAGNETIZATION}

\subsubsection{Definition}

When a rock is heated above the Curie point, $\theta$, of its magnetic minerals and allowed to cool in a weak magnetic field, H, (about 1 oe.), it becomes magnetized parallel to the field, with an intensity, $J_{\theta, H}$, which is usually much greater than the magnetization induced at constant temperature. That is

$$
Q_{\theta}=\frac{J_{\theta, H}}{X_{H}}>1
$$

The ratio, $Q$, is a useful parameter to describe magnetizations. 
$Q_{\theta}$ indicates the $Q$ ratio of a T.R.M. $Q_{n}$ will later be used to specify the ratio of the natural remanent magnetization (N.R.M.), (that is the magnetization before the rock is treated in any way), to the product of susceptibility and the earth's field.

\subsubsection{Partial T.R.M.}

The volume intensity of magnetization acquired in cooling from a temperature $\mathrm{T}$, to room temperature, in a field $\mathrm{H}$, is noted by

$$
\mathrm{J}_{\mathrm{T}, \mathrm{H}} \text {. }
$$

If the magnetic field, $\mathrm{H}$, is only applied between temperatures $\mathrm{T}_{1} \& \mathrm{~T}_{2}, \mathrm{~T}_{1}>\mathrm{T}_{2}$, the rock acquires a partial T.R.M., denoted by

$$
\mathrm{J}_{\mathrm{T}_{2}, \mathrm{H}}^{\mathrm{T}_{1}}
$$

In general $J_{\mathrm{T}, \mathrm{H}}$ increases with $\mathrm{T}$ increasing, slowly at first, then rapidly over a range of temperatures from $200^{\circ} \mathrm{C}$. below, up to the Curie temperature, above which $J_{T, H}$ is constant at a value called the total T.R.M., and denoted by $J_{\theta}, \mathrm{H}$. It is found that in fields less than $10 \mathrm{oe}, \mathrm{J}_{\mathrm{T}, \mathrm{H}}$ is proportional to $\mathrm{H}$, and over a wider range of fields

$$
\mathrm{J}_{\mathrm{T}, \mathrm{H}}=\frac{\mathrm{J}_{\mathrm{T}, 1}}{\mathrm{k}} \tanh \mathrm{kH}
$$

\subsubsection{The Addition Law of P.T.R.M.}

If a rock is given a set of partial thermoremanences in a constant weak field, between, say, the temperatures $\mathrm{T}_{1} \& \mathrm{~T}_{2}$, $\mathrm{T}_{2} \& \mathrm{~T}_{3}, \mathrm{~T}_{3} \& \mathrm{~T}_{4} \ldots \ldots . \mathrm{T}_{\mathrm{n}-1} \& \mathrm{~T}_{\mathrm{n}} ; \mathrm{T}_{\mathrm{n}}>\mathrm{T}_{\mathrm{n}-1}>\ldots . .>\mathrm{T}_{1}$, then it is found that

$$
\sum_{i=2}^{n} \frac{J_{T_{i}, H}}{T_{i}, H}=J_{T_{n}, H}^{T_{1}}
$$


That is, the total T.R.M. between any two temperatures is the sum of any complete set of P.T.R.M.'s between these temperatures. If this is assumed to hold for very small temperature intervals, then we may define a characteristic function of T.R.M.

$$
P(T)=\operatorname{Iim}_{\Delta T \rightarrow 0} \frac{1}{H} \frac{J_{\text {T, H }}^{T}}{\Delta T}
$$

so that

$$
J_{T, H}=H \int_{0}^{T} P(T) d T
$$

The peak of the graph of $\mathrm{P}(\mathrm{T})$ versus $\mathrm{T}$ corresponds to the maximum rate of acquisition of T.R.M. with temperature change, and usually occurs at a temperature $50-100^{\circ} \mathrm{C}$. below the Curie temperature.

$\mathrm{J}_{\mathrm{T}_{2}}^{\mathrm{T}_{1}}, \mathrm{H}$ depends on the temperature at which it is measured. As long as the temperature does not rise above $\mathrm{T}_{1}, \mathrm{~J}_{\mathrm{T}_{2}, \mathrm{H}}^{\mathrm{T}_{1}}(\mathrm{~T})$ changes reversibly with temperature, corresponding to changes in the spontaneous magnetization of the grains. The additivity law can be expressed by saying that the magnetization acquired in any temperature interval is independent of magnetization acquired at temperatures outside this interval. The explanation for this behaviour is that each grain has a temperature, above which it may alter its direction of magnetization, with the assistance of thermal agitation, but below which it is fixed in direction. The form of the distribution of the so-called "blocking temperatures" determines the shape of the P.T.R.M. versus temperature curve. 
2.3.4 Time Dependence of T.R.M.

It is found that the velocity of cooling has little effect on laboratory measurements of T.R.M. (Nagata, 1953). 


\section{THEORY OF ROCK MAGNETISM}

This chapter summarizes the work on this subject by Néel (1955), Everitt (1961, 162) and Stacey (1963).

\subsection{DOMAINS}

The formation of domains, which reduce the net magnetic moment of a grain of crystalline ferromagnetic material is a way of minimizing the total magnetic energy of the grain. The sources of energy, the sum of which is minimised, are (Stacey, 1963)

i. Exchange energy, which is due to the fundamental interaction between electron spins, and which is minimised when all spins are parallel.

ii. Anisotropy energy, which arises through a weak coupling of the spins to the orbital moments, and hence to the crystal structure, so that there is a minimum in the energy of the atoms when their moments point along certain crystallographic axes, called the "easy" directions.

iii. Wall energy is the energy due to the above two effects when the spin directions are changing with position, as they must in the boundary region between two domains with different magnetization directions. The exchange energy is less in a thick wall, and the anisotropy energy less in a thin one, so there is an optimum wall thickness. 
iv. Magnetostrictive strain energy occurs where adjacent domains have non-parallel directions, e.g. at closure domains.

v. Magnetostatic energy arises when the magnetization produces an external field, and therefore selfdemagnetizing effects, and depends, among other things, on the shape of the grain.

vi. Energy due to an extemal field, the effect of which is usually treated as a perturbation of the structure calculated for zero external field.

\subsection{SINGLE DOMAIN GRAIN THEORY}

\subsubsection{Hysteresis of a Single Domain Grain}

There is a critical size of magnetic grain, below which the energy required to form a wall is greater than the decrease in magnetostatic energy which would occur, so that grains smaller than this consist of a single domain. For magnetite this size is probably about $0.03 \mu$ and certainly less than $1 \mu$, which is much smeller than the observed sizes of grains in rocks, (which are usually larger than $1 \mathrm{e}$ ). Hematite grains have much lower spontaneous magnetization than magnetite, which means their critical size is about $1 \mathrm{~mm}$, so that single domain theory should be appropriate to their magnetization.

Néel (1955) has developed a theory of T.R.M. based on single domains which gives a qualitative picture of the actual behaviour of rocks, and which has served as a basis for more refined models. In single domain grains the magnetization may change in magnitude by changes in $\sigma$ (with temperature), and in direction by rotation of $\sigma$ within the domain, against the anisotropy and self-demagnetizing forces. 
We may suppose the typical grain to be approximately spheroidal with demagnetizing factors $N$ and $M$ along the major and minor axes respectively $(M) N)$. Suppose $\sigma$ makes an

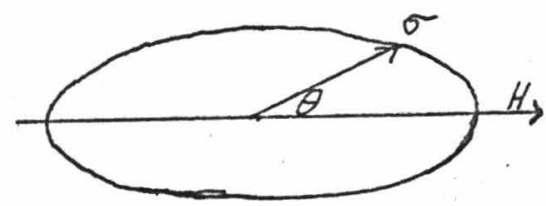
angle $\theta$ with the major axis, and consider the component of external field, $H$, parallel to the major axis. Neglecting magneto-crystalline anisotropy effects, the magnetic potential energy of the grain is $-\mathrm{H} \sigma \cos \theta$, while the demagnetization energy of the grain is $\frac{1}{2} \sigma^{2}\left(N \cos ^{2} \theta+H \operatorname{Hin}^{2} \theta\right)$. The sum of these energies is the total energy, and from the minimum of this total we find (Nagata, 1953, p. 23) that the grain has a rectangular hysteresis loop with coercive force

$$
\mathrm{H}_{\mathrm{C}}=\sigma(\mathrm{M}-\mathrm{N})
$$

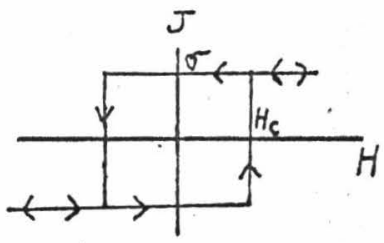

If the field is parallel to the minor axis of an oblate spheroid there is no hysteresis, so no remanent magnetization.

An assembly of randomly oriented grains without interactions will

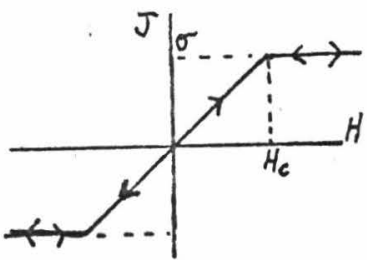
show a smoothed hysteresis curve (Néel, 1955) with remanent magnetization $J_{R}=\frac{1}{2} \sigma$, and coercive force about $\frac{1}{2} \sigma(\mathbb{N}-N)$. This hysteresis makes possible the acquisition of remanent magnetization.

3.2.2 T.R.M. and Isothermal Remanent Magnetization (I.R.M.)

Consider an assemblage of the above grains with coercive forces ranging from zero to a large value $\mathrm{H}_{\mathrm{C}}$. Any isothermal remanent magnetization, which is produced by applying a field 
$\mathrm{H}_{\text {, }}>\mathrm{H}_{\mathrm{c}}$, for a short while, will be due only to the remanence of those grains with coercive force less than $\mathrm{H}$. If the grains are heated, their spontaneous magnetization, and consequently their coercive force, decreases, so that more grains will be aligned parallel to the field, until just below the Curie temperature all grains are magnetized in this direction. On cooling in the field the directions remain parallel to the field while the spontaneous magnetization increases. Grains with axes inclined to the field will obviously contribute a component of their T.R.M. to the final T.R.M.

This gives a reason for the much greater strength and stability of T.R.M. compared with I.R.M., but is obviously oversimplified, and does not explain the dependence of T.R.M. on the magnitude of the applied field.

\subsubsection{Blocking Temperature}

To change from one to the other of its two stable magnetization directions, a single domain grain must cross a potential energy barrier of finite height. The energy of thermal vibrations of the crystal lattice is available to change magnetization directions by means of magnetostrictive and anisotropy effects. In an assemblage of identical noninteracting grains affected by thermal agitation in zero magnetic field, the remanent magnetic moment will decrease exponentially with time, so that

$$
M=\mathbb{M}_{0} \exp \left(-\frac{t}{\tau}\right)
$$

where $\tau$ is the relaxation time.

Neel showed that

$$
\frac{1}{\tau}=C \exp \left(-\frac{E}{k T}\right)
$$


where $\mathrm{E}$ is the height of the potential barrier, and $\mathrm{C}$ is a function of the elastic constants, size, shape and temperature of the grains. Stacey (1963) summarises the various estimates of $\mathrm{C}$, which range from $10^{9}$ to $10^{13} \mathrm{sec}^{-1}$, but the absolute value is not critical. Since $\tau$ is strongly dependent on $\frac{E}{T}$, small increases in temperature will cause large decreases in the time constant, assuming the potential barrier height does not change to compensate (i.e., assuming $\frac{d E}{d T} \ll\left(\frac{E}{T}\right)$. The blocking temperature, $\mathrm{T}_{B}$, is that temperature above which $\tau$ is much less than the duration of laboratory experiments, and below which $\tau$ is much greater than experimental times. This arbitrarily chosen experimental time is denoted by $\tau_{b}$.

At temperatures greater than $\mathrm{T}_{\mathrm{B}}$ and in zero field, the potential barriers may be freely crossed so that the average magnetic moment of the assemblage of grains is zero. The application of a magnetic field at these temperatures induces a magnetization which is found by assuming a Boltzman energy distribution, and a potential barrier voH between direction parallel and antiparallel to the applied field. For an assembly of identical grains the mean magnetization per grain turns out to be, (Néel, 1955),

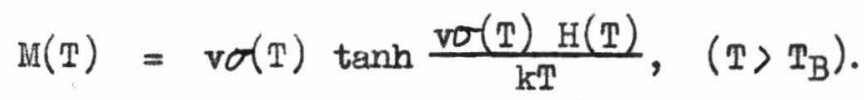

If the assembly of grains is cooled in the field H(T), this equation holds until $\mathrm{T}=\mathrm{T}_{\mathrm{B}}$, below which temperature further crossing of potential barriers of any sort stops, and the only change is in $\sigma$. Thus

$$
M(T)=v \sigma(T) \tanh \frac{v \sigma\left(T_{B}\right) H\left(T_{B}\right)}{k T_{B}}, \quad\left(T<T_{B}\right) .
$$

Thus $\mathbb{M}(\mathrm{T})$ depends on the magnetic field at $\mathrm{T}=\mathrm{T}_{\mathrm{B}}$ and nowhere else. The qualitative properties of T.R.M. are explained 
directly, by assuming a suitable distribution of blocking temperatures of the grains in a rock.

\subsubsection{Comparison With Experiment}

Everitt (1961) has performed a set of combined P.T.R.M. and al ternating field demagnetization experiments on known single domain grains to compare the above results with experiment. His experiments compare coercive force and blocking temperature of grains. From equation 3.2 ,

$$
\tau_{B}=\frac{1}{C} \exp \frac{E}{k T_{B}}
$$

so the blocking temperature depends on barrier height. For single domain grains

so

$$
\begin{aligned}
& \mathrm{E}=\frac{1}{2} \mathrm{v} \sigma \mathrm{H}_{\mathrm{c}} \\
& \mathrm{T}_{\mathrm{B}}=\text { const. } \mathrm{v} \sigma\left(\mathrm{T}_{\mathrm{B}}\right) \mathrm{H}_{\mathrm{C}}\left(\mathrm{T}_{\mathrm{B}}\right)
\end{aligned}
$$

Everitt showed that for hematite grains $\mathrm{T}_{B}$ is proportional to $\mathrm{H}_{\mathrm{c}}$ at room temperature, and also to another factor which could be the grain volume.

Néel (1955) showed that the addition of an external field, $\mathrm{H}$, alters the potential barrier height to

$$
\mathrm{E}=\frac{1}{2} \mathrm{v} \sigma \frac{(\mathrm{Hc} \pm \mathrm{H})^{2}}{\mathrm{H}_{\mathrm{C}}}
$$

so that blocking temperature should depend on the ambient magnetic field, but Everitt's experiments showed this effect to be much smaller than predicted.

Everitt also showed that the intensity of T.R.M. is proportional to tanh aH as predicted from equation 3.4, but the dependence of intensity on the coercive force of the grains was much less than expected from 3.4 and 3.5 . 
This theory appears to give reasonable agreement with experiment, and the deviations from it are probably due to the interactions between grains in experimental samples.

\subsection{MULTI-DOMAIN GRAINS}

\subsubsection{General Principles of Multi-Domain Grain Theory}

Any detailed theory of rock magnetism will attempt to correlate changes in magnetization of minerals with changes in domain structure, which modify the external field of the spontaneous magnetization. The magnitude of the spontaneous magnetization is a function only of the chemical and crystalline nature of the mineral, and the temperature.

It is necessary to study or hypothesise properties of the potential barriers impeding changes in domain structure. Nél's single domain theory assumed that the barrier is caused by the self-demagnetizing field, and gives some agreement with experiment. Theories which consider multi-domain grains have to allow for changes in total magnetization of the grain caused by the growth of some domains at the expense or others. The potential barriers in this case are those opposing movements of the domain walls, and depend on unknown factors such as crystal defects and the area and number of domain walls.

Everitt (1962) and Stacey (1963) have given theories of multidomain grains based on simplified models of the potential barriers. Their approaches are somewhat different, but their general conclusions similar, except in minor details.

Everitt obtains information about the potential barriers opposing domain wall motion from experimental relationships 
be tween $\sigma$ and $T$, and between $\mathrm{H}_{\mathrm{c}}$ and $T$. From this he derives a relationship between blocking temperature and coercive force, and an expression for the variation in total T.R.M. with magnetizing field. Much stress is placed on deriving relationships which may be experimentally verified, and reasonable agreement is generally found. The conclusion of most interest in the present work is that grains with high blocking temperature have high coercive force, although there is also a dependence on other properties of the minerals. This supports the experimental observation that heating a mineral and cooling it in zero field will remove unstable components before the stable ones.

Stacey has developed a detailed picture of domain structure and its dependence on grain size, and used this to derive relationships between the observable magnetic properties. The only aspects considered here are those referring to the question of magnetic viscosity and its effects on the stability of palaeomagnetism.

\subsubsection{Magnetic Viscosity}

Magnetic viscosity is the term used to describe the change with time of an induced or remanent magnetization after changes in the ambient magnetic field have ceased (Street \& Woolley, 1949, Shimizu, 1960). These authors, working with alnico and magnetite respectively, have shown that over a wide range of temperatures

$$
\delta J=\text { constant }+S \log t
$$

where $\delta \mathrm{J}$ is the change in intensity at a time $t$ after changing the ambient magnetic field. The viscosity coefficient, $\mathrm{S}$, is proportional to absolute temperature. 
Logarithmic change is not a characteristic of independent single domain grains, (Stacey, 1963), and is best explained on the basis of strong interactions between grains, for example, by the effect of the overall magnetization of the assembly of grains.

When dealing with multidomain grains, the force on a domain wall depends on the overall intensity of magnetization, J, of the grain, for there is a self demagnetizing field, NJ, within the grain, which acts on the wall. Stacey derives an expression for the change in magnetization with time, which reduces to the logarithmic equation for times common experimentally, but which tends to infinity as the time tends to infinity. His viscosity coefficient, $s$, is proportional to $\frac{T}{\sigma}$, and since $\sigma$ is a function of temperature, is not directly proportional to $T$. However, changes in $\sigma$ for magnetite are greatest about $150^{\circ} \mathrm{C}$. below the Curie temperature, which is just where the linear dependence of $\mathrm{S}$ on $\mathrm{T}$ ceases in Shimizu's paper. Shimizu attempted to relate this lack of linearity to changes in coercive force in a single-domain model, but Stacey's theory provides a more satisfactory explanation.

Experimental work on time effects has largely been confined to induced magnetization or I.R.M. The only reference to time changes of T.R.M. seen by the author is that by Nagata (1953), where the change in $\mathrm{J}_{2}^{\mathrm{T}} \mathrm{T}_{1} \mathrm{H}$ of magnetite with time was measured at temperature $\mathrm{T}_{1}$. In this case there is a wide range of potential barrier heights, ranging from nearly zero for those grains with blocking temperatures near $T_{1}$, to some larger, but finite height for those grains with $\mathrm{T}_{\mathrm{B}}=\mathrm{T}_{2}$. The logarithmic law would not be expected to hold under these circumstances. 
If the T.R.M., of a mineral with most of its magnetization residing in grains of high blocking temperature, were measured at room temperature, one would expect that a logarithmic decay would be observed, for the principle of thermal agitation still applies, and the potential energy barriers are approximately equal, as assumed by Stacey. In Stacey's theory it is assumed that

$$
\mathrm{H}=\mathrm{H}_{\mathrm{e}}-\mathrm{NJ} \ll \mathrm{H}_{\mathrm{C}}
$$

where $\mathrm{H}$ is the field at a wall of coercive force $\mathrm{H}_{\mathrm{C}}$, when the external field is $\mathrm{H}_{e}$. For decay of remanence, $\mathrm{He}_{e}=0$, so NJ $\ll \mathrm{H}_{\mathrm{C}}$

is a necessary approximation. The intensity of T.R.M. is generally much higher than that of similar I.R.M.'s so it is necessary to see whether this approximation is still valid. The coercive force of the barriers opposing change in T.R.M. is known to be higher than those opposing change in I.R.M., by a factor about equal to or greater than the ratio of T.R.M. to induced magnetization in weak fields, so that the approximation will probably be valid.

If one could show that T.R.M. decayed logarithmically with time, for periods up to several million years, then a test of the usefullness of a rock for determination of the intensity of the past earth's magnetic field is obviously possible. A form of the test is used by Thellier (quoted by Doell \& Cox, 1961) who measures viscous changes in magnetization intensity at room temperature over a period of weeks in the earth's field, and rejects samples which, on the basis of logarithmic decay, would have a significant change in intensity over the 2000 years or so of their age. 
A method used in this thesis is to measure directly the decay of T.R.M. with time as soon as possible after cooling to room temperature. Extrapolation allows an estimate of the upper limit of the changes in intensity of the N.R.M. In the absence of detailed testing of the hypothesis that the extrapolation is valid, the results are treated with reserve.

\subsubsection{Temperature and Viscous Magnetization}

If the temperature of a magnetic mineral is increased, thermal activation processes are speeded up, so it might be possible to reproduce in the laboratory at elevated temperatures, effects on the magnetization of rocks which have occurred over geological time at normal temperatures. In order to investigate this possibility, stacey (1963) considers the effects of increased temperature on the time constants for crossing of potential barriers opposing individual domain walls. He expresses the height of the potential barriers in terms of the logarithmic viscosity coefficient, $S$, which he has previously related to various parameters of the domain walls, and which he knows is proportional to $\mathrm{T}$, up to within $150^{\circ}$ of the Curie temperature. The time constant for a single wall crossing the barrier of height $\mathrm{E}$ is

$$
\ln c \tau=\frac{\mathbb{E}}{\mathrm{kT}}
$$

where $\mathrm{c}$ is the constant mentioned in paragraph 3.2 .3 (c about $10^{10} \mathrm{sec}^{-1}$ ), and

$$
\mathrm{E}=\frac{\mathrm{kT}}{\mathrm{NS}}\left(\frac{2}{\pi} \mathrm{H}_{c}^{\prime}-\mathrm{H}\right) \text {. }
$$

$\mathrm{H}_{\mathrm{c}}^{\prime}$ is a "microscopic" coercive force, proportional to $\sigma^{2}$ and independent of grain size or shape. 
If $\mathrm{H} \ll \mathrm{H}_{\mathrm{C}}$, these equations imply

$$
\frac{\ln c \tau_{1}}{\ln c \tau_{2}}=\frac{S_{2} \sigma_{1}^{2}}{S_{1} \sigma_{2}^{2}}=\frac{T_{2}}{T_{1}}\left(\frac{\sigma_{1}}{\sigma_{2}}\right)^{2}
$$

Processes with time constant $\tau_{1}$ at temperature $\mathrm{T}_{1}$ would take place with time constant $\tau_{2}$ at temperature $T_{2}$. Processes may be supposed to be sufficiently complete to measure in a time equal to their time constant.

There are two time dependent effects to study. One is the decay of intensity of an original T.R.M. over geological time, without the simultaneous acquisition of a new direction of magnetization. The other is the acquisition of an I.R.M., when the rock has been situated for a long time in a weak magnetic field.

Stacey implies in his brief description of the uses of equation 3.11 that by heating at a constant temperature $T_{2}$ for a time $\bar{c}_{2}$, a magnetization may be produced in the laboratory which is equivalent to the I.R.M. acquired over geological time $\zeta_{1}$, at temperature $\mathrm{T}_{1}$. The act of heating the rock to $\mathrm{T}_{2}$ will destroy any T.R.M. acquired below this temperature, but the test can be used to find whether any I.R.M. may be expected to be possessed by grains having blocking temperatures greater than $\mathrm{T}_{2}$.

To estimate a value for the temperature $\mathbb{T}_{2}$, it is necessary to decide on $T_{1}, \tau_{1} \& \tau_{2}$, and estimate the variation of $\sigma$ with $T$. In his 1962 paper Everitt publishes some experimental results for magnetite, which show that

$$
=A(1300-T)
$$

( $T$ in ${ }^{\circ} \mathrm{K}$ ) for $300<\mathrm{T}<700^{\circ} \mathrm{K}$. Taking $\tau_{1}=10^{14}$ sec, $\tau_{2}=10^{3}$ sec, $\mathrm{c}=10^{10} \mathrm{sec} .^{-1}$ gives 


$$
\frac{T_{2}}{T_{2}}\left(\frac{1300-T_{1}}{1300-T_{2}}\right)^{2}=2
$$

Substituting $\mathrm{T}_{1}=300^{\circ} \mathrm{K}$ gives

$$
\mathrm{T}_{2}=550^{\circ} \mathrm{K} \doteqdot 300^{\circ} \mathrm{C}
$$

The accuracy of this figure has been estimated, assuming that the theoretical assumptions are justified, and considering only changes in the assumed values for parameters. Equation 3.12 is written as $\sigma=A(B-T)$

which leads to

$$
\begin{aligned}
& \frac{T_{2}}{T_{1}}\left(\frac{B-T_{1}}{B-T_{2}}\right)^{2}=R \\
& d T_{2}=\frac{\partial T_{2}}{\partial B} d B+\frac{\partial T_{2}}{\partial T_{1}} d T+\frac{\partial T_{2}}{\partial R} d R
\end{aligned}
$$

The partial differentials have been calculated from $3.12,3.14$ and 3.16, giving

$$
\mathrm{dT}_{2}=0.6 \mathrm{~dB}+0.6 \mathrm{dT}_{1}+300 \mathrm{dR}
$$

$\delta \mathrm{T}_{2}$ may be supposed to be $\pm 20^{\circ} \mathrm{C}$.

$\delta_{R}$ is about \pm 0.2 for extreme values of $c$.

$\delta B$ is about \pm 100 , estimated from errors in calculation from the graph (not allowing for possible variation between samples.) Thus $\delta \mathrm{T}_{2}$ is about $\pm 100^{\circ} \mathrm{C}$.

This theory indicates that if a rock does not acquire any I.R.M. after heating for about 20 minutes at $400^{\circ} \mathrm{C}$. In the earth's magnetic field, then the N.R.M. remaining after heating to this temperature is probably in the direction of the original magnetization.

This test is more general than the usual methods, which rely on removing I.R.M. at lower temperatures than T.R.M., with a consequent change in direction of magnetization of the sample, unless the two happen to be parallel.

This test could be used to test the stability of the intensity of a T.R.M. produced in the laboratory, for changes in intensity of 
the P.T.R.M. above $400^{\circ} \mathrm{C}$, after heating to this temperature in zero field, might indicate the possible decay over geological time. The results would not be valid if a large proportion of the blocking temperatures was near $400^{\circ} \mathrm{C}$. 
CHAPTER FOUR

\section{PARTIAL DEMAGNETIZATION OF ROCK MAGNETISM}

\subsection{ALTERNATING FIELD DEMAGNETIZATION}

After the discovery of viscous magnetization of rocks it was natural to attempt to demagnetize them by means of an alternating field of peak intensity about the magnitude of the coercive force of the viscous component. It was found by Thellier \& Rimbert (1954, '55) that providing suitable precautions are taken, such as a smooth reduction of the peak field intensity to zero and the cancellation of the ambient magnetic field, it is possible to remove I.R.M.s acquired in fields up to several tens of oersted without affecting a T.R.M. acquired in fields of about 0.2 oe. The method of alternating field (A.F.) demagnetization was used by Brynjolfsson (1957) on some reversely magnetized samples, which showed at first an increase of intensity on demagnetizing. This increase could only have been caused by the removal of an unstable component parallel to the present earth's field. A viscous magnetization acquired in the laboratory was able to be demagnetized without affecting the direction of the stable component. The following year As \& Zijderveld (1958) showed that the direction of magnetization of some samples changed progressively in the plane defined by the present earth's field direction, and that of the previously determined palaeomagnetic pole for that age of rocks, the change being away from the present direction. The effect of demagnetizing a set of specimens was to reduce the scatter of their directions of magnetization. Their A.F. demagnetizations were performed at up to $150^{\circ} \mathrm{C}$. but they give no clear statement on what were the separate effects of heating and of the alternating field. 
Creer in 1959 improved the method of A.F. demagnetization by spinning the sample about two perpendicular axes while applying the field. This ensured equal demagnetization in all directions and also reduced the effect of the ambient stationary field. He found fields of several thousand oersted necessary to completely demagnetize the sedimentary rocks used.

Up till now people had considered the detailed effect on each sample, but in 1961 Irving, Stott \& Ward suggested selecting a set of specimens from a collection, treating them in increasing magnetic fields, and then treating all the samples in that field which gave the greatest value for Fisher's precision, " $k$ ", calculated from the selected specimens. This is a convenient procedure when dealing with a large number of specimens. These authors also noted that the magnetization of the rocks never reached zero intensity, but instead became random in direction after successive treatments in very high fields. This effect was pointed out by Mume (1962) as a limitation to the technique, for, by correlating changes in intensity and changes in direction, he showed that there was a component present after demagnetization in strong fields, which was stable in direction, but masked by the random changes of the unstable component.

\subsection{THERMAI DEMAGNETIZATION}

In view of the connection described fully by Nagata (1953) and others, between coercive force and blocking temperature, it seemed reasonable to a.tempt to remove components of magnetization residing in grains with low coercive force by 
heating the rock and cooling it in zero magnetic field. Cox (1957) reported a reduction in scatter of some basalt samples on heating them and cooling in zero field. Irving and others (1961) constructed a furmace for heating sedimentary rocks in order to demagnetize them, with the particular view to cleaning magnetically some sedimentory rocks with high coercive force which otherwise would require several thousand oested for A.F. demagnetization. As in their work on A.F. demagnetization, they selected a temperature of reheating which gave the least scatter in a trial selection of samples.

The great potential of thermal treatment in the separation of all the information contained in T.R.M.s has been fully exploited by R. I. Wilson (1961, '62a). He was working on some laterites which had been baked by lavas and dykes, and which contained two magnetic minerals, maghemite and hematite. He had constructed a furnace mounted beneath an astatic magnetcmeter, so that measurements of magnetization were made at elevated temperatures. The maghemite was unstable magnetically so that as the temperature was increased the magnetization direction changed, until the temperature reached about $350^{\circ} \mathrm{C}$, after which the intensity continued decreasing, while the direction was constant. These high temperature directions were highly consistent between samples. Demagnetization in increasing alternating fields was found not to lead to a constant direction for each sample. The hematite was found to have no blocking temperatures below $400^{\circ} \mathrm{C}$, and the maghemite none above this. No changes in direction were found above this temperature, so the magnetization of the hematite appeared completely stable. The hematite appeared 
to have a total T.R.M. (i.e., it had been heated above its Curie point), so that an estimate of past field intensity was made by comparing the demagnetization curve for the N.R.M. above $400^{\circ} \mathrm{C}$. with that of T.R.M.s in various fields. The T.R.H. in 0.43 oe proved similar to the N.R.M., so this field was taken to be the past field strength.

Wilson infers from the figure of $670^{\circ} \mathrm{C}$. for the Curie temperature of hematite, and a range from $700^{\circ} \mathrm{C}$. to $850^{\circ} \mathrm{C}$. for the decomposition of maghemite, that the laterite must have been heated to between these temperatures to impose the observed T.R.M. The maximum temperature the country rock is heated to when covered by a non-convecting lava at temperature $\mathrm{T}$ is $\frac{\mathrm{T}}{2}$, (Hatherton, 1954a). This would imply temperatures around $1500^{\circ} \mathrm{C}$. for the lava, which is surprisingly high.

In the 1962a paper, thermal demagnetization studies on a laterite baked by two successive intrusions show two separate directions of magnetization. The maximum temperature of heating in this case was about $550^{\circ} \mathrm{C}$., which was surprising to Wilson, who had apparently assumed the temperature of the country rock would reach nearly that of the dyke.

\subsection{COMPARISON OF ALTERNATING FIELD AND THERMAL DMMAGNETIZATION} Mumme (1962) has compared A.F. and thermal demagnetization on some reversely magnetized basalts, and showed that those rocks with a predominantly high Curie point magnetization were little affected by low peak alternating fields, and vice versa. (Agreeing with Everitt, (1962) and confirming the principle of thermal demagnetization). 
Irving \& Parry, (1963) also report reduction of scatter of magnetization directions which are similar when either A.F. or thermal demagnetization is used. Robertson, (1963), reports slightly better improvements in scatter on treating dyke and contact rocks thermally, and on treating plutonics with alternating field.

The decrease of scatter which can be gained from thermal treatment is similar to that gained by alternating field treatment. The equipment used for thermal cleaning may be used to give such a variety of extra information that it is the most generally useful, al though A.F. demagnetization is simpler and quicker to perform. 


\section{DESIGN AND CONSTRUCTION OF AN OVEN}

FOR THERMAL DEMAGNETIZATION

\subsection{INTRODUCTION}

It is possible to mount an oven directly beneath an astatic magnetometer, which enables measurements of magnetization to be made while the specimen is hot, (Wilson, 1962b, Mumme, 1963). The alternative is to cool the specimen in zero field after heating, and measure its magnetization at room temperatures. Both methods lead to similar information about the N.R.M. of the specimens.

If an oven is to be placed near a magnetometer, it must be free from all ferromagnetic impurities, which would give changing stray magnetic fields with changing temperatures. It is necessary to ensure that the oven does not cause any heating of the magnetometer, for this could lead to convection currents, and possible drift in the zero reading.

The apparently more straightforward method of measuring the magnetization at room temperature, after subjecting it to thermal treatment, was chosen for this work.

5.2 GENERAL DESCRIPTION OF OVEN

The design was based on that of Irving, Robertson, Stott, Tarling \& Ward (1961). This oven allows twelve cylindrical specimens to be heated up to $650^{\circ} \mathrm{C}$. in an atmosphere of nitrogen, and zero magnetic field. It consists of a heating element wound 
on a copper "pot", (Fig. 5.3), which rests on an insulating base and is surrounded by an insulating jacket, (Fig. 5.1), made up of a set of concentric metal cylinders, separated by a $1.2 \mathrm{~cm}$ air gap. Specimens are mounted on a pottery stand, (Fig. 5.2), supported on a ceramic shaft passing through the base, where it is supported by a brass shaft which may rotate about its axis (Fig. 5.5). The oven is made from non-magnetic materials, and is situated at the centre of a set of Parry coils, which are used to cancel the ambient magnetic field, (Fig. 5.4). The following sections present detailed description and design considerations.

\subsection{SIZE OF OVEN}

The larger the oven is, the shorter the average time for treatment of each specimen, for the time for a heating cycle increases at a slower rate than the number of specimens which may be contained in it. A practical limit is set by the need to cancel the ambient magnetic field over the volume of the oven. The oven size was decided by first choosing the arrangement of specimens within the oven (Fig. 5.2), and then calculating the separation between specimens necessary to prevent interaction of their magnetic fields. The criterion assumed was that a cylindrical specimen $35 \mathrm{~mm}$ in diameter and $35 \mathrm{~mm}$ high, with an intensity of magnetization of $10^{-3}$ e.m.u./cc should produce a field less than $20 \gamma$ at its nearest neighbour. This gave a spacing of $9 \mathrm{~cm}$ between the centres of specimens, which led to the choice of a diameter of $24.5 \mathrm{~cm}$ and a height of $20.5 \mathrm{~cm}$. as the internal dimensions of the pot surrounding the specimens. 


\subsection{HEATING EJEMENT}

The heating element is wound on to a $\frac{1}{8}$ " thick copper pot surrounding the specimens. This copper pot assists in the attainment of a uniform temperature distribution within the oven. Seventy feet of 17 B. \& S. gauge nichrome wire, insulated with $\frac{1}{8}$ " ceramic "fish-spine" beads, are noninductively wound in a double spiral groove machined in the pot (see Fig. 5.3). The tension is adjustable and is sufficient to hold the wire in the groove without other support. The resistance of the wire is $26 \mathrm{ohms}$, which allows $2 \mathrm{KW}$ to be dissipated at 230 volts. The beads and wire do not contribute significantly to magnetic fields within the oven.

Electrical connections to the element proved troublesome at first. Sindanyo, which is an asbestos-based electrical insulator intended for moderately high temperature use, lost its mechanical strength after several heating cycles to $600^{\circ} \mathrm{C}$. Steatite, a form of talc, is a soft material, easily worked with hand tools in its natural state, which becomes a hard ceramic very suitable as a high temperature insulator, after heating to $1100^{\circ} \mathrm{C}$. This material was used to insulate the ends of the element, and has proved completely successful. The lower terminal block (Fig. 5.3) is in two parts, held together by a brass nut and bolt. Brass connection strips are hard soldered to the nichrome wire, and are clamped into recesses between the two parts of the block when they are assembled. These strips fit over terminals permanently fixed to the base of the oven, when the pot is placed over the specimens. The block itself fits into a slot cut in the pot, in order to hold it. 
The upper terminal block is a brass wedge which fits into a matching wedge welded to the pot, with a steatite insulator between the two. The wires pass through the block and are held in position by screws, in order to be able to adjust the tension in the wire. The tension holds the wedge in position. Becauge some oxidation of the wire occurs, the two wires are twisted and hard soldered, to make electrical connection.

\subsection{INSUIATION OF OVEN}

This follows the design used by Irving and others. A removable jacket consists of an aluminium frame bolted to a sindanyo plate, on which sit two copper and three aluminium cylinders, separated by air gaps of $1.2 \mathrm{~cm}$. This insulation is light and efficient, and does not require a water supply, which in the present case was an important consideration. The inner, copper, cylinders, were initially chromium plated, but owing to its ferromagnetism the usual base coating of nickel had to be omitted. The copper quickly oxidized beneath the chromium, which peeled off, but this has not seriously affected the performance of the oven. A counterweight arrangement allows the jacket to be easily lifted to give access to the oven.

The base is a hollow sindanyo box, with two copper and two aluminium plates forming horizontal divisions which reduce heat transfer, both by convection and radiation.

\subsection{SAMPLE HOLDER}

It was suggested by Mr Gellen at the start of this work that the effect of stray fields remaining after cancelling the main 
part of the ambient field might be reduced by rotating the specimens about a vertical axis, which would randomize the effective direction of any horizontal component present. The effect of vertical components might be detected by using two specimens from the same core from a sample, which ought both to be magnetized in the same direction. If they were placed above each other, but one upside down with respect to the other, then effects of the vertical field should be able to be distinguished from changes in the magnetization due to instability.

It was envisaged that the holder might sometimes be required to rotate while a vertical field is applied. A metal sample holder in these circumstances might have magnetic fields near it due to eddy currents, so the present sample holder was designed and constructed by Mr Roy Cowan from pottery clay, (Fig. 5.2). The ceramic shaft which supports the holder withstands great thermal stresses, and is a former from a large wire wound resistor. It is attached to the pottery by cold setting cement, and to a cup in a brass fitting at its lower end by type metal, which was poured in while molten, and expanded on freezing to give a very tight joint. This brass fitting screws on to a shaft which is rotated on "tufnol" bearings, (Fig. 5.5), by a pulley and cord drive from a 70 r.p.m. induction motor, placed six feet away from the oven to reduce its effect on magnetic fields at the specimens.

\subsection{INERT ATMOSPHERE}

To prevent oxidation of the specimens, and especially of the copper parts of the oven, nitrogen gas is passed into the oven while it is hot. Commercial nitrogen is passed through 
an ordinary flow regulator, a needle valve to provide sufficient back pressure to ensure correct operation of the regulator, and a differential mercury manometer which allows comparison of flow rates. It has been found necessary to remove traces of oxygen by bubbling the gas through alkaline pyrogallol solution (Thorpe, 1937), and to dry it with concentrated sulphuric acid. An "oxygen-free" grade of nitrogen has recently become available, but has not been used. The nitrogen enters the oven through a copper pipe which extends to near the top of the oven.

\subsection{POWER SUPPLY}

At present control of temperature is achieved by regulating the supply voltage with a variable transformer. Automatic control (available commercially) would be convenient, but expensive. With the present system temperatures can be adjusted to within $20^{\circ} \mathrm{C}$. of the desired temperature.

An isolating transformer is incorporated between the oven and the Variac, in order to reduce voltage stresses on the insulating beads of the element. (It is also a safety precaution). The original arrangement enabled the full mains voltage, of up to $350 \mathrm{v}$. peak, to be applied across one thickness of beads, between the wire and the earthed pot. At high temperatures this was sufficient to cause electrolytic conduction to occur in the porcelain (Riddle, 1927), and resulted in complete breakdown and fusion of the element. The breakdown temperature was found to be highly voltagedependent, so that the isolating transformer, by ensuring that the maximum voltage can occur only across two bead thicknesses, prevents breakdown at temperatures below at least $650^{\circ} \mathrm{C}$. 


\subsection{TEMPERATURE NEASUREMENT}

It is convenient to use thermocouples to measure temperatures because as many as are needed can be easily and cheaply made, connected to a millivolt recorder, and recorded along with information such as changes in the current used to cancel the earth's field. Chromel-alumel and platinum thermocouples are the most resistant to oxidation at the temperatures used, but platinum ones require the provision of a cold junction near the oven, in order to keep leads short (and therefore less expensive). Chromel-alumel ones are used here despite their ability to become permanently magnetized (this is the most serious source of field gradients in the oven).

Junctions are made by cleaning and twisting the wires, and then hard soldering them. When the solder melts (at about $620^{\circ} \mathrm{C}$.) there is a lag in temperature of the junction, owing to the latent heat absorbed, but this is not serious in this application. The wires are insulated by 3 " long two-hole ceramic insulators in the high temperature regions.

Connection to the thermocouples on the rotating sample holder are made via mercury trough slip rings mounted on the drive shaft, (Fig. 5.5). No noise or stray D.C. voltages were detected here.

The E.M.F. of the thermocouples used was measured at the freezing points of tin, lead, and zinc, and found to lie on the calibration curve given by Roeser (1941). For the purposes of these measurements it can be assumed that the E.M.F. varies linearly with temperature, with coefficient $41.7 \mu \mathrm{v} /{ }^{\circ} \mathrm{C}$. 
5.10 UNIFORMITY OF TEMPERATURES IN OVEN

Specimen temperatures were measured by means of thermocouples inserted in holes drilled in some dummy specimens. With the heating rates used the inside of a specimen could be about $10^{\circ} \mathrm{C}$. cooler than the outside, but this became practically zero five minutes after holding the oven temperature constant.

The temperature of the pot at its bottom was about $25^{\circ} \mathrm{C}$. lower than that at its top at $300^{\circ} \mathrm{C}$. , with very little change with time. This is presumably due to thermal conduction through the base being greater then that through the jacket, and leads to a difference in temperature between specimens on the top and bottom of the sample holder. The temperature difference is about $25^{\circ}$ to $50^{\circ}$ at low temperature $\left(<200^{\circ} \mathrm{C}\right.$.) but decreases with increasing oven temperature, so that separate measurements of top and bottom layer temperatures are usually required. There is no difference in temperature greater than $1^{\circ} \mathrm{C}$. between similar specimens on the same layer.

An attempt to supply extra heat to the bottom of the oven, with a flat heating coil, resulted in cracks forming in the sindanyo of the base, and was not repeated. A heavy copper plate on the base might assist in attaining uniform temperatures, but the oven is useful as it stands, so further work has been directed towards getting results from the present design. 


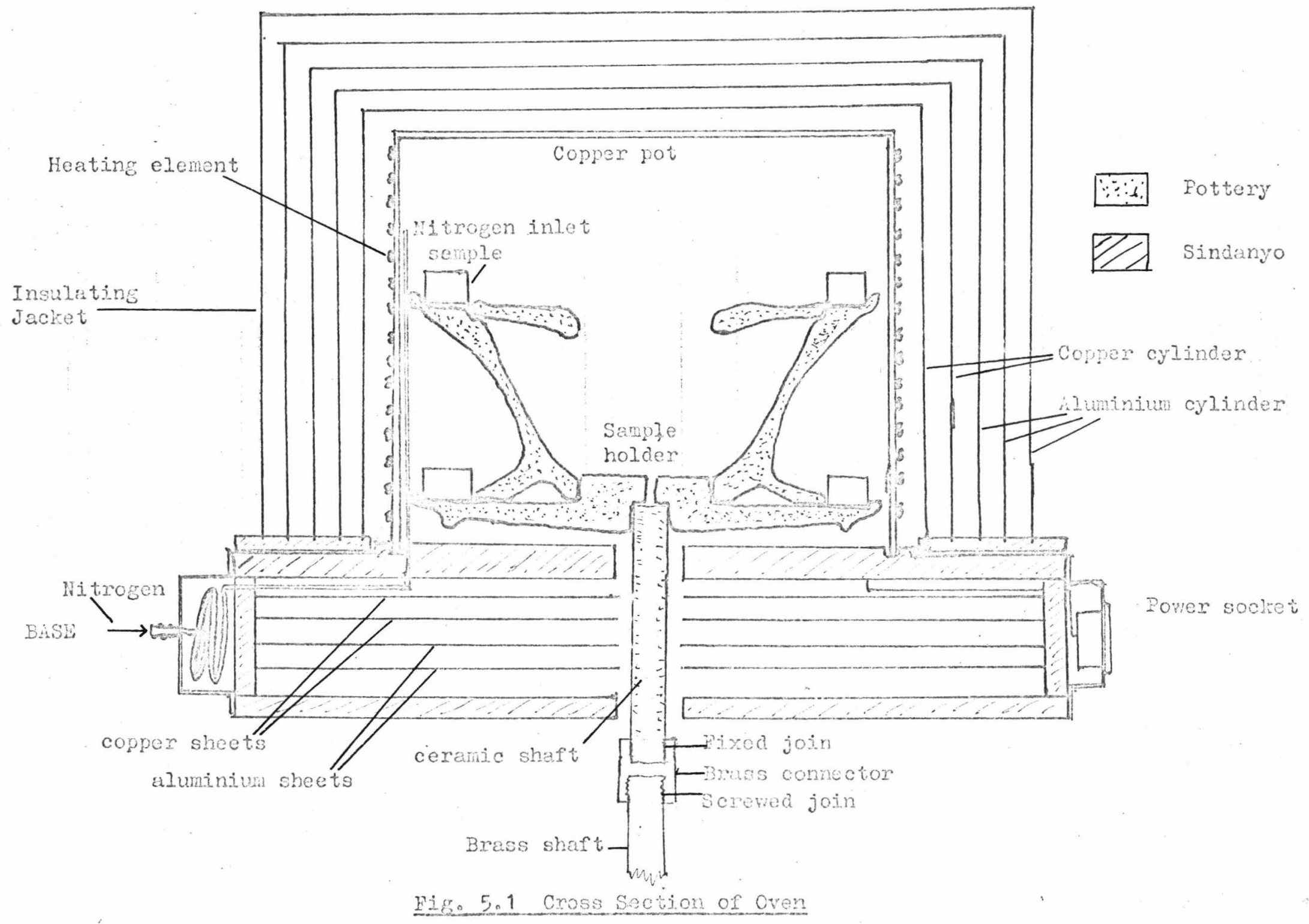




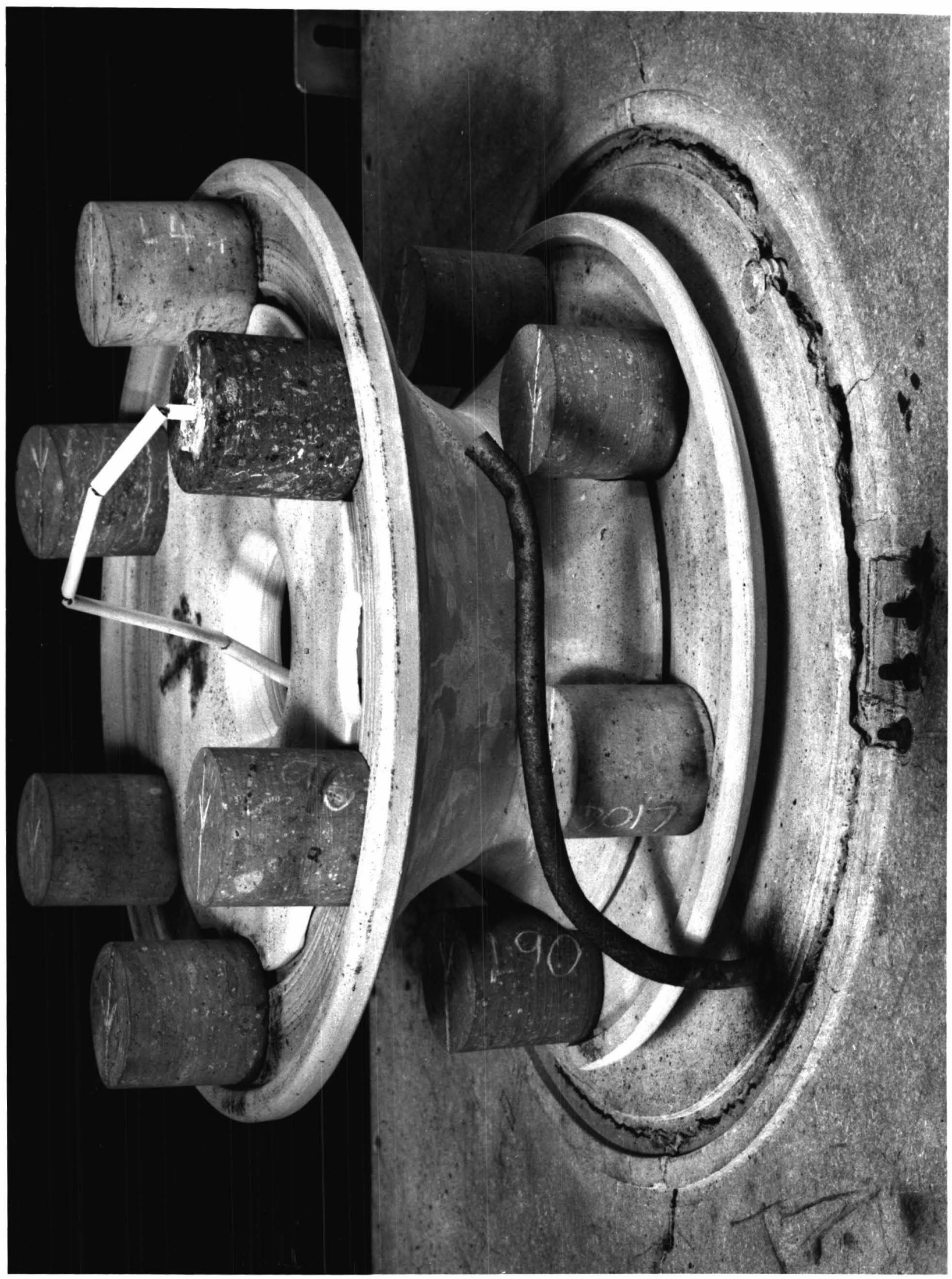


40

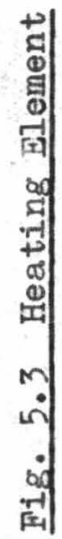


Fig. 5.4 Oven and Field Cancellation Coils 


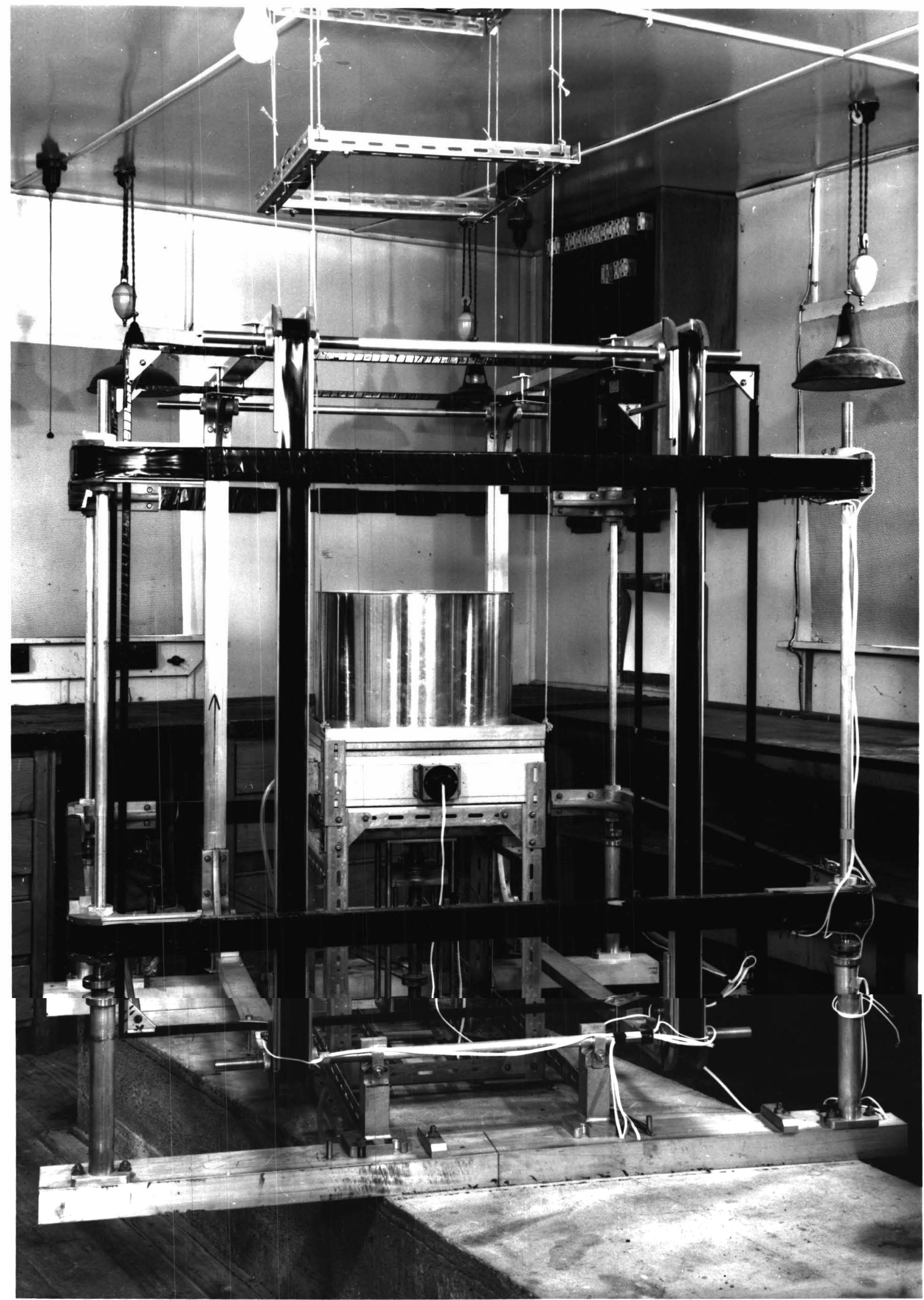




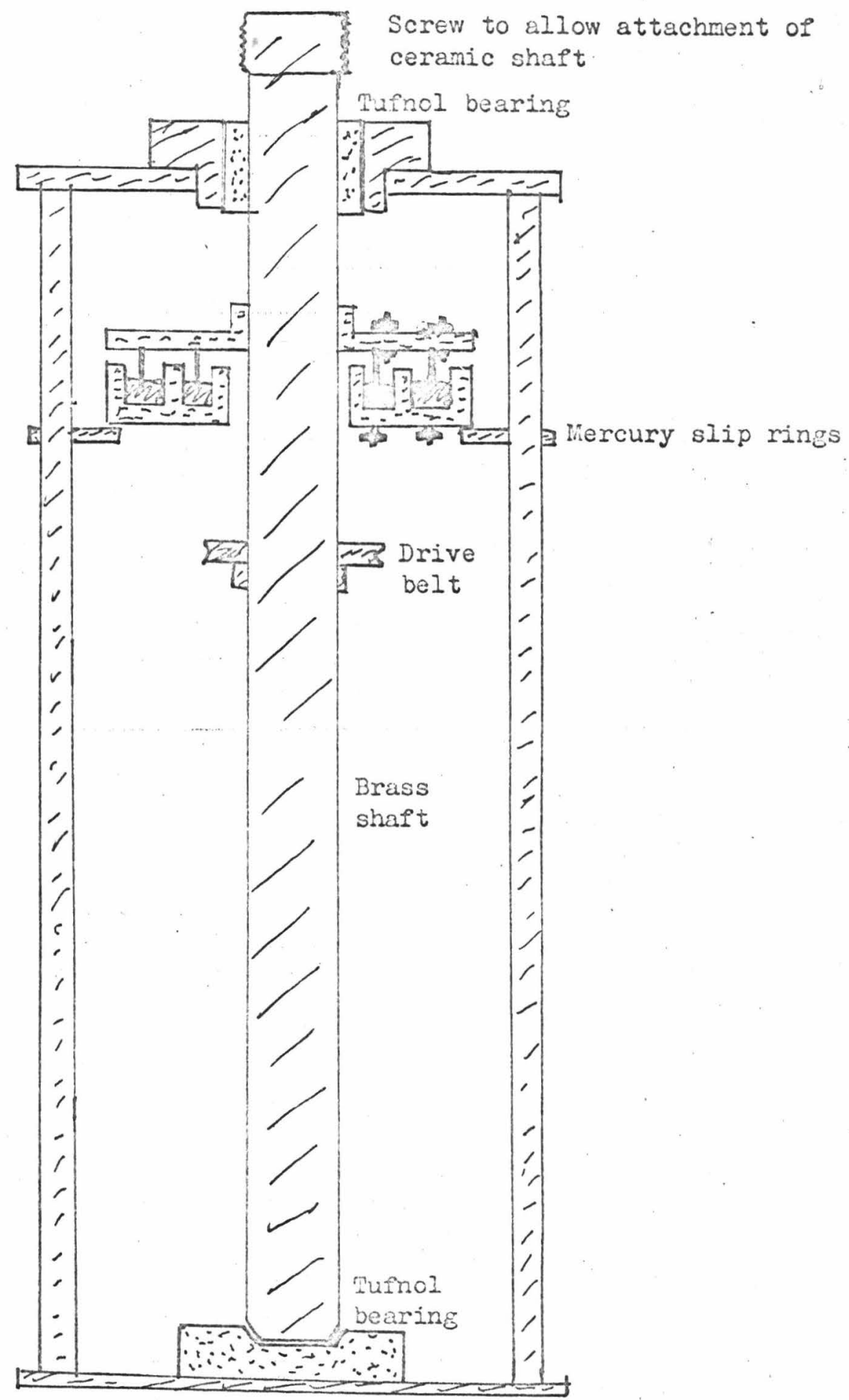

Eig. 5.5 Rotating Support for Sample Holder 


\section{FIELD CANCELIATION COILS}

\subsection{GENERAI}

It is necessary to cancel the earth's magnetic field over the useful volume of the oven. One method is to surround it with mu-metal, but a simpler and more common method is to cancel the field with another produced by the currents in a set of coils. It is usual to have three sets of coils and cancel the components of the earth's field in the three directions parallel to their axes. To ensure that the field produced in each direction is sufficiently uniform it is necessary in this case to use either a very large single coil or a pair of smaller coils spaced in such a way that the first three differentials of the field at the centre of the pair are all zero. Even smaller coils could be used by using three or four coils, but this restricts access to the oven.

Preliminary calculations for circular (Helmholtze) coils showed that a diameter of about four feet would be necessary. This is too large to be machined in the college workshop, and such coils would cost about $£ 300$ if cast and machined commercially.

The method of construction used was to make the coils square, the sides being cut from $2^{\prime \prime} \times 1^{\prime \prime}$ outside dimensions U-section extruded aluminium channelling. These were joined at the comers by screwing them to machined aluminium castings. The coils have uniformity comparable to circular coils, are simpler to construct, and provide good access to the central space. The finished coils are visible in Fig. 5.4. 
The calculations which follow, on the properties of square coils, were carried out with greater accuracy than needed for the coils associated with the oven, for it was expected that a similar set of coils would be required for the magnetometer at some future date. The requirement in this case would be that field gradients at the centre of the coils should be very small over a relatively small volume.

\subsection{FIEID OF PARRY COII SET}

\section{2 .1 Introduction}

Previous calculations of the field of square coils have been made by Parry (1957), but have not been published. Accordingly, Mr I. D. Cave started in 1962 the task of calculating the field at off centre points between a pair of coils spaced so the first three differentials of the field at the centre are zero, (Parry spacing).

\subsubsection{Parry Spacing}

The field at a point $P$ on the axis of a square coil of side $2 a$, and distant $z$ from the centre of the coil, is along the axis and is given by Robertson (1960), as

$$
\begin{aligned}
H & =\frac{8 i a^{2}}{\left(a^{2}+z^{2}\right)\left(2 a^{2}+z^{2}\right)^{\frac{1}{2}}} \\
& =\frac{8 i}{a} \frac{1}{\left(1+s^{2}\right)\left(2+s^{2}\right)^{\frac{1}{2}}}
\end{aligned}
$$

where $s=\frac{z}{a}, i$ is measured in abamps, and $a$ and $z$ are in cm. This is an even function of $s$, so that if $P$ is at the centre of a pair of similar coils the odd differentials will cancel. The Parry condition is that

$$
\frac{\partial^{2} \mathrm{H}}{\partial z^{2}}=0
$$


and the only real value of $s$ for which this occurs is

$$
s=\frac{z}{a}=0.5445
$$

The corresponding coil spacing is

$$
\mathrm{d}=1.089 \mathrm{a}
$$

and is called the Parry spacing.

The field at the central point $P$ corresponding to this spacing is

$$
\mathrm{H}=\frac{\mathrm{gNi}}{\mathrm{a}} \times 1.018
$$

where $\mathrm{Ni}$ is the number of abamp turns per coil.

\subsubsection{FIELD AT OFF-CENTRE POINTS}

These equations were derived by Mr Cave and checked by the author, and are given here for reference.

Consider a single square coil of side 2a. A coordinate system $(x, y, z)$ has as its $z$ axis the axis of the coil, and $x$ \& $y$ axes parallel to the coil sides. The origin is distant $b$ from the centre of the coil, (see diagram). $P$ is a general point between the coil and the $x-y$ plane. The current circulates in a left handed sense about the $z$ axis.

Hy is the component of $\mathrm{H}$ in the $\mathrm{y}$ direction at $\mathrm{P}, \mathrm{Hx}$ that in the $x$ direction and $\mathrm{Hz}$ in the $\mathrm{z}$

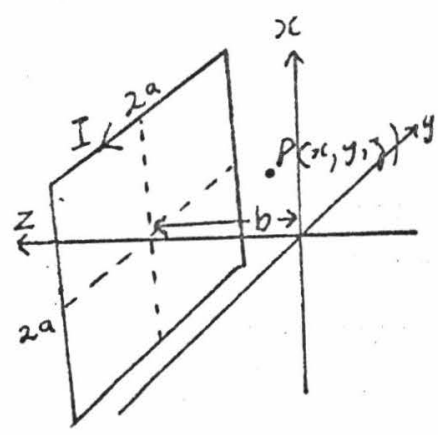
direction, due to one coil at $\mathrm{z}=+\mathrm{b}$. 
Writing $u=x-a, v=y-a, w=z-b$, then:

$$
\begin{aligned}
\mathrm{Hx}= & \frac{w i}{w^{2}+u^{2}}\left[\frac{v}{\left(u^{2}+v^{2}+w^{2}\right)^{\frac{1}{2}}}-\frac{v+2 a}{\left(u^{2}+(v+2 a)^{2}+w^{2}\right)^{\frac{1}{2}}}\right] \\
+ & \frac{w i}{w^{2}+(u+2 a)^{2}}\left[\frac{-v}{\left((u+2 a)^{2}+v^{2}+w^{2}\right)^{\frac{1}{2}}}\right. \\
& \left.+\frac{v+2 a}{\left((u+2 a)^{2}+(v+2 a)^{2}+w^{2}\right)^{\frac{1}{2}}}\right]
\end{aligned}
$$

$$
\begin{aligned}
\text { Hy } & =\frac{w i}{\left(w^{2}+v^{2}\right)}\left[\frac{u+2 a}{\left((u+2 a)^{2}+v^{2}+w^{2}\right)^{2}}-\frac{u}{\left(u^{2}+v^{2}+w^{2}\right)^{\frac{1}{2}}}\right] \\
+ & \frac{w i}{\left(w^{2}+(v+2 a)^{2}\right)}\left[\frac{u}{\left.u^{2}+(v+2 a)^{2}+w^{2}\right)^{\frac{4}{2}}}\right. \\
& \left.-\frac{u+2 a}{\left((u+2 a)^{2}+(v+2 a)^{2}+w^{2}\right)^{\frac{1}{2}}}\right]
\end{aligned}
$$$$
H z=\frac{v i}{v^{2}+w^{2}}\left[\frac{u}{\left(u^{2}+v^{2}+w^{2}\right)^{2}}-\frac{u+2 a}{\left((u+2 a)^{2}+v^{2}+w^{2}\right)^{2}}\right]
$$$$
+\frac{(v+2 a) i}{(v+2 a)^{2}+w^{2}}\left[\frac{-u}{\left(u^{2}+(v+2 a)^{2}+w^{2}\right)^{\frac{1}{2}}}\right.
$$$$
\left.+\frac{u+2 a}{\left((u+2 a)^{2}+(v+2 a)^{2}+w^{2}\right)^{\frac{1}{2}}}\right]
$$$$
+\frac{(u+2 a) i}{(u+2 a)^{2}+w^{2}}\left[\frac{-v}{(u+2 a)^{2}+v^{2}+w^{2}}\right.
$$$$
\left.+\frac{v+2 a}{\left((u+2 a)^{2}+(v+2 a)^{2}+w^{2}\right)^{2}}\right]
$$$$
+\frac{u i}{u^{2}+w^{2}}\left[\frac{v}{u^{2}+v^{2}+w^{2}}-\frac{v+2 a}{\left(u^{2}+(v+2 a)^{2}+w^{2}\right)^{\frac{1}{2}}}\right]
$$

The field of the other one of a pair whose centre is at the origin is found by substituting $(z+b)$ for $(z-b)$, that is $w^{\prime}=w+2 b$ is substituted for $w$. The $x$ or $y$ component for one coil is subtracted from the $\mathrm{x}$ or $\mathrm{y}$ component for the other, and the $\mathrm{z}$ components are added. 
From these equations the field was calculated for points with coordinates of the form $(0,0,1),(1,0,0)$ and $(1,1,1)$, with 1 taking various values, and the results expressed as $\frac{\mathrm{HO}-\mathrm{H}}{\mathrm{HO}}$, where Ho is the field at the centre of the coils. The results are graphed in Fig. 6.1.

A maximum change of $50 \gamma$ from the centre of the coils to the point $(1,1,1)$ requires $\frac{H O-H}{H}$ to be less than $10^{-3}$, which corresponds to $\frac{1}{a}$ less than 0.13 . Since in this case $I$ is about $10 \mathrm{~cm}$, a must be about $80 \mathrm{~cm}$, which means the side of the coils is about five feet.

\subsubsection{Effect of Construction Accuracy}

It was decided that accuracy of $\pm 1 \mathrm{~mm}$ in major distances was a reasonable requirement for coils of this size made from available extruded u-section aluminium channel. Gellen (1959) showed that when considering the effect of errors in construction of circular coils, a fair estimate is obtained by treating the area, A, between the theoretical and the actual position, a.s a magnetic shell of moment nIA, which for points near the centre of the coil acts as a dipole with its axis normal to the area. This approximation was checked for the case of a straight line filament with dimensions about those of the coil set, and found to give an over-estimate by a factor of about two. The effect of a displacement of the nearest coil side on the field at an extremity of the oven is estimated below, and it is assumed that the total error field will be less than four times this for the $\mathrm{x}$ component (or $\mathrm{y}$ component) and no more than eight times this for the $\mathrm{z}$ component. This will give a large overestimate of the effect of constructional inaccuracy. 
Consider the change in field produced at a point $P$ distant $r=\left(x^{2}+z^{2}\right)^{\frac{1}{2}}$ from a line current of length $2 a$, due to small displacements of that current. The displacements $\mathrm{x}$ and $\mathrm{z}$ parallel to the $\mathrm{x}$ and $\mathrm{z}$ axes produce the magnetic moments $\mathrm{m}_{1}$ and $\mathrm{m}_{2}$ parallel to the $\mathrm{z}$ and

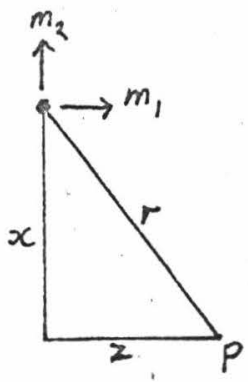
$x$ axes respectively.

$$
\begin{aligned}
& \mathrm{m}_{1}=2 \mathrm{nIadz} \\
& \mathrm{m}_{2}=2 \mathrm{nIadx}
\end{aligned}
$$

where I abamps flow through each of $\mathrm{n}$ turns, and distances are measured in centimeters. The $x$ component of field at $P$ due to $\mathrm{m}_{1}$ is denoted by $\left.\mathrm{H}_{\mathrm{X}}\right)_{1}$ and similar definitions hold for other components. It is easily shown that

$$
\begin{aligned}
& \left.\mathrm{H}_{\mathrm{z}}\right)_{2}=-\frac{3 \mathrm{~m}_{2} \mathrm{xz}}{\mathrm{r}^{5}} \\
& \left.\mathrm{H}_{\mathrm{z}}\right)_{1}=\frac{\mathrm{m}_{1}}{\mathrm{r}^{5}}\left(2 \mathrm{z}^{2}-\mathrm{x}^{2}\right) \\
& \left.\mathrm{H}_{\mathrm{x}}\right)_{1}=\frac{3 \mathrm{~m}_{1} \mathrm{xz}}{\mathrm{r}^{5}} \\
& \left.\mathrm{H}_{\mathrm{x}}\right)_{2}=\frac{-\mathrm{m}_{2}}{\mathrm{r}^{5}}\left(2 \mathrm{x}^{2}-\mathrm{z}^{2}\right)
\end{aligned}
$$

For the worst possible case the total field $\mathrm{H}_{\mathrm{X}}$ is

$$
\mathrm{H}_{\mathrm{x}}=\frac{\mathrm{m}_{1}}{\mathrm{r}^{5}}\left(2 \mathrm{x}^{2}-\mathrm{z}^{2}+3 \mathrm{xz}\right)
$$

With $\mathrm{a}=80 \mathrm{~cm}, \mathrm{x}=70 \mathrm{~cm}, \mathrm{z}=35 \mathrm{~cm}$ and $\mathrm{nI}=2.5$ abamp turns

$$
\begin{aligned}
\mathrm{H}_{\mathrm{X}} & =5 \times 10^{-5} \mathrm{oe} \\
\text { so } 4 \mathrm{H}_{\mathrm{X}} & =20 \%
\end{aligned}
$$

Similarly

$$
\begin{aligned}
& \mathrm{H}_{Z}=2.5 \times 10^{-5} \mathrm{oe} \\
& 8 \mathrm{H}_{Z}=20 \gamma
\end{aligned}
$$

so e. constructional accuracy of $\pm 1 \mathrm{~mm}$ with this size of coil will give sufficiently uniform fields. 


\subsection{Construction of Coils}

The design and drawing of the castings forming the corner pieces of the coils was done by $\mathrm{Mr}$ Gellen, and the coils were made in the College workshop.

The windings of the vertical component coils (called the "V" coils) were as follows -

a) In the bottom of the channel, and insulated from it by $0.005^{\prime}$ polythene, was a single layer coil of 64 turns of 23 B.S.G. enamel insulated copper wire.

b) The next coil, insulated from the first by $0.010^{\prime \prime}$ "Paxolin" sheet, contained another four layers of the same wire, each layer being separated by $0.005^{\prime \prime}$ thick insulating paper from its neighbours. Each layer was varnished before winding the next.

c) Four further sections of four layers each followed these, each section being insulated from the others by "Paxolin" sheet.

d) The coils were finished by being pressed firmly into the channel, and binding with PVC insulating tape.

Each section was tested at $600 \mathrm{v}$. D.C. for insulation to the frame. To test for shorted turns the coil was made the secondary winding of a transformer, the primary of which was supplied with $230 \mathrm{v}$. A.C. The voltages induced in all the sections were compared, and were found to be equal to within $0.2 \%$ when the number of turms in each section was equal, which indicated that no shorted turns were present.

The extra sections on the $V$ coils were to allow the application of fields up to 10 oe if required. 
The North-South component coils ("N-S" coils) are of the same design as the vertical component coils, except that the sides are short enough that they may fit inside the $V$ coils, and they have only one layer of 64 turns.

The sides of the $\mathrm{V}$ coil are $128.2 \mathrm{~cm}$ long and those of the N-S coils are $120.0 \mathrm{~cm}$ long. The spacing has been set without allowing for the finite width of the coils.

\subsection{The East-West Component Coils}

These, the "E-W" coils, are of different construction because it was proposed to line up the other coils so that the residual field, after cancelling that component of the earth's field in the plane defined by their axes, would be very small. The field of these coils is small, so the accuracy of their construction and their rigidity is not as important as in the others. The former for these coils is made from lengths of 表" $x \frac{1}{2}$ " outside dimensions extruded u-section aluminium, which are joined at the comers by screwing them into a triangular section of $\frac{1}{2}$ " aluminium plate. The coils have sides $115.0 \mathrm{~cm}$ long, to fit inside the $\mathrm{N}-\mathrm{S}$ coils, and are wound with 20 turns of 23 B.S.G. wire.

\subsection{Installation of the Coils}

The magnetometer was to be erected at the D.P.I. field station at Moore's Valley, so for convenience of measurement the oven was installed in another hut on the site. This hut already contained a concrete instrument pillar 8' long and 2' 6" wide with its short side pointing geographic North-South. The coils were mounted on $4^{\prime \prime} \times 2^{\prime \prime}$ u-section aluminium beams, 4' 8" long, with their long axes magnetic North-South. 
The $\mathrm{V}$ and $\mathrm{N}-\mathrm{S}$ coils were mounted on aluminium supports bolted to the beams, and the $E-W$ coils were clamped to the N-S coils. These coils were sufficiently rigid not to need extra bracing.

The coils were adjusted on the spacer rods so the four corners of each coil lay in a plane, and that these planes were parallel. The planarity of one coil was measured by defining the diagonals of the coils by string clamped between the collars and castings of each corner. Their intersection could easily be ensured to within $\pm 1 \mathrm{~mm}$. The spacing of the other coil in the pair was set at each corner to the length of a rod $59.06 \pm 0.03 \mathrm{~cm}$ long in the case of the N-S coils, and to the length of this rod, plus one $4.60 \pm 0.01 \mathrm{~cm}$ long, for the V coils. These distances make the centre of the coils' sides a distance apart equal to the Parry spacing. No correction has been made for the finite width of the coils.

It is necessary that the axes of the coils coincide, but this was not checked geometrically. However, the accuracy of construction, particularly the machining of the holes and collars at the corners, should be accurate enough to ensure this.

The centres of the $\mathrm{V}$ and $\mathrm{N}-\mathrm{S}$ coil pairs were made as coincident as possible, testing being performed with diagonal strings, but because there is insufficient screwed length on the $\mathrm{V}$ coil supports, the N-S coil centre is $\frac{1}{z}^{n}$ vertically above the $\mathrm{V}$ coil centre. 
6.6 FIELD CANCELIATION PROCEDURE

\subsubsection{Fluxgate Magnetometer}

To detect and measure the magnetic field a portable fluxgate magnetometer was borrowed from the Geophysics Division of D.S.I.R. The detecting head of this instrument contains two parallel mu-metal wires $3 \frac{1}{2} "$ long and $1 / 16$ " wide, each inside a solenoid 3/16" diameter. These solenoids are in two arms of a bridge circuit, the other arms of which are two $100 \mathrm{ohm}$ resistors. A 200c/s alternating voltage is applied as shown, and a detector tuned to the first harmonic is placed across the other two corners of the bridge. The coils are arranged so that in the presence of a steady magnetic

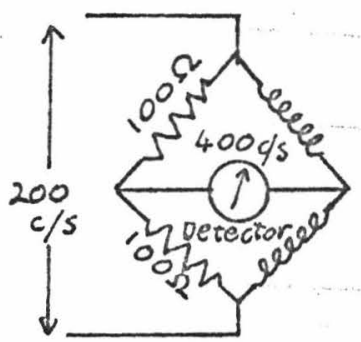
field, saturation of the core occurs in one solenoid before the other. This gives rise toa first harmonic signal, which is detected, and is a minimum when no direct field is present. It is possible to measure fields by passing a direct current through the coils to produce a steady field which cancels the ambient one, the magnitude of this current being proportional to the field.

Some trouble was experienced with the instrument, it giving apparently different strengths for the field when pointing parallel or antiparallel to the field. It was suspected that the cores had a permanent magnetization or too high a coercive force, so they were sent to the firm of Telcon, England, for demagnetization and annealing. The effect 
persisted, though to a lesser degree, and the explanation may lie in a difference between the solenoids or resistor arms of the bridge. The difficulty was avoided by adjusting the direct current through the solenoids to about $13 \mu \mathrm{A}$. When the external field is then adjusted for minimum signal with the Parry coils, the fluxgate will give the same signal independently of its orientation. Under these conditions the field can be cancelled to about $10 \gamma$.

\subsubsection{Alignment of Coil Axes}

In order that most of the cancellation can be carried out with the $\mathrm{V}$ and $N-S$ coils, it is necessary that the axes of these coils and the earth's magnetic field vector at the oven all lie nearly in a plane. Preliminary adjustments were to level the sides of the $\mathrm{V}$ coils and align the separating rods of the $\mathbb{N}-\mathrm{S}$ coils parallel to a compass needle. With the aid of the magnetometer the axis of the $V$ coils was brought into the plane defined by the earth's field and the $\mathbb{N}-\mathrm{S}$ coil axis, using the following method.

If the magnetometer axis is perpendicular to each of two different field vectors, then any third vector perpendicular to the magnetometer lies in the plane of the other two. A holder for the magnetometer was devised which enabled it to be rotated about an axis, A, perpendicular to the

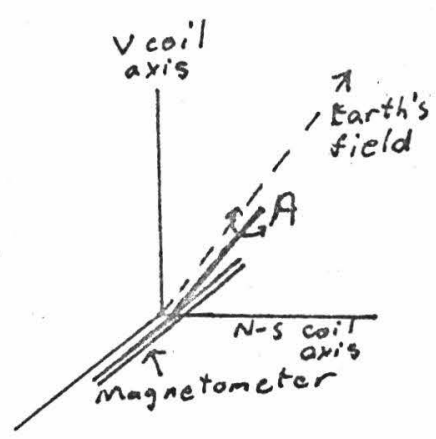
magnetometer axis, the orientation of $\mathrm{A}$ being adjustable so it could be made parallel to the earth's magnetic field vector. A was set approximately in this direction by eye, and then adjusted 
till the signal wo.s a minimum and did not change on rotating the magnetometer about $A$.

An approximately horizontal field was applied by the N-S coils, in the same direction as the earth's field component, and the magnetometer rotated about $\mathrm{A}$ until minimum signal was again obtained. The direction of the magnetometer was then perpendicular to the N-S coils and the earth's field, and was almost horizontal and East-West.

Application of the $V$ field gave a signal, which was minimised by raising the eastern side of the $\mathrm{V}$ coils a few millimeters.

\subsubsection{Cancellation}

To cancel the field the magnetometer is set approximately parallel to the axis of one coil-pair, say the vertical one. The current is adjusted to give minimum signal, and then the magnetometer is set approximately horizontal. With the vertical field nearly cancelled from the previous adjustment, the horizontal component may now be almost exactly cancelled, even though the magnetometer is not parallel to the coil axis. Having done this the vertical field may now be exactly cancelled. The coil axes are near enough to perpendicular that the component of field of one along the other is negligible. There may be a small East-West component of field remaining, which is cancelled by placing the magnetometer parallel to the E-W coil axis. Because of the small fields in this direction, it has not proved necessary to align these 
coils perpendicular to the others, or to adjust the field produced by the main coils after altering the $\mathrm{E}-\mathrm{W}$ current.

Cancellation to about $\pm 20 \gamma$ has been easily achieved over the volume of the oven, although once set up to this accuracy, magnetic objects in or near the hut, such as motor vehicles and portable meters should not be moved. 


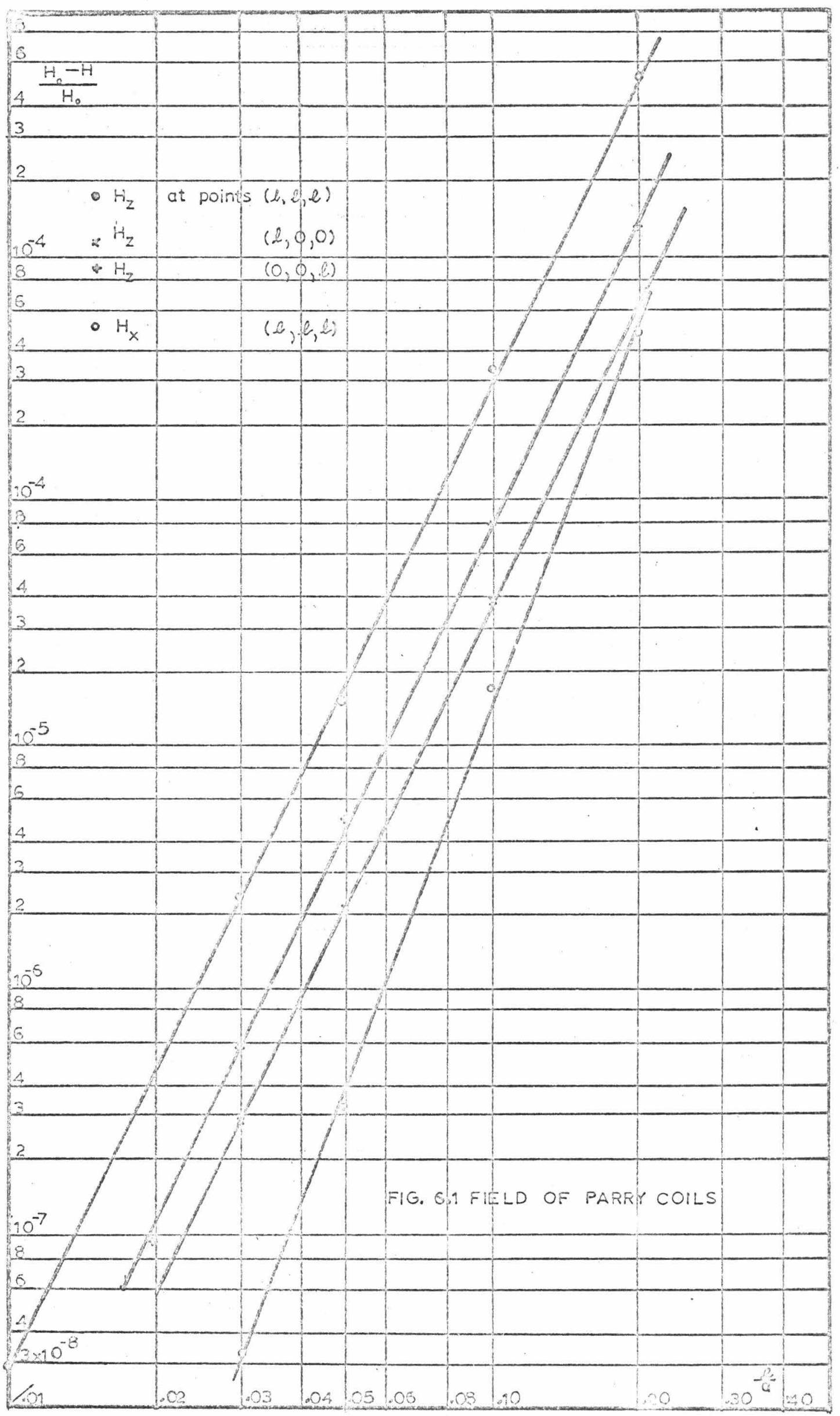




\section{CONSTANT CURRENT POWER SUPPLY}

\subsection{SPECIFICATIONS}

The field cancellation coils require a current of up to one ampere, and a voltage of about 25 volts. To keep field fluctuations within $\pm 25 \gamma$ of the mean field, the current must vary by less than $\pm 0.05 \%$. An important source of current fluctuations without regulation is the change in load resistance with temperature, which is about $0.4 \%$ per ${ }^{\circ} \mathrm{C}$. Supply voltage variations will also be important.

To reduce the engineering problems, lead-acid accumulators are used as the voltage source, instead of a transformer and rectifier system. These have the advantage of almost constant voltage, over the time taken for each cycle of the oven.

\subsection{SIMPLE REGULATOR}

A simple transistor series current regulator circuit, published by Schwartz (1960), appears, at first sight, to have sufficient stability for this purpose. A slightly modified version of this was constructed, according to the circuit shown in Fig. 7.1. The current from the supply passes through the resistance $R_{\mathrm{g}}$ and transistors $\operatorname{Tr} 1$ and $\operatorname{Tr} 2$. The OAZ2O2 is a zener diode, the voltage across which is almost independent of the current through it. The voltage $V_{S}$ is equal to this voltage, less the 
base-emitter voltage drops of transistors $\operatorname{Tr} 1$ and $\operatorname{Tr} 2$. The base-emitter voltage of the transistors used is about half a volt and is not strongly dependent on collectoremitter voltage, while the zener voltage is about $6 \mathrm{v}$. , so $V_{S}$ is almost independent of the voltage across the regulator. If $\mathrm{R}_{\mathrm{S}}$ is constant, this means the current passing through the load is almost independent of the magnitude of the load, within obvious limits.

The particular diode chosen has the property that at a certain current its temperature coefficient of voltage, which is otherwise considerable, is zero. A variable resistor was provided to enable the diode to be operated at this current.

The arrangement used to test the stability of the regulated supply is shown in Fig. 7.2(a). The current, $i$, from the supply is passed through a $2 \mathrm{ohm}$ constantan resistor, and adjusted to develop just over one volt across it. This voltage is compared with the E.M.F. of a Weston cell and the difference measured on a Philips recording potentiometer operated at $1 \mathrm{mV}$ full scale deflection. Changes in current as small as $0.001 \%$ could be detected with this arrangement.

Although the regulator prevented significant changes in current due to load changes, it was very sensitive to ambient temperature fluctuations. The temperature effects proved to be due to variation with temperature of the base-emitter voltage of the regulating transistors. It has been mentioned that this voltage is in series with the comparison voltage, and will directly affect the current. In fact the specified value for $\frac{\partial V_{b e}}{\partial T}$ led to precisely the observed value for change in current with temperature $\left(0.1 \% 1^{\circ} \mathrm{C}.\right)$ 


\subsection{SATISFACTORY REGULATOR}

\subsubsection{Basic Circuit}

Just after this effect was recognised, two successive issues of "Electronic Engineering" carried articles on current stabilized transistor power supplies (Walker, 1962, and Lovick, 1962). These stabilizers avoid temperature effects by using a differential "long tailed pair" amplifier, in which the change in $\mathrm{V}_{\text {be }}$ affects two transistors equally, which means there is no change in current. A regulator based on Walker's circuit was designed to the above specifications, (Fig. 7.3).

In this circuit transistors $\operatorname{Tr} 4$ and $\operatorname{Tr} 5$ correspond to $\operatorname{Tr} 1$ and $\operatorname{Tr} 2$ in Fig. 7.1. $\operatorname{Tr} 4$ is driven by $\operatorname{Tr} 3$ from the differential amplifier transistors $\operatorname{Tr} 1$ and $\operatorname{Tr} 2$. The base potentials of $\operatorname{Tr} 1$ and $\operatorname{Tr} 2$ will be nearly equal, because of the equal base-emitter voltages, so that the voltage across $R_{B}$ is the same as the centre tap voltage of the helipot. This voltage is stabilized by means of a zener diode, and its range is altered when changing current ranges. Adjustment of current is in six equal ranges from $200 \mathrm{~mA}$ to $800 \mathrm{~mA}$, the calibration of the helipot being linear within each range.

\subsubsection{Temperature Regulation}

The problem of temperature variations affecting the zener diode voltage will be encountered unless the current through it is about $\frac{1}{2} \mathrm{~mA}$ (cf Section 7.2 ). It can be seen from the part of the circuit shown in Fig. 7.4 that such low currents are not possible. For linear variation of current with helipot position, the transistor base 
current must be much less than the current in the helipot. The maximum base current is $40 \mu \mathrm{A}$, so the minimum helipot current may be $4004 \mathrm{~A}$. This occurs when $\mathrm{R}_{a}$ is maximum, so when $\mathrm{Ra}$ is a minimum, the helipot current will be $\frac{9 \times 0.4}{3}=1.2 \mathrm{~mA}$. As this change in current must be supplied by the zener diode, its operating current should be much greater than $1 \mathrm{~mA}$. This means it is not possible to operate the diode near the current required for zero temperature coefficient. The operating current was chosen as $20 \mathrm{~mA}$ to give low dynamic impedance.

The temperature of the reference diodes and differential amplifier transistors are regulated (using the method described by Kemhadjian, 1958,) for two reasons: 1. To prevent changes in zener diode voltage. 2. To eliminate possible troubles arising from imperfect balancing of the differential amplifier. The circuit is showr in Fig. 7.5 . The transistors 0071 and 0072 are mounted in holes drilled in a cylindrical copper block $1 \frac{1}{4} "$ in diameter and $\frac{3}{4} "$ high, (see centre of Fig. 7.7). Three strands of resistance wire wound around the outside and connected in parallel form a heater of 12 ohms resistance, which is supplied with current at a rate controlled by $\operatorname{Tr} 4$. Tr 1 has its base open circuited, and is connected to $\operatorname{Tr} 2$ in such a way that its

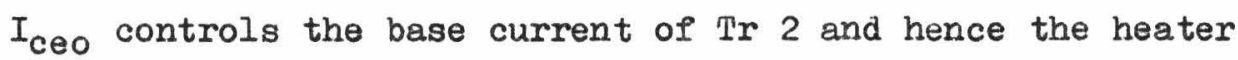
current. The value of $I_{c e o}$ is very temperature dependent, so that $\operatorname{Tr} 1$ acts as a thermometer and regulates the temperature of the block. The devices whose temperatures are to be regulated are mounted in other holes drilled in the block.

The resistance of 12 ohms for the heater in the present device is higher than the 8 ohms quoted by Kemhadjian, but 
at first sight this appears immaterial, as, although it increases the time to heat up, it reduces thermal overshoot. However, there turned out to be a somewhat subtle effect of this change. If $\mathrm{V}_{\text {cel } 1}$ represents the collector-emitter voltage of transistor $\operatorname{Tr} 1$, and so on for the other voltages possible, then

$$
\mathrm{V}_{\text {ce1 }}=\mathrm{V}_{\mathrm{be} 3}+\mathrm{V}_{\mathrm{be} 4}-\mathrm{V}_{\mathrm{be} 2}
$$

$V_{b e}$ decreases as $I_{c 4}$ decreases, so a decrease in $I_{c 4}$ decreases $\mathrm{v}_{\text {ce1 }}$.

Suppose the temperature of the block increases slightly above the equilibrium temperature. I I $I_{\text {ce1 }}$ increases, which decreases $I_{c e}$ and hence the heater current. It also decreases $V_{\text {be } 4}$ and hence $V_{c e 1}$ decreases, which lowers $I_{c e 1}$ electrically, allowing the temperature of the block to rise slightly above its previous value. With an 8 ohm heater the current required at equilibrium is such that $V_{c e} 1$ is greater than $\frac{1}{2} \mathrm{v}$. In this case $\frac{\partial I_{c e}}{\partial V_{c e}}=0$ so the electronic feedback is negligible. With the $12 \mathrm{ohm}$ heater $\mathrm{V}_{\mathrm{ce} 1}$ is low enough that the feedback considerably reduced the thermal regulation.

Rather than rewind the heater, a 2 ohm emitter resistor, consisting of 3 " of resistance wire instead of a copper connecting wire, was inserted in the emitter circuit of Tr 4. After this modification a change in ambient temperature of $5^{\circ} \mathrm{C}$. produced $1 / 40^{\circ} \mathrm{C}$. change in temperature of the copper block. This degree of regulation was considered very satisfactory.

\subsubsection{Final Design}

Two independent regulated supplies are required, one for each pair of field cancellation coils. These are both 
constructed on a single panel of $\frac{7}{4} "$ aluminium, which also serves as a heat sink for the 0C26 transistors. The GET114's and the OAZ2O2's are mounted in the temperature regulated copper block. The two regulators shared a $24 \mathrm{v}$. and $12 \mathrm{v}$. zener regulated supply, the OAZ213's of which are mounted in holes drilled in a $\frac{1}{2}$ " diameter brass supporting rod, which acts as a heat sink.

Meters are provided to measure the supply voltage, and the current in both outputs. Terminals are provided on the front of the panel for insertion of a shunt and potentiometer, for accurate current measurements. A rear view of the instrument is shown in Fig. 7.7, and it is visible in the rack in Fig. 7.8 .

\subsection{TESTING AND MODIFICATION OF REGULATOR}

\subsubsection{Effect of Ioad Changes}

The current changes by $0.01 \%$ for a $10 \%$ change in load resistance.

\subsubsection{Ambient Temperature Effects}

The temperature coefficient was initially about $0.1 \%$ per ${ }^{\circ}$. change in ambient temperature, part of which was due to the use of a common positive lead to the $\operatorname{Tr} 4$ of the temperature regulator and the helipots of the current regulator. Although very small, the resistance of the wire was sufficient that the varying current in the thermostat with ambient temperature produced a significantly variable voltage drop in the leads to the 
differential amplifier, which caused changes in current with the temperature. A separate lead corrected this problem.

A temperature coefficient of $0.02 \% /{ }^{\circ} \mathrm{C}$. remained. It was suspected that this was due to the different temperature coefficients of the helipots and the resistors in series with them. The temperature coefficients of commercially available resistors were measured using the circuit shown in Fig. 7.2(b). One of the two similar resistors to be tested, $R_{1}$ and $R_{2}$, was cooled in a test tube immersed in ice and water. The change in reading of the potentiometer when the resistors were brought to the same temperature gives the resistance change, since

$$
\frac{d V_{1}}{V_{1}}=\frac{1}{2} \frac{d R_{1}}{R_{1}}
$$

The best resistors available had a coefficient of $0.002 \% /{ }^{\circ} \mathrm{C}$. which is similar to that of the helipots, but substitution of these for the previously used ones did not significantly alter the temperature coefficient of the regulator.

A possible source of the temperature effect is the variation in the characteristics of transistors $\operatorname{Tr} 4$ and $\operatorname{Tr} 5$, in Fig. 7.3, with temperature, for the base current of $\operatorname{Tr} 4$ passes through the current sensing resistor, but not the load. The effect of variations in gain was calculated to be $0.003 \% /{ }^{\circ} \mathrm{C}$, and in $I_{\text {ceo }} 4 \times 10^{-4} \% / 0 \mathrm{C}$, which are too small to matter at the present level of stability. Despite this calculation the effect seems to be connected with the temperature of these transistors, as shown by local heating of the heat sink with a soldering iron. 
It is possible to insert a temperature dependent resistance, $R_{X}$, in series with the current sensing resistor, $R_{S}$, to compensate for temperature changes in these transistors. Let $R=R_{S}+R_{X}$

$\frac{1}{V} \frac{d V}{d t}=\frac{1}{I} \frac{d I}{d t}+\frac{1}{R} \frac{d R}{d t}$

$(t=$ temperature $)$

The voltage $\mathrm{V}$ may be supposed to be held constant by the feedback

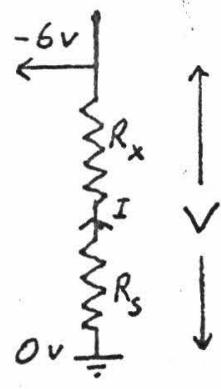
system, and it is desired to alter the current I with temperature changes, in order to compensate for changes in the base current of $\operatorname{Tr} 4$, which does not flow through the load. The measured change in load current is $+0.02 \% /{ }^{\circ} \mathrm{C}$., so

$$
\begin{aligned}
\frac{1}{V} \frac{d V}{d t} & =0 \text { and } \frac{1}{I} \frac{d I}{d t}=-0.02 \% /{ }^{\circ} \mathrm{C} . \\
\text { so } \frac{1}{R} \frac{d R}{d t} & =+0.02 \% /{ }^{\circ} \mathrm{C} .
\end{aligned}
$$

If copper wire is used for $\mathrm{R}_{\mathrm{X}}, \frac{\mathrm{d} \mathrm{R}_{\mathrm{X}}}{\mathrm{R}_{\mathrm{X}} \mathrm{dt}}=0.4 \% /{ }^{\circ} \mathrm{C}$.

$$
\begin{aligned}
& \quad \frac{d R}{R d t}=\frac{d R_{X}}{\left(R_{X}+R_{S}\right) d t}=2 \times 10^{-4} \\
& \text { so } \frac{R_{X}+R_{S}}{R_{S}}=20, \\
& \text { i.e. } R_{S}=19 R_{X}
\end{aligned}
$$

Thus the value of the stabilizing resistor depends on the range used. For the vertical component power supply $R_{S}=10$ ohms, so $R_{X}=\frac{1}{2}$ ohm.

The resistor was constructed from 6" of $40 \mathrm{~g}$ copper wire, which was wound on the surface of a $1 "$ square $x \frac{1}{8}$ " thick copper plate, and insulated from it by paper glued over its 
surface (Fig. 7.2(c) and (d)). The plate was then screwed on to the heat sink with the wire between the two.

With this modification the temperature coefficient was $+0.003 \% /{ }^{\circ} \mathrm{C}$., which was expected to be sufficiently low.

\subsubsection{Supply Voltage Variations}

The regulator was powered from a DC supply with a 2 volt $(7 \%)$ peak to peak $50 \mathrm{c} / \mathrm{s}$ ripple voltage superimposed. This resulted in a $0.1 \%$ ripple current in the output, so that current stability better than $0.01 \%$ requires input voltage stability about $1 \%$. At a $1 \mathrm{amp}$ discharge rate a typical change in voltage is $0.1 \%$ per hour for heavy duty lead acid accumulators, which gives the required degree of current stability over a 10 hour day. The temperature coefficient of voltage, being $0.015 \% /{ }^{\circ} \mathrm{C}$., is negligible.

\subsection{LOAD IMPEDANCE RESTRICTIONS}

\subsubsection{Open Circuit Conditions}

Current regulators in general are susceptible to damage under these conditions, so an analysis was performed to determine what factors were involved.

As the load increases, the voltage drop across $\operatorname{Tr} 5$ (Fig. 7.3) drops, regulation ceasing when $V_{\text {ce } 5}=V_{\text {knee }}$. As the load continues increasing, $\operatorname{Tr} 2$ becomes cut off because its base voltage becomes more positive while its emitter is held at constant voltage by $\operatorname{Tr} 1$. The lowered current in its $8.2 \mathrm{k}$ collector resistor makes the base of 
Tr 3 become more negative, so more current flows through the circuit: $\operatorname{Tr} 3$ collector-emitter, $\operatorname{Tr} 4$ base-emitter diode, $\operatorname{Tr} 5$ base-emitter diode, $R_{S}$, to ground. Assuming Tr 2 completely cut off, the maximum base current in $\operatorname{Tr} 3$ is $3 \mathrm{~mA}$, corresponding to an emitter current of $100 \mathrm{~mA}$, which flows through the two base-emitter diodes. This does not exceed the rating of the transistors, but the current would have to pass through the zener diode 23 , which is rated at $50 \mathrm{~mA}$ maximum. By putting a $1 \mathrm{~K}$ collector resistor on $\mathrm{Tr} 3$ the maximum current is limited to $10 \mathrm{~mA}$, which when combined with the normal current in 23 of $30 \mathrm{~mA}$, is a safe rating. Normal operation is not affected by the presence of this resistor because the usual current of $3 \mathrm{~mA}$ produces a drop of $3 \mathrm{v}$. and leaves the $V_{c e}$ of $\operatorname{Tr} 3$ at at least $2 \frac{1}{2} \mathrm{v}$. , which is ample to run it. Because of the small value of $\frac{\partial\left(I_{c e}\right)}{\partial\left(V_{c e}\right)}$ this resistor introduces negligible feedback. This modification successfully protected the circuits, but a 25 ohm dummy load, which was previously connected across the output when the polarity switch was in the off position, has been left connected.

\subsubsection{Short Circuit}

The maximum allowable collector emitter voltage on the OC26 is -40 volts, so voltage ratings cannot be exceeded with supply voltages less than this. The power dissipation in the transistor should be limited to 12.5 watts. Under short circuit conditions, therefore,

$$
\begin{aligned}
\left(v_{c c}-6\right) I & =12.5 \\
\text { so } \quad I=\frac{12.5}{32} & =0.4 \text { amps }
\end{aligned}
$$

Thus the supply will not be damaged on short circuit if it is operating on the $0.4 \mathrm{amp}$ range or lower. To protect it 
on higher current ranges it is necessary to use a lower supply voltage, or insert another 0C26 in parallel with $\operatorname{Tr} 5$. The maximum current, $I_{\max }$, with a given load impedance, $R_{I}$, or minimum load wi th a given current, is found from

$$
I_{\max }^{2} R_{L}-\left(V_{c c}-6\right) I_{\max }+12.5=0
$$

where $V_{c c}$ is the supply voltage. Any alterations in supply voltage will require adjustment of the load resistors of zener diodes $Z 2$ and 23 to keep their current at $20-30 \mathrm{~mA}$.

\subsection{TRANSIENTS}

It is necessary that no destructive transients are produced when switching currents or loads. This was checked on the final installation at Moore's Valley, the greatest transients found being only $15 \mathrm{v}$. peak for about $1 \mathrm{~m} s$, and across collector emitter junctions.

\subsection{FINAL CIRCUIT}

The final circuit is as shown in Fig. 7.6. Any future modifications should be recorded in the book for circuits at Moore's Valley. 


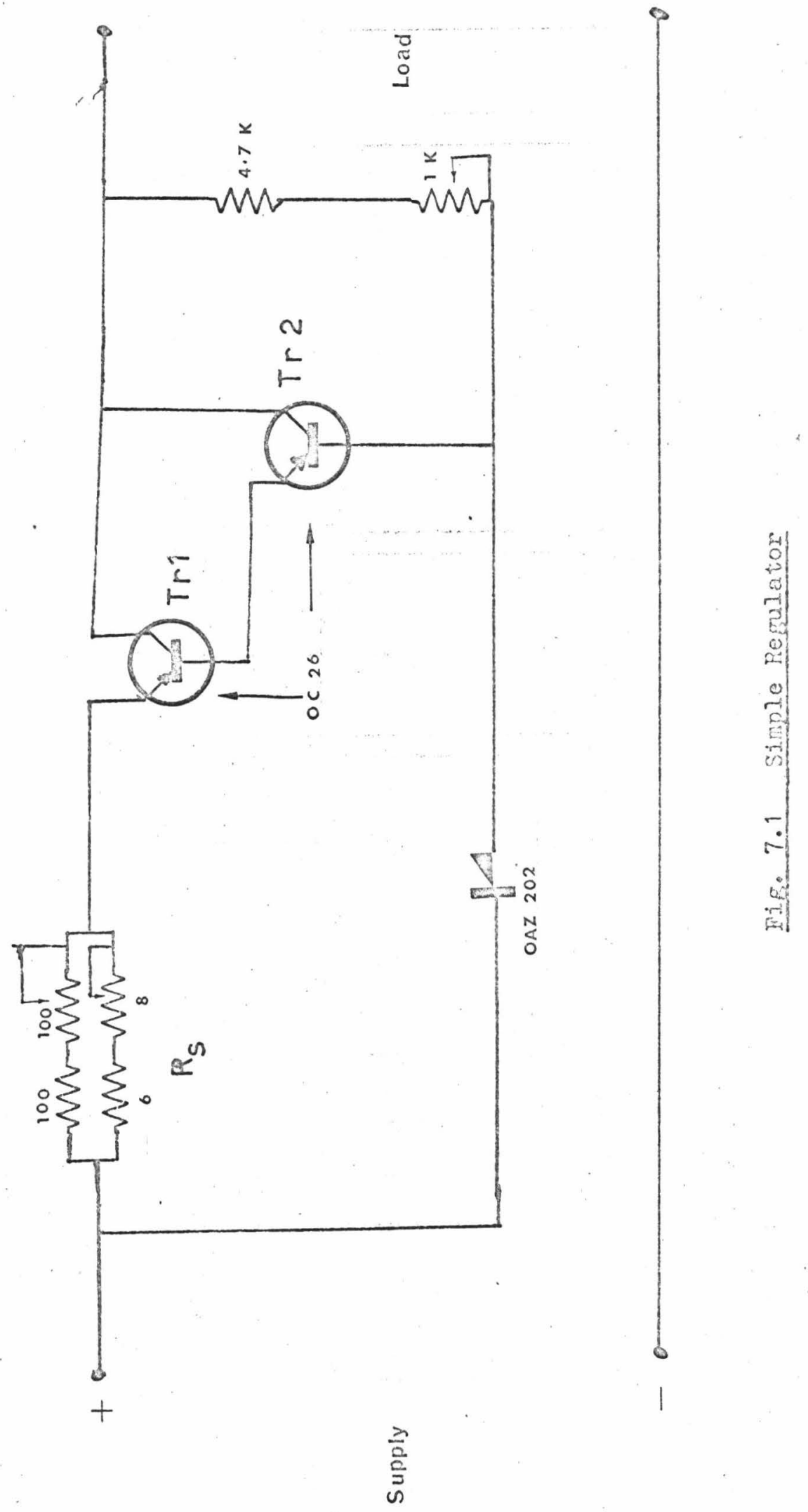



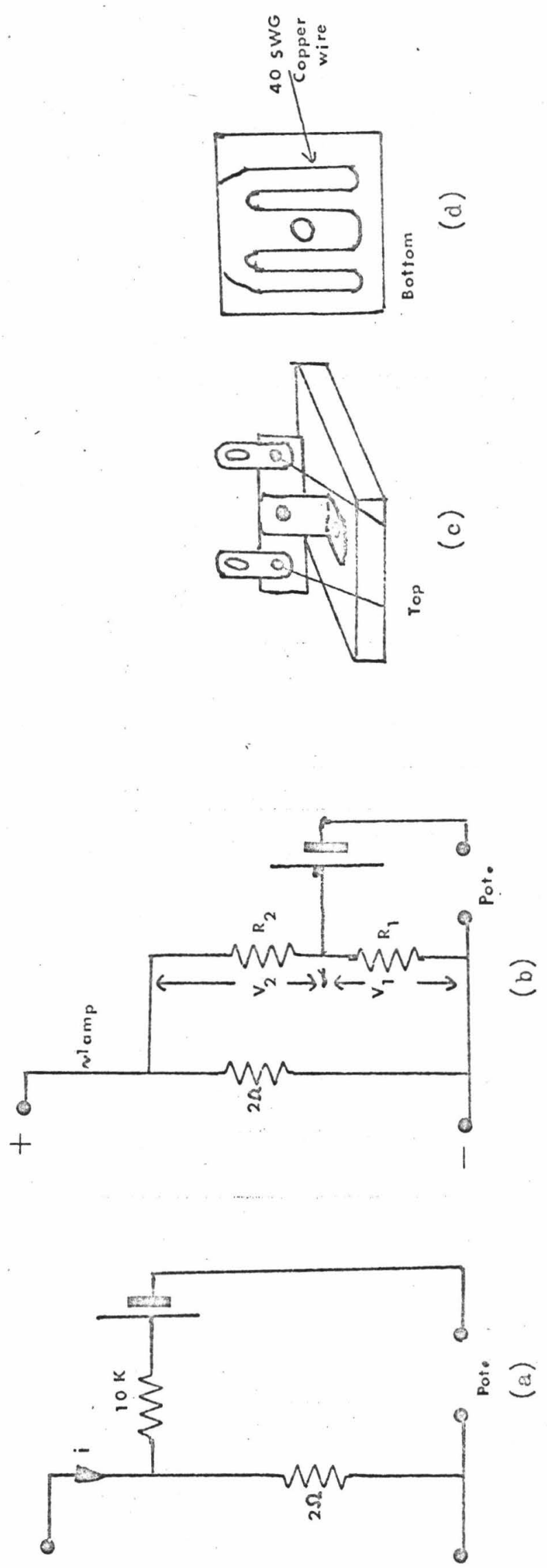


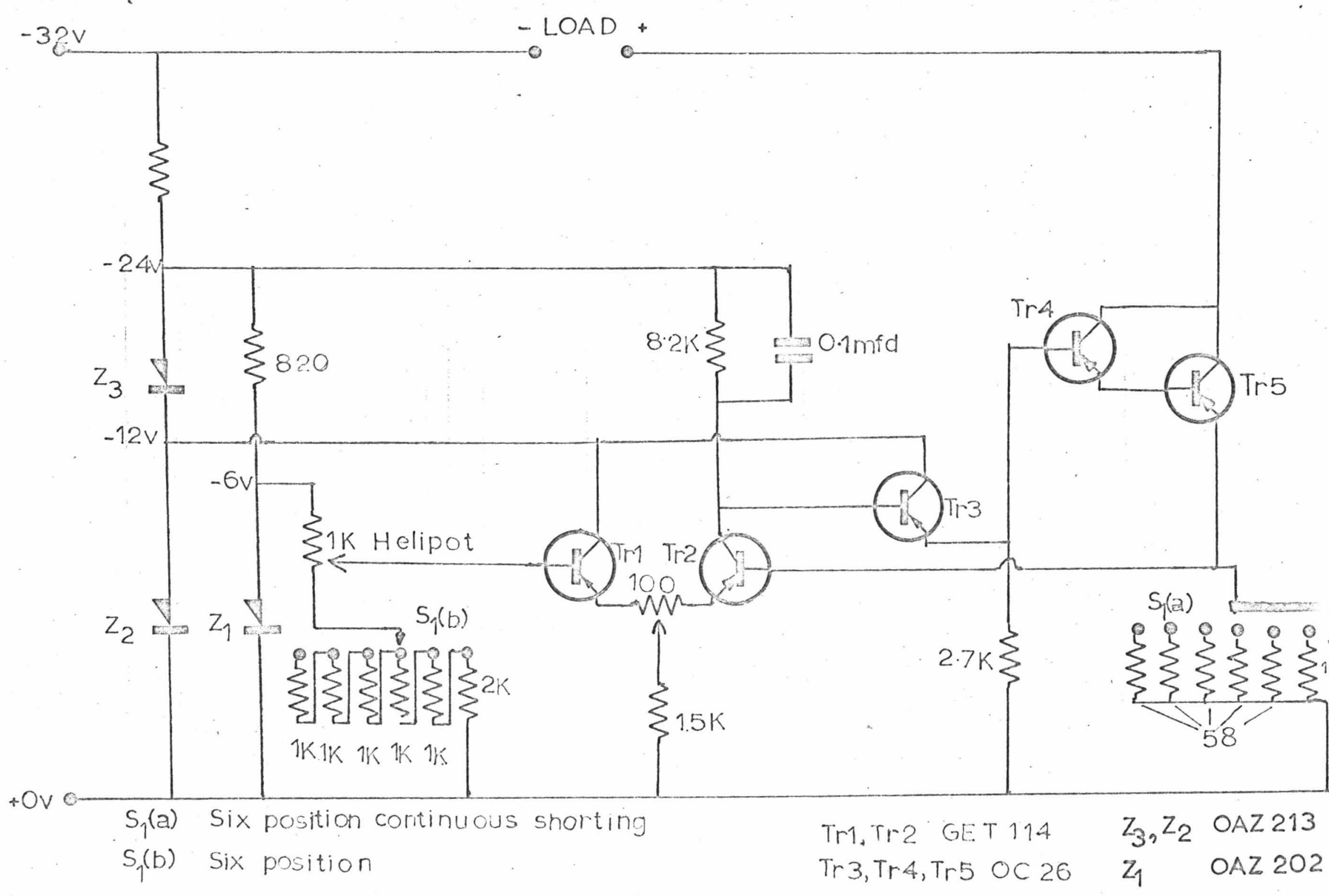

Eig. 7.3 Basic Circuit of Current Regulator 


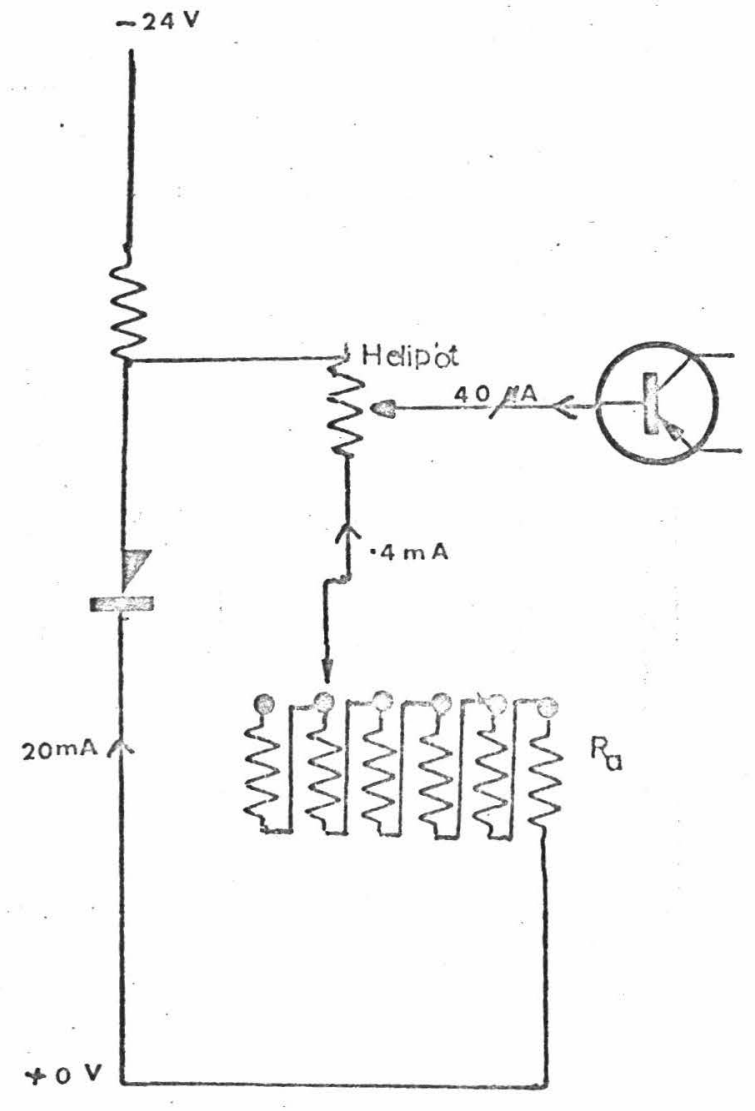

Fif. $7.4 \quad$ Purt of Fig. 7.3

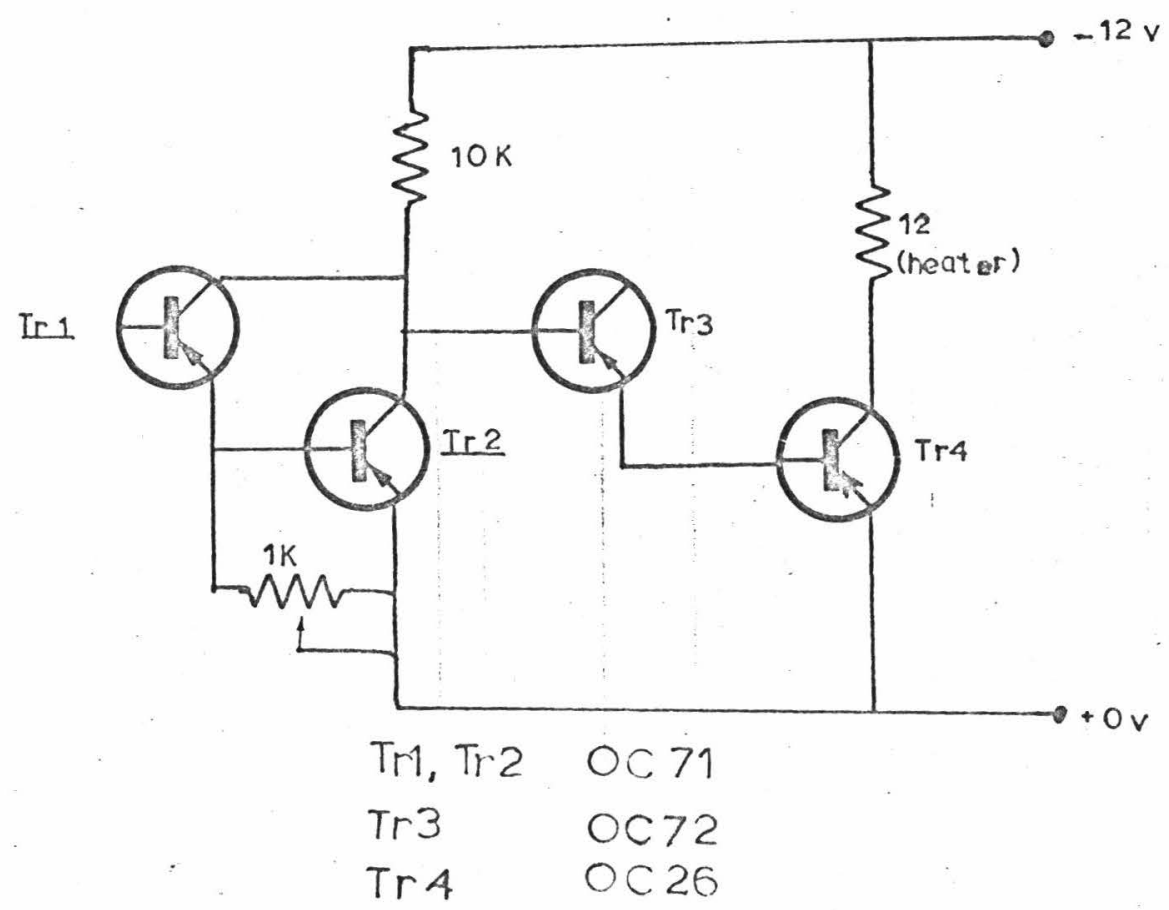

Fig. 7.5 Temperature Regulator 


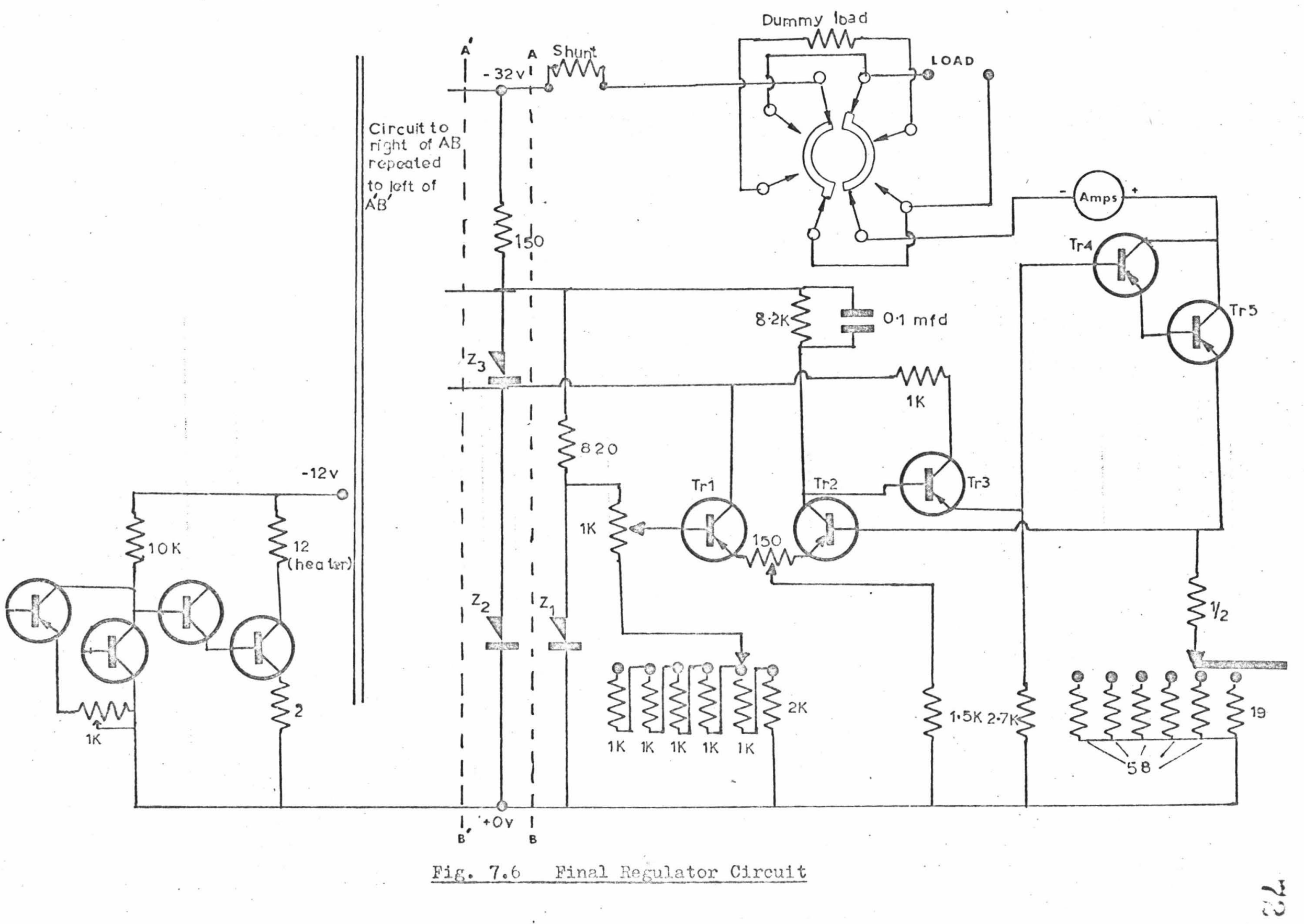




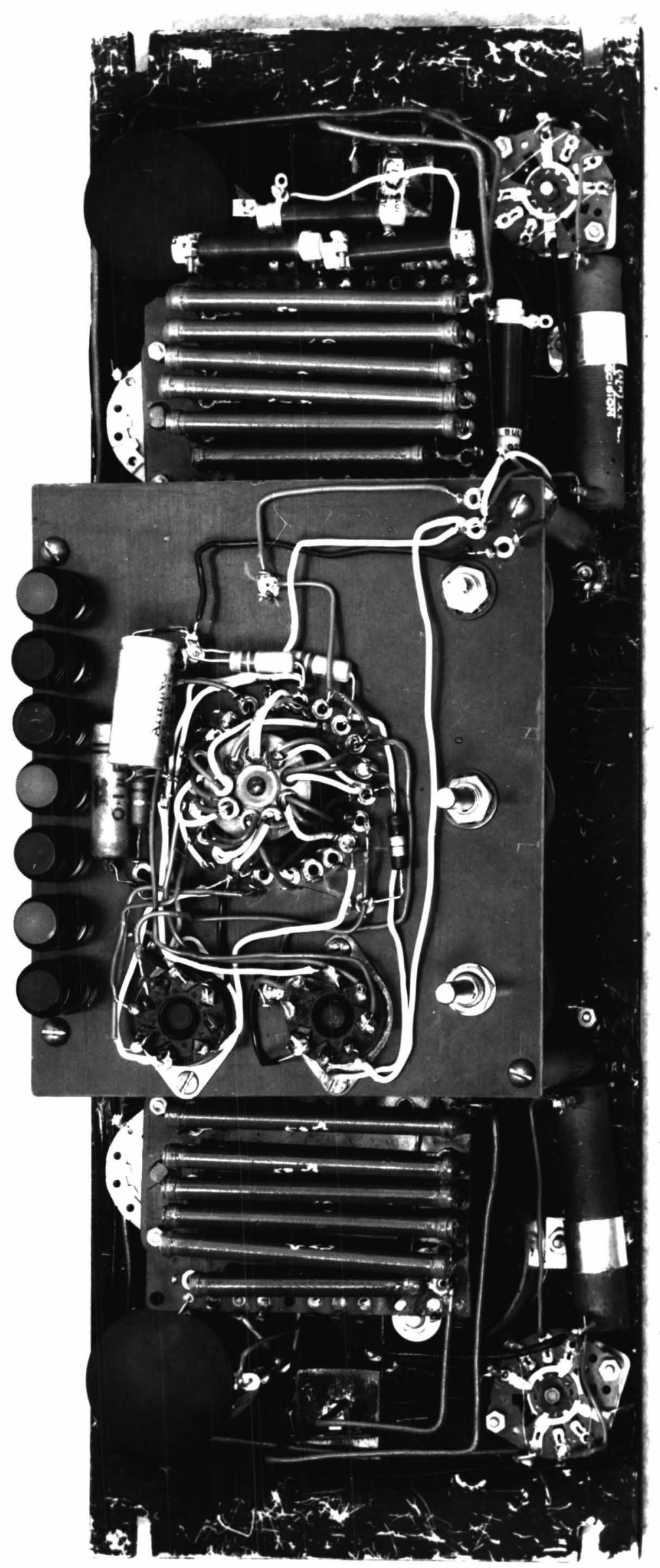


Recorder battery distribution

\begin{abstract}
E-W control
Recorder terminals

$\begin{array}{ll}\text { Current regulator } & \text { battery } \\ \text { charger }\end{array}$

ntrol
\end{abstract}

Fig. 7.8 Control Equipment nitrogen

cylinder

magnetic

valve

oxygen

Variac removal 


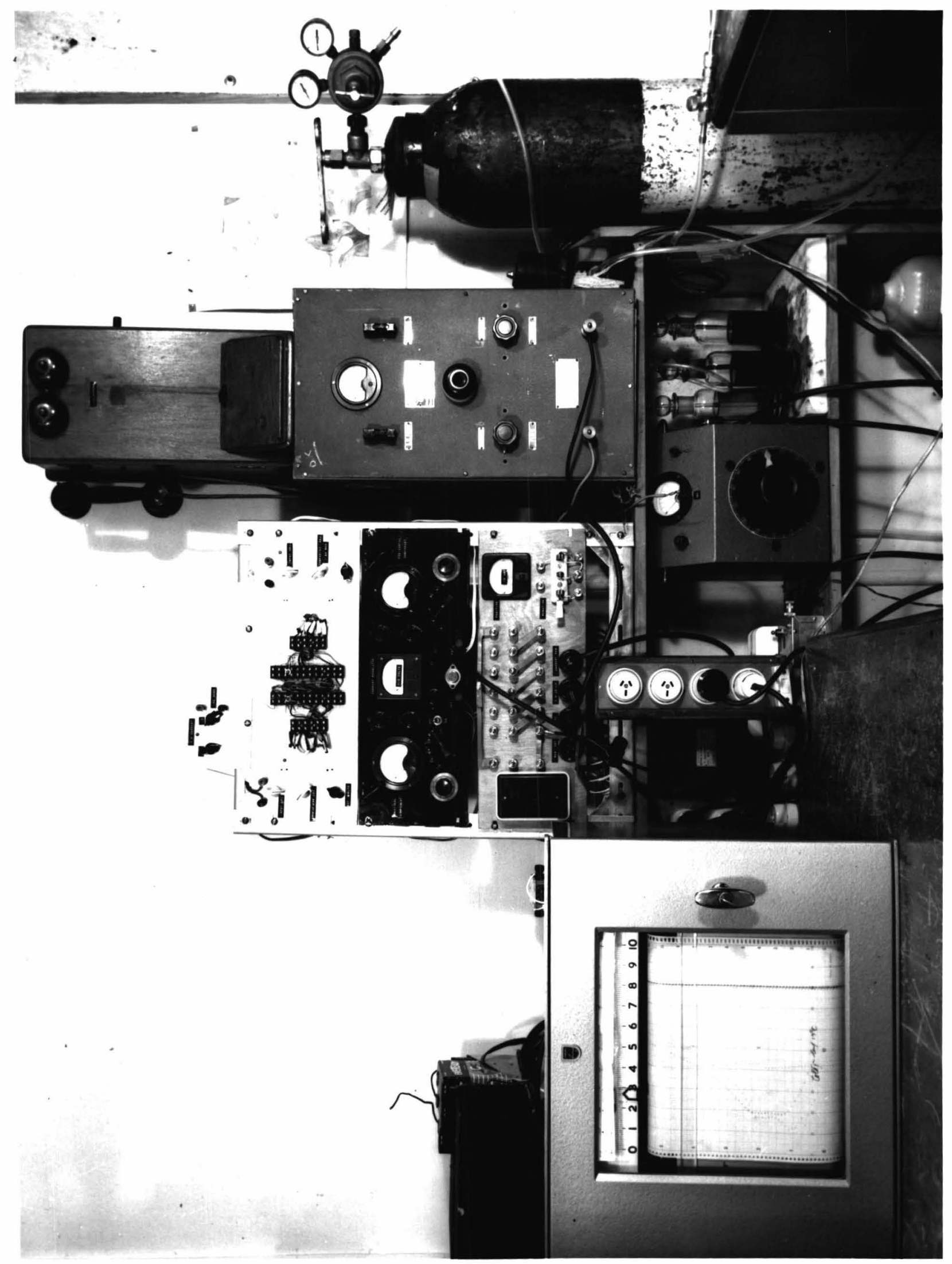


THE MAGNETOMETER

\subsection{GENERAL DESCRIPTION}

This astatic magnetometer is a modification, designed by Clegg, of Blackett's instrument (Blackett, 1952). It was originally installed at V.U.W. by Mr Gellen (1959), who performed most of the work involved in setting it up at a more magnetically quiet site at Moore's Valley. It remained for the author to level and centre the sample holder before using it in the investigation in this thesis. A method of cancelling the ambient magnetic field was devised by the author.

The astatic magnetometer consists of a pair of magnets $P_{1}$ and $P_{2}$ (Fig. 8.1) rigidly fixed to a beam, and magnetized equally in opposite directions. The beam is suspended from a fine fibre, and rotation of it is detected by the deflection of a light spot reflected from a mirror attached to the beam (not shown in Fig. 8.1). When $P_{1}$ and $P_{2}$ are equal no torque is exerted on the beam by a uniform magnetic field. The earth's field is cancelled with Helmholtze coils. If a magnetized body is placed beneath the lower magnet, the field produced at $P_{1}$ is greater than that at $\mathrm{P}_{2}$ so a torque proportional to the field difference is exerted on the beam, and the deflection produced by it is a measure of the difference in horizontal field, in the direction perpendicular to the magnetization directions, between $P_{1}$ and $P_{2}$. 
To measure the vertical component of the magnetization of the specimen, it may be offset from the central position a distance $x_{0}$, which results in a horizontal component of field at the magnets, due to this vertical component of magnetization. The sample is rotated about a vertical axis to find the two horizontal components.

\subsection{CENTRING AND LEVELIING}

This was accomplished with the aid of a spirit level, and measurements on the field of a small coil mounted on the sample holder. The coil is supposed to act as a dipole of moment $\mathrm{H}$, which makes a small

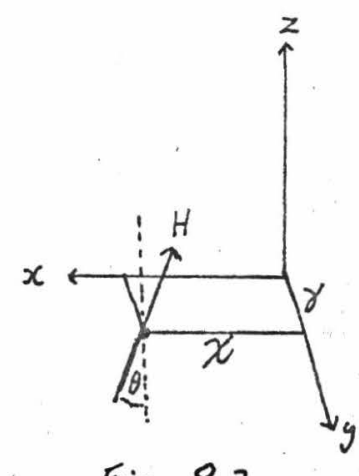

Fig 8.2 angle $\theta$ with the vertical. The centre of this dipole is a distance $z_{0}$ below the lower magnet, which is assumed to be the only one affected by the field, and is offset distances $\mathcal{Z}$ and $\gamma$ in the $\mathrm{x}$ and $\mathrm{y}$ directions (see Fig. 8.2). The dipole may be rotated in the sample holder about an axis which it is desired to make vertical, and which is nearly parallel to the direction of $\mathrm{H}$.

It is of interest to consider the sum of the deflections produced with the dipole in two positions, one of which is that attained by rotating $180^{\circ}$ about the above axis from the other position. Call the components of $\mathrm{H}$ along the $\mathrm{x}, \mathrm{y}$, and $\mathrm{z}$ axes $\mathrm{L}, \mathrm{M}$, and $\mathrm{N}$ respectively where $\mathrm{N}$ is very much greater than M or I. Cave (1961) showed that the horizontal component of the field, in the $x$ direction, at the lower magnet is approximately given by

$$
x=-\frac{L}{z_{0}{ }^{3}}-\frac{3 y N}{z_{0}{ }^{4}}-\frac{3 x y M}{z_{0}{ }^{5}}
$$


Write

$$
\begin{aligned}
& I=p_{x}+q_{x}+r_{x} \\
& M=p_{y}+q_{y}+r_{y} \\
& N=p_{z}+q_{z}+r_{z}
\end{aligned}
$$

where $p, q$ and $r$ are the components of $H$ along coordinate axes $P, Q, R$, where $R$ is parallel to the rotation axis, and $p_{x}, p_{y}$, etc. are components of these components, along the $\mathrm{x}, \mathrm{y}$, and $\mathrm{z}$ axes. On rotating the dipole $180^{\circ}$ about $R, p$ and $q$ change sign, so that

$$
x_{0}+x_{180}=-2\left(\frac{r_{x}}{z_{0}^{3}}+\frac{3 x_{r_{z}}}{z_{0}{ }^{4}}+\frac{3 x y r_{y}}{z_{0}}\right)
$$

In practice, the centre of the dipole will not be exactly on the rotation axis, but this merely alters $\mathcal{X}$ slightly, and does not affect the argument.

If the dipole is almost parailel to the rotation axis, then $r_{y} \ll r_{z} \cdot \quad$ Since also $\frac{\gamma}{z_{0}} \quad 1$

$$
\begin{aligned}
x_{0}+x_{180} & =-2\left(\frac{r_{x}}{z_{0}{ }^{3}}+\frac{3 \chi r_{z}}{z_{0}{ }^{4}}\right) \\
& =A\left(z_{0} r_{x}+3 z_{z}\right)
\end{aligned}
$$

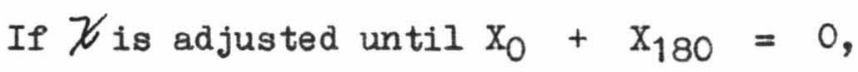

then

$$
\frac{r_{x}}{r_{z}}=-\frac{3 \chi \chi}{z_{0}}
$$

$\frac{r_{x}}{r_{z}}$ is the tangent of the angle between the rotation axis and the vertical, and the magnetometer is said to be levelled when this angle is zero. The condition $\mathrm{X}_{0}+\mathrm{x}_{180}=0$ is the condition that the relationship 8.2 between centring and levelling holds. 
Levelling was achieved to $\pm 0.02^{\circ}$ with a spirit level. With this degree of levelling, the criterion (8.1) would give

$$
\begin{aligned}
X & <\frac{8}{3} \times \frac{0.02 x \pi}{180} \mathrm{~cm}\left(z_{0} \doteq 8 \mathrm{~cm}\right) \\
& =0.001 \mathrm{~cm} .
\end{aligned}
$$

This is better than the accuracy of setting samples in the holder, and is quite sufficient.

Centring in the $x$ direction was limited to $\pm 0.02 \mathrm{~cm}$ by random movements of the sample holder.

Centring in the $\mathrm{y}$ direction was accomplished to $\pm 0.1 \mathrm{~cm}$ by a no parallax method.

\subsection{CANCELTATION OF EARTH'S MAGNETIC FIEID}

This was initially done using a single magnet suspended in the magnetometer, for the horizontal components, and using a fluxgate for the vertical component. When the Avo used to record the currents became faulty it became necessary to set the currents up again, for the meter had been used across an external shunt, on low current ranges to obtain sufficient sensitivity as a voltmeter. The readings depended on the unknown internal resistance of the meter. Rather than risk damage to the magnetometer suspension, on removing it to use the single magnet, a cubical box of $\mathrm{MnSO}_{4} \cdot 4 \mathrm{H}_{2} \mathrm{O}$ was placed in the sample position, and the currents in the Helmholtze coils altered so that it had no detectable induced magnetic moment. The procedure is simple and fairly obvious. The $x$ component is cancelled with zero offset, and then the $\mathrm{z}$ component with about $1 \mathrm{~cm}$ offset. The $\mathrm{y}$ component Helmholtze current was set to be the same as the previous 
reading on the meter incorporated in the control panel, which ought to be accurate enough for this component. The $\mathrm{x}$ and $\mathrm{z}$ component currents could be set to $1 \%$ with this salt, the main difficulty being the smallness of the induced moment. Greater accuracy could be attained with a more strongly paramagnetic salt. 

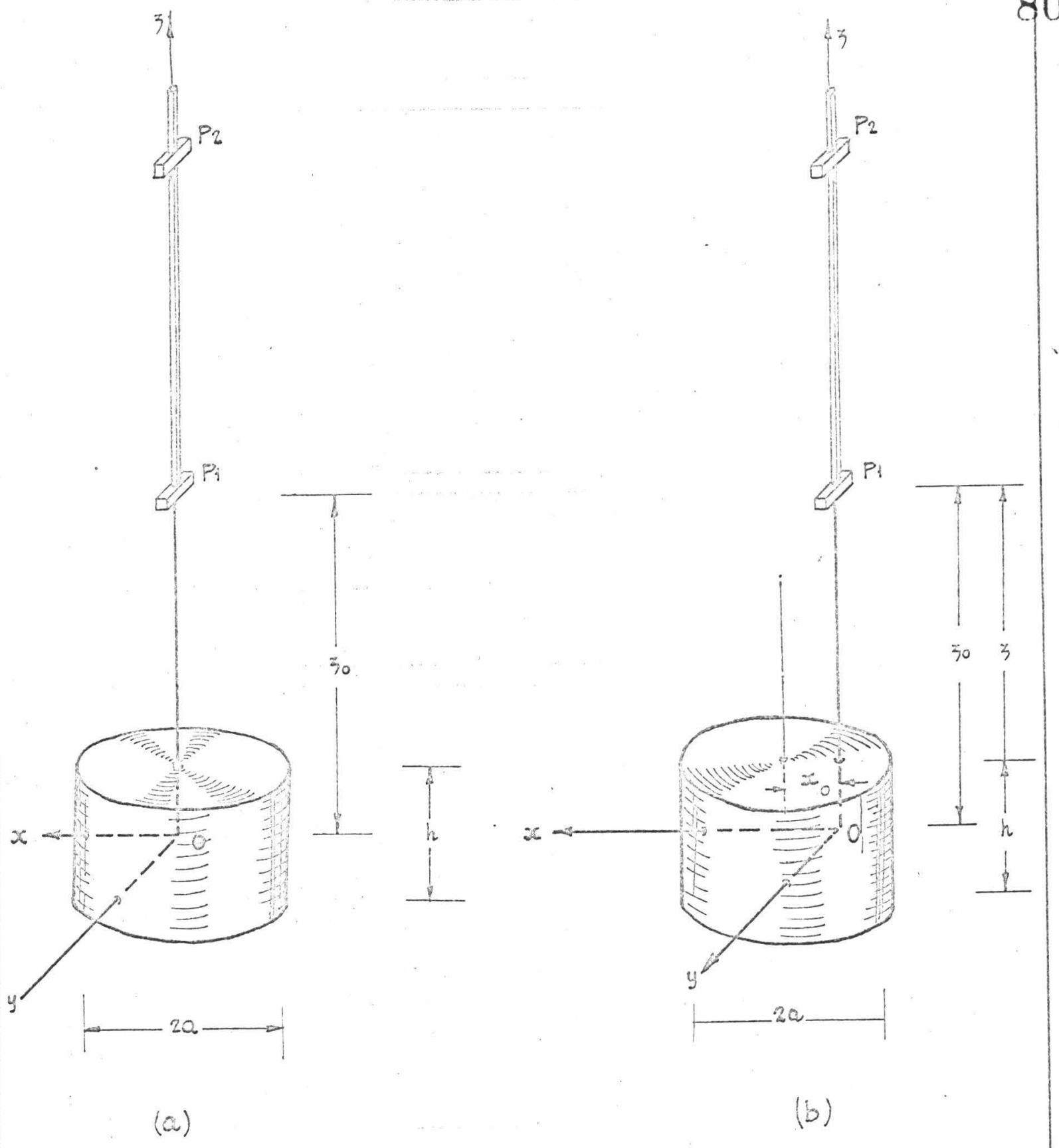


\subsection{GENERAL GEOLOGICAL DESCRIPMION}

Ignimbrites (also called welded tuffs and other names) are an igneous rock, usually characterised by their occurrence in extensive, flat-lying sheets up to several hundred feet in thickness. They were first recognised as a distinct class of rock by Marshall (1932, '35) and have since been frequently described in many parts of the world. They occur in large volume in the central part of the North Island, where Martin (1959, '61, '64) has described several tens of different examples, whose ages probably span a large proportion of the Pleistocene.

The flatness of the surface of the flows over distances up to thirty miles indicates extreme fluidity of the original flow, which is usually explained by supposing that the incandescent particles were still emitting gas as the sheet moved, the turbulence produced being sufficient to allow a large amount of solid material to be transported with low viscosity, in much the same way as modern methods for transporting powders through pipelines.

Alternative theories of the mode of emplacement of ignimbrites have been proposed by Grange (1937) and Steiner (1960), but neither of these have much support. The properties and theories of origin of ignimbrites in general have been extensively discussed by Smith (1960). 
The ignimbrite sheets show variations in texture from bottom to top which give some indications as to their mode of formation. Near the bottom they are generally very soft and friable, with many easily visible pumice fragments. Further up they become more closely compacted, and the pumice becomes crushed into "lenticles". Welding of particles becomes progressively more pronounced, until in the centre of the sheet the rock is hard, non-porous, and completely welded. Near the top the welding becomes less pronounced and the density decreases again. Vertical jointing, which often occurs in the central region, indicates that the rocks were at rest while cooling.

Glass shards were observed by Marshall (1935) to have been distorted by flowage. Experiments on softening temperatures indicate that for this to occur the temperature of the fluid rock must have been about $1000^{\circ} \mathrm{C}$.

\subsection{PREVIOUS PALAEOMAGNETIC WORK}

Hatherton (1954a, b) has investigated various magnetic properties of the Whakamaru ignimbrite sheets. The main conclusions in these papers are based on studies of the variations in the ratio $Q=\frac{M}{\chi H}$, where $\mathrm{H}$ is the intensity of the magnetization, $\chi$ is the susceptibility and $\mathrm{H}$ is the earth's magnetic field (assumed constant, and about $\frac{1}{2}$ oe).

Hatherton found that $Q$ varied between sheets differentiated on petrological grounds, and that near the edge of each sheet the value of $Q$ greatly increased. In addition, $Q$ increased in $a$ similar manner at other positions in the ignimbrite, so he proposed division of it into several more sheets. He calculated the variation in cooling rate with distance from 
the surface of a horizontal cooling sheet and produced graphs which correlated with those of the variation of $Q$ with distance. This agreed nicely with the hypothesis that the value of $Q$ was related to physical properties of the magnetic grains, which depend on the rate of cooling of the rock when the grains were forming.

The direction of magnetization of the rocks is about that of the present field, as expected for rocks of this age (lower Pleistocene) (Torreson and others, 1949). There appears to be a somewhat large scatter in the inclination directions, but the dip directions suggest secular variation effects.

Hatherton determined the magnitude of the T.R.M. acquired in the present earth's field for some samples, and found that the ratio of this to the natural magnetic moment was about 1.1. This is usually taken to indicate that the earth's field when the rocks were formed was about the same intensity as now, and that the magnetization intensity of the rocks is stable over the geological time involved.

Bailey (unpublished) of the U.S. Geological Survey, collected some oriented samples from the Matahina ignimbrite sheet, the magnetization directions of which were determined by Geophysics Division, D.S.I.R. The directions of magnetization obtained are rather scattered, with some directions being opposite to that expected. There appear to be variations in $Q$ throughout the sheet, but no definite conclusions are obvious. It was thought worthwhile to investigate the same ignimbrite again. 


\subsection{THE MATAHINA IGNIMBRITE}

This formation covers a large area in the North East of the central North Island (see Fig. 9.1). It is, like many of the N.Z. ignimbrites, mostly lying horizontally, indicating that it has not been shifted since fornation.

A detailed petrographic axamination was performed by $\mathrm{Mr}$ R. A. Bailey about 1956, but so far this work is not published.

Near its eastern boundary, the ignimbrite has been completely cut through by the Rangitaiki river, which has a gorge with numerous rock outcrops convenient for sampling. The Ministry of Works are currently building a hydro-electric dam at Matahina, so many drilled cores and much geological information are available. It appears that the Rangitaiki gorge has been cut along the trace of a large fault. The western side of the river is practically horizontal and shows little evidence of movement, but the eastern side has been raised several hundred feet. There appears also to be some buckling of the rocks on the eastern side, as if the fault has some transcurrent component which exerts a lateral pressure. This infornation has been obtained from M.0.W. geological reports by $\mathrm{J}$. Healy, and was not available when samples of ignimbrites were being collected, so that no thought was given at the time to possible movements of the ignimbrite on the eastern side of the Rangitaiki, where the Luke's farm section was collected. In order to fully interpret the results of the work described in the next chapter, estimates of the movements of the outcrop will be necessary, but are not available. 


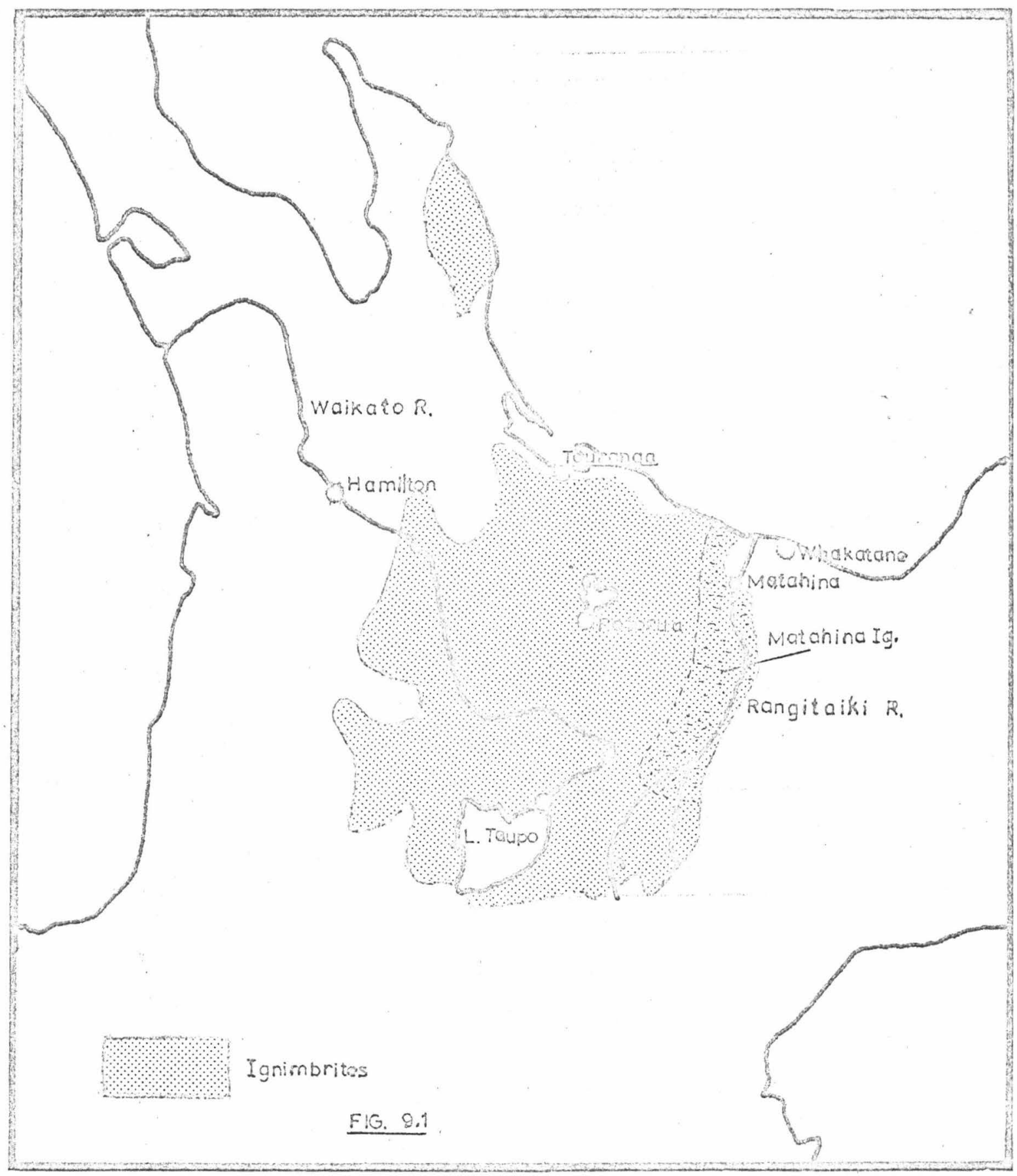


SOME MAGNETIC PROPERTIES OF THE MATAHINA IGNIMBRITE

\subsection{SAMPLE COLIECTION}

\subsubsection{Collection Locality}

During the summer of 1961-62, Mr Gellen, assisted by the author, collected a set of oriented rock samples from an exposure of the Natahina ignimbrite at Luke's Farm, near the site of the Matahina hydro-electric dam. The exposure is in two parts. Exposure 1 is a steep cliff face parallel to the road and river, on which apparently undisplaced rock outcrops in many places, through vegetation and rock debris. Exposure 2 is a vertical cliff about $\frac{1}{4} \mathrm{mile}$ from the other exposure, and separated from it by a small spur ("Sugar-loaf Spur"), (see map, Fig. 10.1). At the time of making the collection it was believed that this exposure, like most of the ignimbrites, had not been moved more than a degree or two from its original flat-lying position. It has since been learnt, from geological reports supplied to the Ministry of Works by Mr J. Healy, that faulting, and tilting up to $20^{\circ}$, is common on the easterm side of the Rangitaiki, and that less than a mile from the collection area, the Matahina ignimbrite dips $20^{\circ}$ downwards towards the North.

Two rock samples were taken from each of twenty collection sites, nine of the sites being on exposure 1, and eleven on exposure 2. (The samples from each site are supposed to have the same properties). At the time of collection it 
was thought that both exposures would be equivalent, but the results indicate the desirability of treating them separately.

All samples in this collection belong to Mr Gellen's collection "L", that is, they are recorded in field books and in the rock store as sample I53 etc. The prefix I has here been omitted.

\subsubsection{Sample Altitudes}

It was desired to sample the sheet at vertical intervals of 10 to 20 feet throughout its thickness, in order to repeat the measurements made by Bailey in 1956 (unpublished). To this end, the altitude of each sample was determined with a Paulin aneroid barometer. It is necessary when using an aneroid barometer to make an allowance for changes in air pressure due to causes other than changes in altitude, so each day readings were taken, every hour or half hour, of the height indicated by another Paulin barometer at base station, which was the M.O.W. camp about three miles from the exposure. This gives some indication of the trends in barometric pressure, but no correction can be made for the pressure changes occurring in the valleys and on the cliffs of the exposures due to local wind and temperature changes. It is probable that the heights determined by this method are in error by \pm 20 feet and sometimes even more.

Heights were corrected for the daily pressure variation by recording the time at which each field reading was taken, and finding the change in height indicated at base station at that time, from a graph of pressure versus time. 
This procedure initially led to some obviously wrong relative positions. Two samples, one collected on the first day, the other on the last, were known to have the same altitude, but were apparently 45 feet apart. The density of the ignimbrite was expected to increase steadily upwards through the lowest hundred feet, but the pair of samples with the lowest density were not at the bottom. It was found possible to locate most collection sites on photographs taken at the time, and from these to determine relative order within each of the exposures. Table 10.1 gives the apparent height of each sample, corrected for the diumal variation of air pressure, and the difference in reading of the two barometers at base each day (zero correction). Table 10.2 has been derived from this information, the known relative positions of samples 43 and 44, and the information that samples 53 and 54 are the lowest ones, and shows the stratigraphic sequence (i.e. relative vertical position), of the samples. No allowance has been made for possible tilting of the ignimbrite sheet, which, if present, would mean that present altitudes alone would be insufficient to determine relative vertical positions within the original sheet.

\subsubsection{Orientation Method}

Samples were chosen which had one flat face, either natural or chiseled. On this face a horizontal line was drawn with a felt-tipped pen. The dip of the face was measured, being that angle through which a horizontal surface through the line must be rotated, in order to make the upper

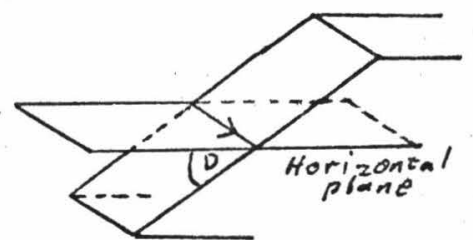


side of the surface coincident with the outer side of the face. The angle was measured in a right handed sense about an arrow drawn on the orientation line. The magnetic declination of this arrow was also measured. Both measurements were made to the nearest degree with a Brunton combined compess and inclinometer. None of the rocks were found to be sufficiently magnetic to deflect the compass.

\subsubsection{Preparation of Specimens}

One cylindrical specimen was cut from each of the 40 oriented samples, using non-magnetic diamond cutting tools. Each specimen is $3.46 \pm 0.01 \mathrm{~cm}$ in diameter and about $3.5 \mathrm{~cm}$ long. The axis of the cylinder is perpendicular to the oriented face of the sample, and a reference line is drawn on the end of the cylinder near the face, parallel to the original orientation line. A specimen coordinate system has its $x$ axis parallel to this line, and $z$ axis along the cylinder axis. Marking of the specimens was originally with Indian ink, but later they were re-marked with white "Chinagraph" pencil before heating to high temperatures.

10.2 DENSITY OF SPECIMENS

Differences in texture and density between specimens were obvious to the eye and appeared to vary in a regular manner. Martin (1959) has described typical variations of these properties throughout the sheet, and it is interesting to compare the Matahina sheet with his generalized description.

Dry densities were determined to about $1 \%$ by weighing the cylinders (after heating above $600^{\circ} \mathrm{C}$.) and calculating their 
volume from the dimensions. A graph of density against altitude is show in Fig. 10.2. and it can be seen that density decreases near the top and bottom of the sheet. Owing to the uncertainty in altitudes and the approximate (but simple) method of finding density, nothing can be said about the possibility of the existence of more than one sheet within the ignimbrite from these results (refer Section 11.2).

Samples 51 to 56 are pinkish in colour and comparatively friable, corresponding to Martin's basal zone. Those next above them $(49,50)$ are very granular and contain up to $5 \%$ of black, glassy, obsidian-like material, in grains several $\mathrm{mm}$ in diameter, as expected from Martin's description, while further up the rock is uniformly welded and grey in colour, becoming lighter in colour over the top 30 feet. It appears that the exposure includes only one typical ignimbrite.

\subsection{NATURAL REMANENT MAGNETIZATION}

\subsubsection{Notation}

"Ine 'ròlıowing symbols have been used: The angles $\gamma$ and $\phi$ give the specimen magnetization direction measured in the specimen coordinate system defined

by the orientation line, and the

cylinder axis, as shown in the

diagram.

$M$ is the intensity of magnetization,

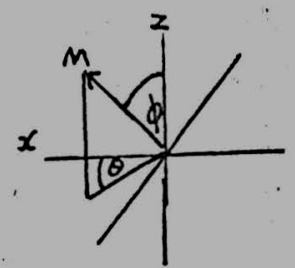
per unit volume, of the specimen, (measured in oersteds). 


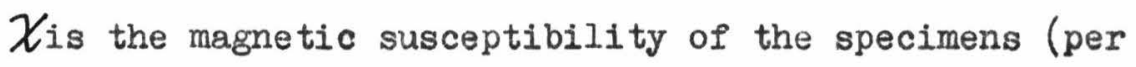
unit volume). The values tabulated are 1.06 times the actual values, but because of the large random errors inherent in the susceptibility measurement procedure used, this has no effect on any conclusions drawn here.

N.R.M. is an abbreviation of "natural remanent magnetization". T.R.M. is an abbreviation of "thermoremanent magnetization". C.R.M. is an abbreviation of "chemical remenent magnetization".

\subsubsection{Measurements of Direction}

The N.R.M.s of the specimens were first measured in November, 1963, with the magnetometer fitted with a phosphor bronze suspension. Table 10.3 gives these directions of magnetization for all samples except 53 and 54, which were too weakly magnetized to measure.

After measurement the specimens were stored in the earth's field for three months, and remeasured in February 1964, using a more sensitive quartz fibre suspension. The direction of the field was $\theta=90^{\circ} \pm 5^{\circ}$ and $\phi=26^{\circ} \pm 5^{\circ}$ in the specimen coordinate system, for all specimens. The new directions also appear in table 10.3

There is a small average decrease in the values of $\theta$ and $\phi$, but this is probably not significant, and is in the opposite sense to the changes to be expected from viscous magnetization.

The directions of magnetization in local geomagnetic coordinates (i.e. relative to the present magnetic north direction, the magnetic east direction, and the vertical), were calculated 
using a stereographic projection (see Appendix III), and are shown in table 10.4 and Fig. 10.3. The points have been plotted on two stereograms, one for specimens from exposure 1, the other for specimens from exposure 2.

10.3.3 Intensity and Susceptibility of N.R.M.

Table 10.5 displays these as well as other quantities which will be explained later. The ratio $\frac{M}{\bar{X}}$ is a useful parameter as it eliminates effects due only to differences in amount of magnetite. Variation of $\frac{\mathbb{M}}{x}$ can be due either to differences in the nature (e. g. grain size) of the magnetic fraction, or to the magnetization process and history. This ratio is included in table 11.2. No definite trends in the changing values of $\frac{M}{X}$ with position were noted at first, partly because of difficulties in deciding the altitudes of the samples.

10.4 THERMAI DEMAGNETIZATION OF N.R.M.

10.4.1 Choice of Specimens for Trial Demagnetization Only nine specimens could be treated at a time because of the need to include two dummy specimens for temperature measurement, and the partly broken sample holder.

Because of limited time only one set of nine specimens was fully investigated. These specimens were chosen to fairly represent both position in the sheet and the measured value of $\frac{M}{x}$. Specimens chosen were from five sites. In four cases one specimen was treated from each of the two samples collected at each site, and the other site was represented by a single specimen. The purpose 
of the pairs of specimens was to provide a check against errors in measurement, but it was found that such errors were sufficiently uncommon and obvious that a better procedure would be to use only one specimen from more sites.

\subsubsection{Heating and Measuring Procedure}

The specimens were heated to successively higher maximum temperatures, held at these temperatures for $20-30$ minutes, and then allowed to cool, all this being in zero magnetic field. Their magnetizations were then measured in a vertical magnetic field equal to twice the vertical component of the earth's field, which allowed measurement of susceptibility (see Appendix II). The magnetization intensity, $M$, after heating to the successively higher temperatures, $\mathrm{T}$, is plotted against $\mathrm{T}$ in Figs. 10.5 to 10.13, and corresponding changes in magnetization direction from the initial value are plotted in Figs. 10.14 and 10.15.

\subsubsection{Changes in Directions of Magnetization}

These are generally small, and show no trends which might be attributable to the removal of a viscous magnetization inclined to a more stable component.

The large changes in direction observed in specimens 53 and 54 may be due to the removal of P.T.R.M.'s in different directions, originally acquired as the somewhat friable and vesicular lower layers compacted during the cooling period after deposition.

\subsubsection{Changes in Intensity}

The graphs showing the reduction in intensity of N.R.M. by heating are of several types, indicating differences between 
magnetic minerals at different parts of the ignimbrite. The simplest graphs are those of specimens 49 and 50, whose intensities remain practically constant up to a temperature of about $350^{\circ} \mathrm{C}$, decrease to $50-60 \%$ of their initial values by $500^{\circ} \mathrm{C}$, and then drop rapidly to a minimum (not zero) value at about $570^{\circ} \mathrm{C}$. The graphs for both specimens from the site are almost identical in this and the other cases, which supports the view that oniy one specimen from each site need be investigated in detail for this purpose.

Specimens 47 and 48 behave in a similar manner to these two, except that their intensity starts to decrease at lower temperatures. These four specimens have a relatively high $\frac{M}{x}$, which Hatherton (1954Q) has suggested is associated with rapid cooling, and they also show the glassy black vitrophyre which Martin (1959) associates with rapid cooling on petrological grounds.

Specimens 97 and 98 are somewhat different from those above, in that the intensity decreases by about $20 \%$ between $200^{\circ} \mathrm{C}$. and $300^{\circ} \mathrm{C}$, and is then constant up to $400^{\circ} \mathrm{C}$., above which temperature it drops uniformly to a small constant value above $590^{\circ} \mathrm{C}$. The change at $200^{\circ} \mathrm{C}$. could be due to any of the following causes:

a) Removal of a F.T.R.M. acquired at temperatures below $300^{\circ} \mathrm{C}$. in a field of $20 \%$ greater intensity than, but within $1^{\circ}$ in direction of, the original magnetizing field.

b) Removal of an I.R.M. in the direction of the original field. 
c) A mineral of Curie point about $250^{\circ} \mathrm{C}$. was present.

d) A magnetic mineral chemically unstable above $250^{\circ} \mathrm{C}$. was present.

Specimen 41 shows a gradual change in intensity right from $100^{\circ} \mathrm{C}$, with an inflection at about $200^{\circ} \mathrm{C}$. which might be due to any of the causes listed above.

Specimens 53 and 54 are sinilar to 41 , but they do not show the inflection.

Before discussing these results further, it is useful to know more about the T.R.M. of the rocks.

\subsubsection{Changes in Susceptibility}

There is a general increase of 20 to $30 \%$ in susceptibility of the rocks as the temperature of heating increases to $600^{\circ} \mathrm{C}$, although the scatter of the values is large owing to the inaccurate susceptibility measuring procedure (Figs. 10.16-10.20). This is almost certainly due to mineralogical changes, but the particular reaction is hard to identify. Oxidation of magnetite to hematite would lead to a lowering of susceptibility, and the reverse reaction is unlikely because of the oxidizing conditions probably present in the oven. A possible, but unrecorded, reaction involves the oxidation of a sulphide mineral to magnetite. Chlorophaeite is a mineral found sometimes as an alteration product of olivine, which changes to various ferromagnetic minerals on heating (Weaving, 1962). If present, this could lead to the observed behaviour.

After heating for about $\frac{1}{2}$ hour above $600^{\circ} \mathrm{C}$. all samples showed a decrease in $\mathcal{X}$, this being especially great in 
specimens 97,98 , and 41 , which were those showing a decrease in $\mathrm{M}$ at $200^{\circ} \mathrm{C}$.

10.5 THERMAL DEMAGNETIZATION OF T.R.M.

To help decide whether the N.R.M. was in fact a T.R.M., the specimens whose demagnetization was described above were all given a T.R.M. in the earth's field. This was then demagnetized in the same way as the N.R.M., and the information obtained plotted on the same graphs as the N.R.M. data.

10.6 COMPARISON OF N.R.M. AND T.R.M.

i. The T.R.M. is in all cases $4-5$ times greater in intensity than the N.R.M.

ii. The low temperature changes in the demagnetization of N.R.M. of specimens 97, 98 and 41 are not present in the demagnetization of T.R.M.

iii. The demagnetization of T.R.M. of specimens 53 and 54 shows a slower rate of decrease at low temperatures than the corresponding N.R.M. curve.

iv. The susceptibility increases as demagnetization of the T.R.M. proceeds.

Whatever the cause of the differences between the T.R.M. and N.R.M. demagnetization graphs, it seems that some of the N.R.M. of some specimens resides in grains of low Ourie temperature, and so is to be regarded with caution.

\subsection{THERMAL WASHING AT $300^{\circ} \mathrm{C}$.}

\subsubsection{Experimental}

On the basis of the experiments on demagnetization described 
above, it was decided to heat all the remaining specimens to between $300^{\circ} \mathrm{C}$, and $350^{\circ} \mathrm{C}$, cool in zero field, and remeasure the magnetization. It was expected that this would remove any secondary or unstable components of magnetization. The results of this experiment are shown in the columns headed $" 300^{\circ} \mathrm{C}$ wash" in tables 10.3 and 10.5 .

\subsubsection{Changes in Direction}

These are generally small, with no obvious consistency in the directions of change. Specimens 42, 43, 44, 53, and 54 show surprisingly large changes in direction, away from the present field direction, but although the changes are larger for these samples than for others, they are not larger than existing scatter between samples. This could be due to the samples having been moved since emplacement, by undetected faulting or slumping, and then acquiring an I.R.M. in the present field direction. The I.R.M. has been removed so the magnetization direction rotates away from the mean direction, which is nearly parallel to the present field direction. Since most of the change is in the declination, it is not possible to refer to rock structure to find further evidence for post-depositional movement. No change in the dispersion of the directions is obvious after this treatment, so it appears that over the whole collection I.R.M. is unimportant in altering directions.

\subsubsection{Changes in Intensity of Magnetization}

Table 10.5 lists the new values of intensity and susceptibility. It will be seen that after heating to $300^{\circ} \mathrm{C}$. $\chi_{\text {has }}$ increased by $10-30 \%$, indicating that the 
effect observed when studying the first selection of specimens in detail is a general one in this ignimbrite. Discussion of the details of the change in intensity of magnetization is left until Chapter 11, where it is compared with other properties of the rock.

10.8 EFFECT OF THE EARTH'S MAGNETIC FIELD AT ELEVATED TEMPERATURES Nine specimens which had previously been demagnetized at $300^{\circ} \mathrm{C}-350^{\circ} \mathrm{C}$ and measured, were reheated to just below $300^{\circ} \mathrm{C}$ in zero field. The field cancellation coils were then switched off, and the temperature held constant or allowed to increase slightly for 40 minutes, after which the field was again cancelled and the specimens allowed to cool to room temperature. No consistent change in direction was observed, (see tables 10.3 and 10.6), although the directions of specimens 42 and 101 shifted slightly towards the field direction in a horizontal plane, with no change in the vertical direction. In view of the uncertainties surrounding the theory of this test (see paragraph 3.3.3), no conclusions are drawn from it. If work on known unstable rocks could show some correlation between instability and changes at elevated temperatures, this might prove a useful and simple test.

10.9 DECAY OF T.R.Ni. WITH TIME

The specimens used in the previous experiment were given a T.R.M. in the earth's field by cooling them in it after holding them at a temperature of about $650^{\circ} \mathrm{C}$ for half an hour. This T.R.M. was measured 3 hours after the start of the cooling operation, which was as soon as is possible with this equipment. Sixty hours after this first measurement 
the T.R.M.s were measured again. From the results, which are shown in table 10.7, it appears that changes in direction and intensity between the two measurements are not greater than the accuracy of measurement. Also the random changes in $x$ between the two measurements give an idea of the accuracy of measurement of $x$, which is about $\pm 20 \%$.

\subsection{T.R.M. OF ALI SPECINENS}

To complete the data on the samples, all specimens were given a T.R.M. in the earth's field. The values of $M$ and Xof the T.R.M. are included in table 10.5. Implications of these results are discussed in Chapter 11. 
\begin{tabular}{lllll} 
T A B I E & 10.1 \\
\hline
\end{tabular}

Correction

Date of Sample Nominal for Pressure Zero Corrected Collection Number Altitude Variation Correction Altitude

\begin{tabular}{|c|c|c|c|c|c|}
\hline $12 / 12 / 61$ & 35 & 336 & -26 & 0 & 310 \\
\hline$n$ & 36 & 334 & -26 & 0 & 308 \\
\hline$"$ & 37 & 325 & -36 & 0 & 289 \\
\hline$"$ & 38 & 322 & -36 & 0 & 286 \\
\hline$"$ & 39 & 404 & -52 & 0 & 352 \\
\hline$"$ & 40 & 400 & -52 & 0 & 348 \\
\hline$n$ & 41 & 453 & -85 & 0 & 368 \\
\hline$"$ & 42 & 450 & -85 & 0 & 365 \\
\hline$"$ & 43 & 462 & -85 & 0 & 377 \\
\hline $18 / 12 / 61$ & 44 & 242 & -83 & +265 & 424 \\
\hline $13 / 12 / 61$ & 45 & 242 & 5 & 78 & 325 \\
\hline$"$ & 46 & 244 & 5 & 78 & 327 \\
\hline$"$ & 47 & 202 & -14 & 78 & 266 \\
\hline$"$ & 48 & 205 & -14 & 78 & 269 \\
\hline$"$ & 49 & 192 & \multicolumn{2}{|c|}{$269-13^{\prime}$} & 256 \\
\hline$"$ & 50 & 191 & \multicolumn{2}{|c|}{$269-14^{\prime}$} & 255 \\
\hline$"$ & 51 & 191 & \multicolumn{2}{|c|}{$256-15^{\prime}$} & 241 \\
\hline$"$ & 52 & 192 & \multicolumn{2}{|c|}{$256-14^{\prime}$} & 242 \\
\hline$"$ & 53 & 185 & -2 & 78 & 261 \\
\hline$"$ & 54 & 185 & -2 & 78 & 261 \\
\hline$"$ & 55 & 205 & -44 & 78 & 239 \\
\hline$"$ & 56 & 209 & -44 & 78 & 243 \\
\hline $18 / 12 / 61$ & 87 & 20 & -16 & 265 & 269 \\
\hline$n$ & 88 & 22 & -16 & 265 & 271 \\
\hline$"$ & 89 & 29 & -26 & 265 & \\
\hline$"$ & 90 & 32 & -26 & 265 & \\
\hline
\end{tabular}


T A B L E 10.1 (Cont.)

Correction

Date of Sample Nominal for Pressure Zero Corrected

Collection Number Altitude Variation Correction Altitude

$\begin{array}{crrrrr}18 / 12 / 61 & 91 & 62 & -32 & 265 & 295 \\ " & 92 & 63 & -32 & 265 & 296 \\ " & 93 & 90 & -40 & 265 & 315 \\ " & 94 & 93 & -40 & 265 & 318 \\ " & 95 & 107 & -50 & 265 & 322 \\ " & 96 & 107 & -50 & 265 & 322 \\ " & 97 & 130 & -54 & 265 & 341 \\ " & 98 & 132 & -54 & 265 & 343 \\ " & 99 & 153 & -56 & 265 & 362 \\ " & 100 & 151 & -56 & 265 & 360 \\ " & 101 & 163 & -60 & 265 & 368 \\ " & 102 & 162 & -60 & 265 & 367 \\ " & 103 & 212 & -82 & 265 & 395 \\ " & 104 & 213 & -82 & 265 & 396\end{array}$


$\begin{array}{ll}\text { T A B I E } & 10.2\end{array}$

Sarnole Number

$\begin{array}{rr}43, & 44 \\ 41, & 42 \\ 103, & 104 \\ 39, & 40 \\ 101, & 102 \\ 99, & 100 \\ 97, & 98 \\ 35, & 36 \\ 45, & 46 \\ 95, & 96 \\ 93, & 94 \\ 91, & 92 \\ 37, & 38 \\ 89, & 90 \\ 87, & 88 \\ 47, & 48 \\ 49, & 50 \\ 51, & 52 \\ 55, & 56 \\ 53, & 54\end{array}$

Density

$1.76,1.85$

$2.04,2.02$

$2.02,1.94$

$2.24,2.24$

$2.25,2.23$

$2.24,2.26$

$2.25,2.26$

$2.29,2.27$

$2.31,2.30$

$2.24,2.25$

$2.26,2.27$

$2.32,2.25$

$2.27,2.26$

$2.32,2.31$

$2.28,2.23$

$2.29,2.29$

$2.17,2.24$

$1.86,1.93$

$1.78,2.16$

$1.35,1.43$
Altitude

420

410

400

390

370

360

340

340

330

320

320

300

300

270

270

270

260

240

230

220 
T A B I E 10.3

DIRECTIONS OF MAGNETIZATION,

in the samples' coordinate systems

\begin{tabular}{|c|c|c|c|c|c|c|c|c|}
\hline \multirow[t]{2}{*}{ Sample } & \multicolumn{2}{|c|}{$\begin{array}{l}\text { Sample } \\
\text { Orientation } \\
\text { in situ }\end{array}$} & \multicolumn{2}{|c|}{$\begin{array}{l}\text { 1st Measurement } \\
\text { of Sample } \\
\text { Magnetization }\end{array}$} & \multicolumn{2}{|c|}{$\begin{array}{l}\text { 2nd Measurement } \\
\text { of Sample } \\
\text { Magnetization }\end{array}$} & \multicolumn{2}{|c|}{$\begin{array}{l}\text { Sample } \\
\text { Magnetization } \\
\text { after } 300^{\circ} \mathrm{C} \text { Wash }\end{array}$} \\
\hline & Dec. & Dip & $\theta$ & $\phi$ & $\theta$ & $\phi$ & $\theta$ & $\phi$ \\
\hline 35 & - & - & 8 & $40 \frac{3}{4}$ & $9 \frac{3}{4}$ & $40 \frac{3}{4}$ & $9 \frac{1}{4}$ & $39 \frac{1}{4}$ \\
\hline 36 & 195 & 081 & $132 \frac{1}{2}$ & $80 \frac{1}{4}$ & $132 \frac{1}{4}$ & $78 \frac{3}{4}$ & $133 \frac{3}{4}$ & $79 \frac{1}{4}$ \\
\hline 37 & 243 & 121 & $102 \frac{1}{4}$ & $76 \frac{1}{4}$ & 103 & $76 \frac{3}{4}$ & $102 \frac{1}{2}$ & $74 \frac{1}{4}$ \\
\hline 38 & 224 & 076 & $102 \frac{3}{4}$ & $61 \frac{1}{2}$ & $103 \frac{3}{4}$ & $62 \frac{1}{2}$ & $103 \frac{1}{2}$ & 59 \\
\hline 39 & 242 & 057 & 124 & 33 & $122 \frac{3}{4}$ & $32 \frac{1}{2}$ & 123 & $28 \frac{1}{4}$ \\
\hline 40 & 215 & 074 & 131 & 58 & 131 & $59 \frac{1}{2}$ & $130 \frac{1}{2}$ & $55 \frac{1}{2}$ \\
\hline 41 & 106 & 073 & $105 \frac{1}{2}$ & 127 & 105 & 127 & $107 \frac{1}{4}$ & 127 \\
\hline 42 & 180 & 090 & 115 & $87 \frac{1}{2}$ & $114 \frac{3}{4}$ & $90 \frac{1}{2}$ & $116 \frac{1}{2}$ & $80 \frac{3}{4}$ \\
\hline 43 & 215 & 073 & $112 \frac{1}{2}$ & $55 \frac{1}{2}$ & $112 \frac{1}{4}$ & $56 \frac{1}{4}$ & $114 \frac{3}{4}$ & $44 \frac{1}{4}$ \\
\hline 44 & 262 & 020 & $255 \frac{3}{4}$ & $16 \frac{1}{4}$ & $253 \frac{1}{2}$ & 18 & $262 \frac{3}{4}$ & $12^{\frac{1}{2}}$ \\
\hline 45 & 135 & 076 & $119 \frac{2}{2}$ & 124 & $117 \frac{1}{2}$ & $115 \frac{1}{2}$ & $111 \frac{1}{4}$ & $117 \frac{1}{2}$ \\
\hline 46 & 227 & 067 & $132 \frac{1}{4}$ & $51 \frac{1}{2}$ & 132 & $51 \frac{1}{4}$ & 132 & $51 \frac{1}{4}$ \\
\hline 47 & 126 & 076 & 123 & $101 \frac{1}{2}$ & 123 & $100 \frac{3}{4}$ & 123 & $101 \frac{1}{2}$ \\
\hline 48 & 046 & 080 & 63 & $128_{2}^{1}$ & $62 \frac{1}{2}$ & $127^{\frac{1}{4}}$ & $62 \frac{3}{4}$ & $127^{\frac{1}{2}}$ \\
\hline 49 & 124 & 095 & 123 & $124 \frac{1}{4}$ & $123 \frac{1}{4}$ & $122_{2}^{7}$ & $123 \frac{3}{4}$ & 123 \\
\hline 50 & 209 & 071 & $116 \frac{3}{4}$ & $80 \frac{3}{4}$ & $116 \frac{1}{4}$ & $80 \frac{3}{4}$ & $116 \frac{1}{2}$ & $79 \frac{1}{4}$ \\
\hline 51 & 128 & 078 & $114^{\frac{1}{2}}$ & 104 & 114 & 102 & 114 & 103 \\
\hline 52 & 119 & 108 & $123 \frac{1}{2}$ & 141 & 123 & $138 \frac{1}{2}$ & $127^{\frac{1}{2}}$ & $139 \frac{3}{4}$ \\
\hline 53 & 040 & 077 & - & - & $56 \frac{1}{4}$ & $119 \frac{3}{4}$ & $52 \frac{1}{2}$ & $109 \frac{1}{4}$ \\
\hline 54 & 130 & 075 & - & - & $114 \frac{1}{4}$ & $109 \frac{3}{4}$ & $111 \frac{1}{4}$ & $116 \frac{1}{4}$ \\
\hline 55 & 216 & 072 & $135 \frac{3}{4}$ & $53 \frac{1}{4}$ & $132 \frac{1}{2}$ & $53 \frac{1}{2}$ & 137 & $50 \frac{1}{2}$ \\
\hline 56 & 208 & 111 & 130 & $101 \frac{1}{2}$ & $129 \frac{3}{4}$ & 95 & $132 \frac{1}{4}$ & $90 \frac{1}{4}$ \\
\hline
\end{tabular}




\section{P A B L E 10.3 (Cont)}

\begin{tabular}{ccccccccc} 
Sample & $\begin{array}{l}\text { Sample } \\
\text { Orientation } \\
\text { in situ }\end{array}$ & $\begin{array}{l}\text { 1st Measurement } \\
\text { of Sample } \\
\text { Magnetization }\end{array}$ & $\begin{array}{l}\text { 2nd Measurement } \\
\text { of Sample } \\
\text { Magnetization }\end{array}$ & $\begin{array}{c}\text { Sample } \\
\text { Magnetization } \\
\text { after }\end{array}$ \\
\hline & Dec. & Dip & $\theta$ & $\phi$ & $\theta$ & $\phi$ & $\theta$ & $\phi$ \\
87 & 282 & 088 & $78 \frac{1}{2}$ & $57 \frac{3}{4}$ & $77 \frac{1}{2}$ & 58 & $76 \frac{3}{4}$ & $56 \frac{1}{2}$ \\
88 & 012 & 274 & 301 & $75 \frac{1}{4}$ & 301 & $75 \frac{3}{4}$ & 301 & $73 \frac{1}{4}$ \\
89 & 256 & 155 & 89 & 125 & $89 \frac{1}{4}$ & $124 \frac{1}{2}$ & $88 \frac{3}{4}$ & 125 \\
90 & 333 & 095 & $58 \frac{3}{4}$ & $87 \frac{1}{2}$ & 59 & $86 \frac{1}{2}$ & $59 \frac{1}{2}$ & 85 \\
91 & 145 & 056 & 113 & $69 \frac{3}{4}$ & 113 & $70 \frac{3}{4}$ & 112 & $69 \frac{1}{2}$ \\
92 & 044 & 000 & $28 \frac{1}{2}$ & 29 & $28 \frac{3}{4}$ & 29 & $29 \frac{1}{2}$ & $27 \frac{1}{2}$ \\
93 & 233 & 099 & 108 & $74 \frac{3}{4}$ & $107 \frac{1}{2}$ & 71 & $108 \frac{1}{2}$ & $73 \frac{1}{2}$ \\
94 & 204 & 107 & $112 \frac{3}{4}$ & 91 & $112 \frac{1}{4}$ & $89 \frac{1}{2}$ & $111 \frac{3}{4}$ & $89 \frac{1}{4}$ \\
95 & 180 & 064 & 120 & $67 \frac{1}{2}$ & 119 & $68 \frac{1}{4}$ & $118 \frac{1}{4}$ & 67 \\
96 & 185 & 085 & 122 & $80 \frac{1}{2}$ & $121 \frac{3}{4}$ & $81 \frac{1}{4}$ & $122 \frac{3}{4}$ & $80 \frac{1}{2}$ \\
97 & 105 & 106 & $99 \frac{1}{4}$ & $131 \frac{1}{4}$ & $101 \frac{1}{2}$ & $130 \frac{3}{4}$ & $97 \frac{1}{2}$ & 133 \\
98 & 134 & 088 & $104 \frac{3}{2}$ & $102 \frac{1}{2}$ & $108 \frac{1}{2}$ & $101 \frac{1}{2}$ & $108 \frac{1}{4}$ & 101 \\
99 & 247 & 072 & 101 & 47 & $100 \frac{3}{4}$ & $46 \frac{1}{4}$ & $100 \frac{3}{4}$ & 43 \\
100 & 218 & 095 & $113 \frac{3}{4}$ & $80 \frac{1}{2}$ & $114 \frac{1}{2}$ & 80 & 116 & $77 \frac{1}{4}$ \\
101 & 033 & 009 & 48 & $37 \frac{1}{4}$ & $48 \frac{1}{4}$ & 38 & $44 \frac{3}{4}$ & $35 \frac{3}{4}$ \\
102 & 340 & 004 & $339 \frac{3}{4}$ & $28 \frac{3}{4}$ & $342 \frac{1}{2}$ & $29 \frac{1}{2}$ & $343 \frac{1}{2}$ & 27 \\
103 & 165 & 084 & $117 \frac{1}{4}$ & 101 & $117 \frac{1}{4}$ & $100 \frac{1}{2}$ & 119 & 103 \\
104 & 156 & 088 & 120 & $89 \frac{1}{4}$ & 121 & $89 \frac{1}{2}$ & 125 & 86 \\
& & & & & & & &
\end{tabular}


Magnetizations in geographic coordinates (declinations from magnetic north, and inclinations from vertical).

Exposure No. 1

Sample

Number

35

36

37

38

39

40

45

46

47

48

49

50

51

52

53

54

55

56

Exposure No. 2

002

003

352

000

N.R.M. Inclination
N.R.M. After $300^{\circ}$ Wash Declination Inclination
010

350

015

003

006

010

012

341

344

350

044

352

345

347

006

000

001
41

46

18

33

40

48

40

41

54

42

26

34

40

53

42

42

46
009

350

007

358

000

019

013

342

343

350

042

352

353

359

013

358

007
43

48

21

35

41

46

38

41

54

42

27

34

43

49

46

46

46
42

43

44

41
56

25

26

38
000

56

339

27

336

35

354 
TA B I E 10.4 (Cont.)

Sample

Number

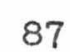

88

89

90

91

92

93

94

95

96

97

98

99

100

101

102

103

104
N.R.M. Declination Inclination

32

33

31

31

25

29

33

26

26

31

27

22

29

28

31

31

32

31

017

337

31
N.R.M. After $300^{\circ}$ Wash Declination Inclination

351

34

347

344

351

353

014

359

350

002

356

003

350

351

003

359

009

019

335

33

32

32

24

28

31

26

26

33

28

24

30

30

30

25

34

34 
T A B I E 10.5

N.R.M.

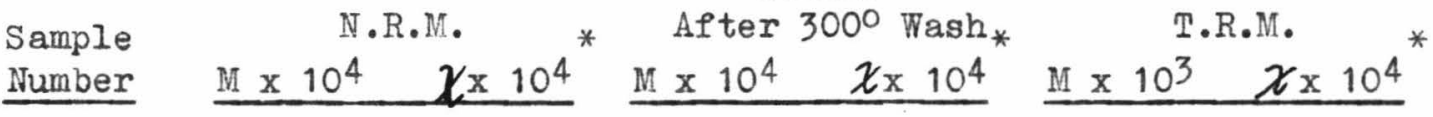

35

32.3

6.0

29.5

$7 \cdot 3$

9.6

3.8

36

37

28.9

5.9

25.8

7.9

11.0

4.4

38

32.5

5.5

28.2

6.7

11.0

6.4

39

40

41

42

30.0

6.5

27.1

$7 \cdot 5$

10.0

8.9

23.5

5.6

19.5

6.3

10.4

5.7

6.7

16.9

7.8

9.1

5.9

9.4

6.7

5.7

8.5

5.9

1.4

9.5

6.5

6.4

8.1

6.5

5.3

43

7.5

5.6

$4 \cdot 3$

7.1

5.7

7.2

44

13.2

7.0

9.2

8.0

6.1

9.5

45

57.6

4.4

56.8

3.9

22.5

6.9

46

55.8

4.8

56.3

4.8

21.0

6.2

47

51.7

2.0

51.4

4.8

20.8

3.3

48

54.5

4.4

49.8

4.7

2.7

49

23.8

3.2

24.8

4.7

17.8

3.7

50

27.8

4.1

27.6

4.5

16.1

5.5

51

9.9

4.0

7.1

4.8

12.4

8.7

52

13.7

3.5

11.1

5.0

5.4

10

53

1.63

2. 2

0.75

2. 4

6.8

2.1

54

2.30

2.0

1.72

2.1

0.66

0.42

55

10.3

3.0

8.4

4.0

1.02

4.6

56

3.1

5.5

4.0

2. 59

7.3

87

88

89

90

91

31.3

5.6

28.5

6.3

10.0

$5 \cdot 3$

29.4

5.5

26.6

6.9

10.6

5.0

34.1

6.8

30.7

7.1

10.2

7.0

6.0

32.1

$7 \cdot 3$

11.2

6.3

5.3

30.6

6.4

10.4

5.2 


\begin{tabular}{|c|c|c|c|c|c|c|}
\hline \multirow{2}{*}{$\begin{array}{l}\text { Sample } \\
\text { Number }\end{array}$} & \multicolumn{2}{|c|}{$\mathrm{N} \cdot \mathrm{R} \cdot \mathrm{M}$} & \multicolumn{2}{|c|}{ N.R.M. } & \multicolumn{2}{|c|}{$\mathrm{T} \cdot \mathrm{R} \cdot \mathrm{M}$. } \\
\hline & $\mathrm{M} \times 10^{4}$ & $\chi \times 10^{4}$ & $\mathrm{M} \times 10^{4}$ & $\underline{x \times 10^{4}}$ & $\mathrm{M} \times 10^{3}$ & $\not \times 10^{4}$ \\
\hline 92 & 34.8 & 5.7 & 31.8 & 6.6 & 10.4 & 5.3 \\
\hline 93 & 27.9 & 6.4 & $24 \cdot 5$ & 7.3 & 9.9 & 6.0 \\
\hline 94 & 23.6 & 7.5 & 25.8 & 8.2 & 8.9 & 6.6 \\
\hline 95 & 27.5 & 8.2 & 22.2 & 9.9 & 7.6 & 5.8 \\
\hline 96 & 18.4 & 7.8 & 18.7 & 9.2 & 7.7 & 5.7 \\
\hline 97 & $24 \cdot 2$ & 7.8 & 20.0 & 9.2 & 10.5 & 2.5 \\
\hline 98 & 24.9 & 8.1 & 20.1 & 9.0 & 7.1 & 1.4 \\
\hline 99 & $24 \cdot 9$ & 7.5 & 20.3 & 8.6 & 8.0 & 7.2 \\
\hline 100 & 22.9 & 6.4 & 19.0 & 7.8 & 7.6 & 6.3 \\
\hline 101 & 21.8 & $7 \cdot 3$ & 18.2 & $9 \cdot 3$ & 6.9 & 5.6 \\
\hline 102 & 17.6 & 7.9 & 14.2 & 8.8 & 6.5 & 7.0 \\
\hline 103 & 9.8 & 6.5 & 5.8 & 7.0 & 7.4 & 5.8 \\
\hline 104 & 8.0 & 5.4 & 4.2 & 6.0 & $4 \cdot 9$ & 5.3 \\
\hline
\end{tabular}

* See Chapter 10.3.1 for a note on the values of $\chi$. 


\section{TA B I E 10.6}

Magnetic Properties After Heating at $300^{\circ} \mathrm{C}$. in the Earth's Field.

\begin{tabular}{rrrrr} 
Sample & \multicolumn{1}{c}{$\boldsymbol{\theta}$} & \multicolumn{1}{c}{$\mathbb{\mathrm { M }}$} & $\underline{\boldsymbol{x}}^{*}$ \\
55 & 137 & $49 \frac{3}{4}$ & 8.2 & 4.3 \\
45 & 111 & $117 \frac{1}{2}$ & 55.0 & 4.5 \\
95 & 119 & $65 \frac{1}{2}$ & 21.9 & 10.3 \\
36 & 134 & $80 \frac{1}{4}$ & 24.7 & 7.7 \\
91 & $112 \frac{1}{2}$ & 68 & 30.9 & 6.7 \\
87 & $80 \frac{1}{4}$ & $56 \frac{1}{2}$ & 28.5 & 6.6 \\
100 & $116 \frac{1}{4}$ & $78 \frac{1}{2}$ & 19.8 & 8.3 \\
42 & $113 \frac{1}{4}$ & 82 & 6.3 & 8.1 \\
101 & $49 \frac{1}{4}$ & $36 \frac{1}{4}$ & 18.8 & 9.6
\end{tabular}

T A B I E 10.7

Decay of T.R.M. With Time.

\begin{tabular}{|c|c|c|c|c|c|c|c|c|}
\hline Sample & $\theta$ & $\begin{array}{c}\text { After } \\
\phi\end{array}$ & $\begin{array}{l}\text { Hours } \\
\mathrm{M} \times 10^{3}\end{array}$ & $x \times 104^{*}$ & $\theta$ & $\begin{array}{c}\text { After } \\
\phi\end{array}$ & $\begin{array}{l}60 \text { Hours } \\
\mathrm{M} \times 10^{3} \\
\end{array}$ & $x \times 10^{*}$ \\
\hline 101 & 354 & $25 \frac{1}{2}$ & 6.86 & 5.6 & 354 & 26 & 6.73 & 6.5 \\
\hline 95 & $357 \frac{3}{4}$ & $20 \frac{1}{2}$ & 7.65 & 5.8 & 358 & $20 \frac{3}{4}$ & 7.58 & 6.0 \\
\hline 42 & $356 \frac{1}{2}$ & 18 & 6.53 & 5.3 & $355 \frac{1}{2}$ & 18 & 6.61 & 5.9 \\
\hline 100 & $348 \frac{1}{4}$ & $16 \frac{1}{2}$ & 7.61 & 6.3 & $349 \frac{3}{4}$ & 17 & 7.52 & 6.2 \\
\hline 55 & $357 \frac{3}{4}$ & 21 & 2.59 & 4.6 & 357 & $20 \frac{3}{4}$ & 2.61 & 4.8 \\
\hline 91 & $355 \frac{1}{2}$ & $22 \frac{1}{4}$ & 10.4 & 5.2 & $354 \frac{3}{4}$ & $22 \frac{1}{4}$ & 10.7 & 5.7 \\
\hline 87 & 357 & $28 \frac{3}{4}$ & 10.0 & 5.3 & 358 & $28 \frac{1}{2}$ & 10.0 & 6.8 \\
\hline 45 & $008 \frac{3}{4}$ & $26 \frac{1}{4}$ & 22.5 & 6.9 & $008_{2}^{\frac{1}{2}}$ & $26^{\frac{1}{2}}$ & 22.2 & 6.5 \\
\hline 36 & $005^{\frac{1}{2}}$ & 24 & 11.0 & 4.4 & $005 \frac{3}{4}$ & $23 \frac{3}{4}$ & 11.1 & 4.6 \\
\hline
\end{tabular}

* See Chapter 10.3.1 for a note on the values of $\boldsymbol{X}$. 


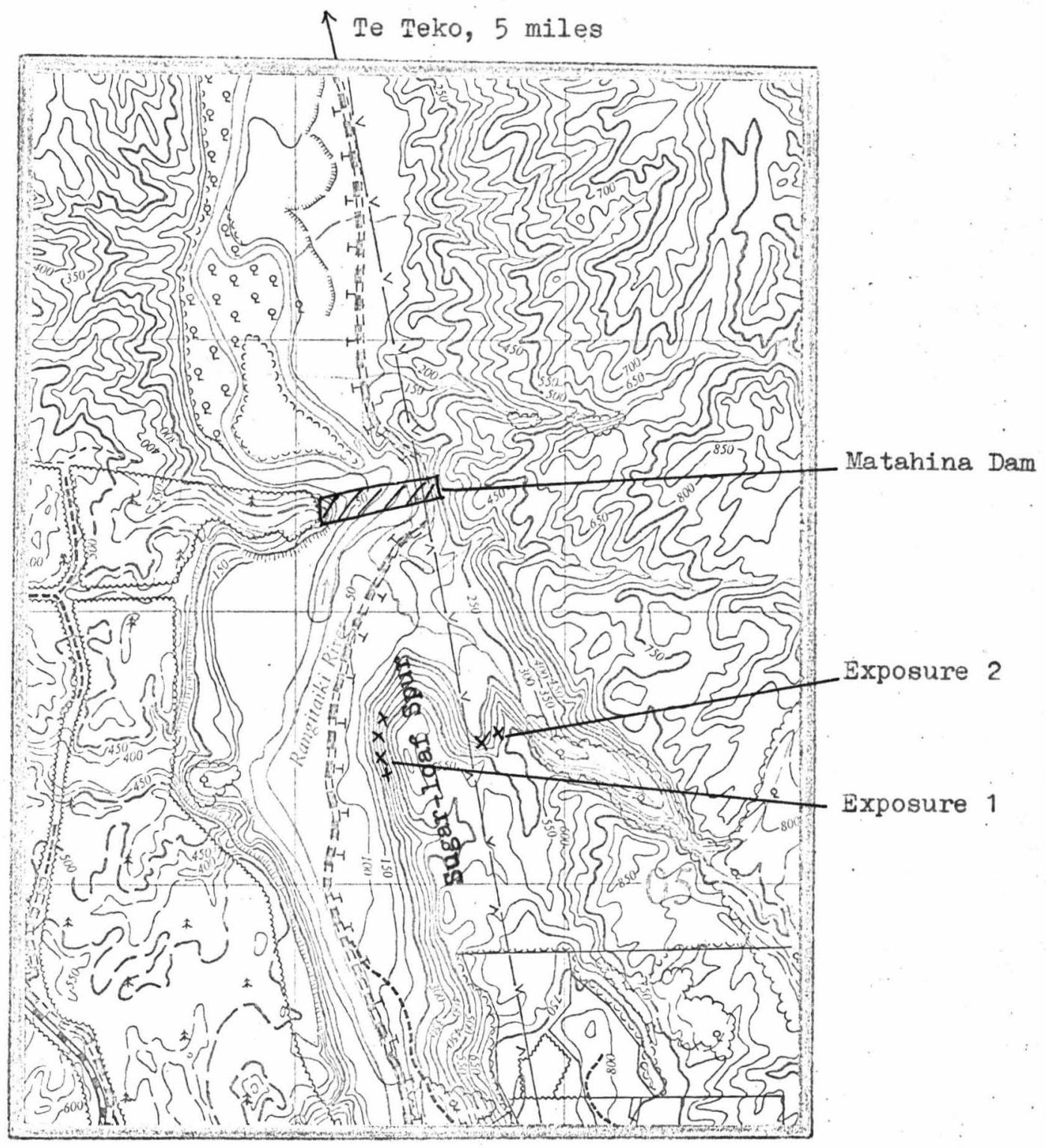

Fig. 10.1 Collection Iocality

Scale 1:25,000 


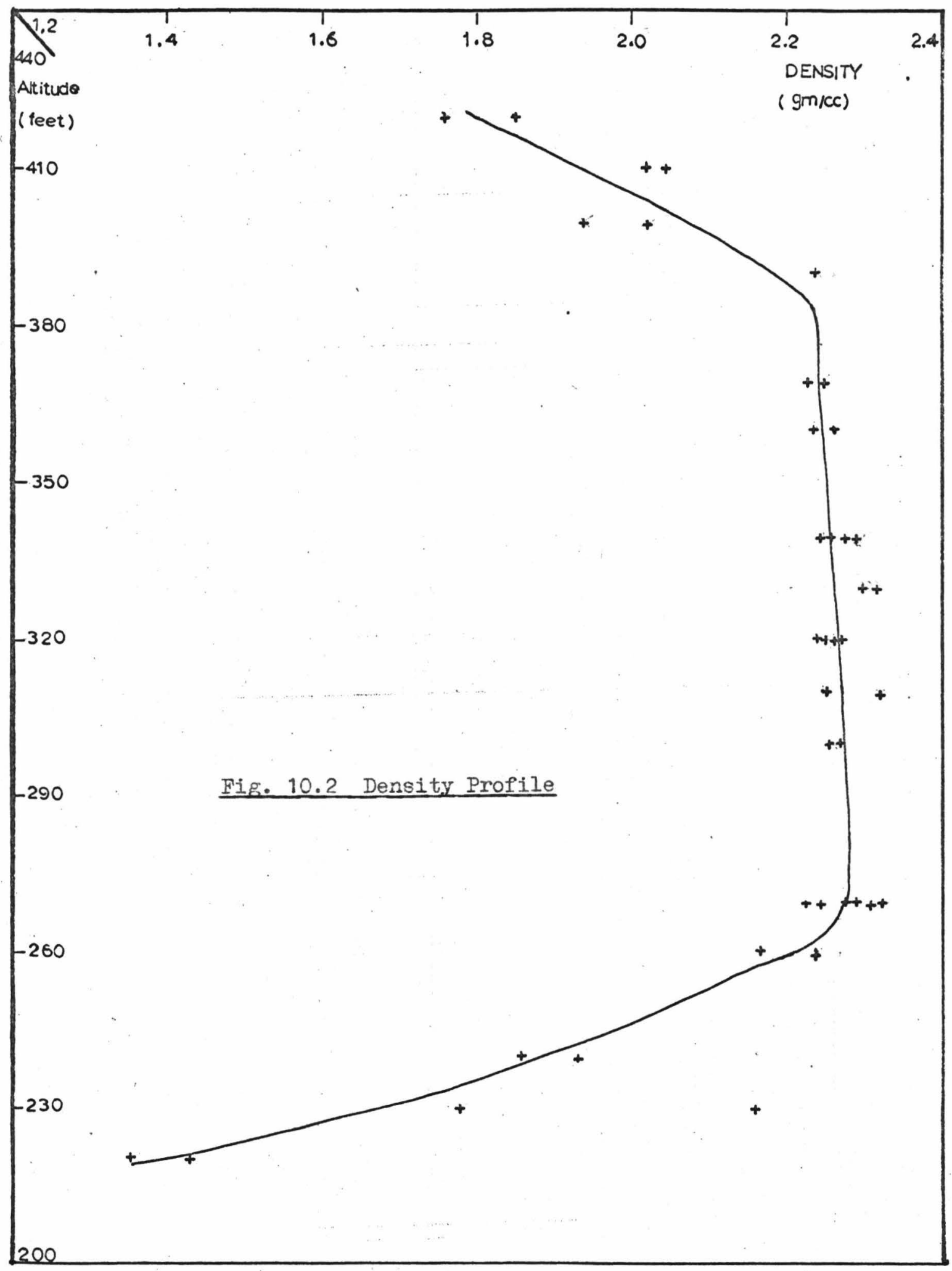



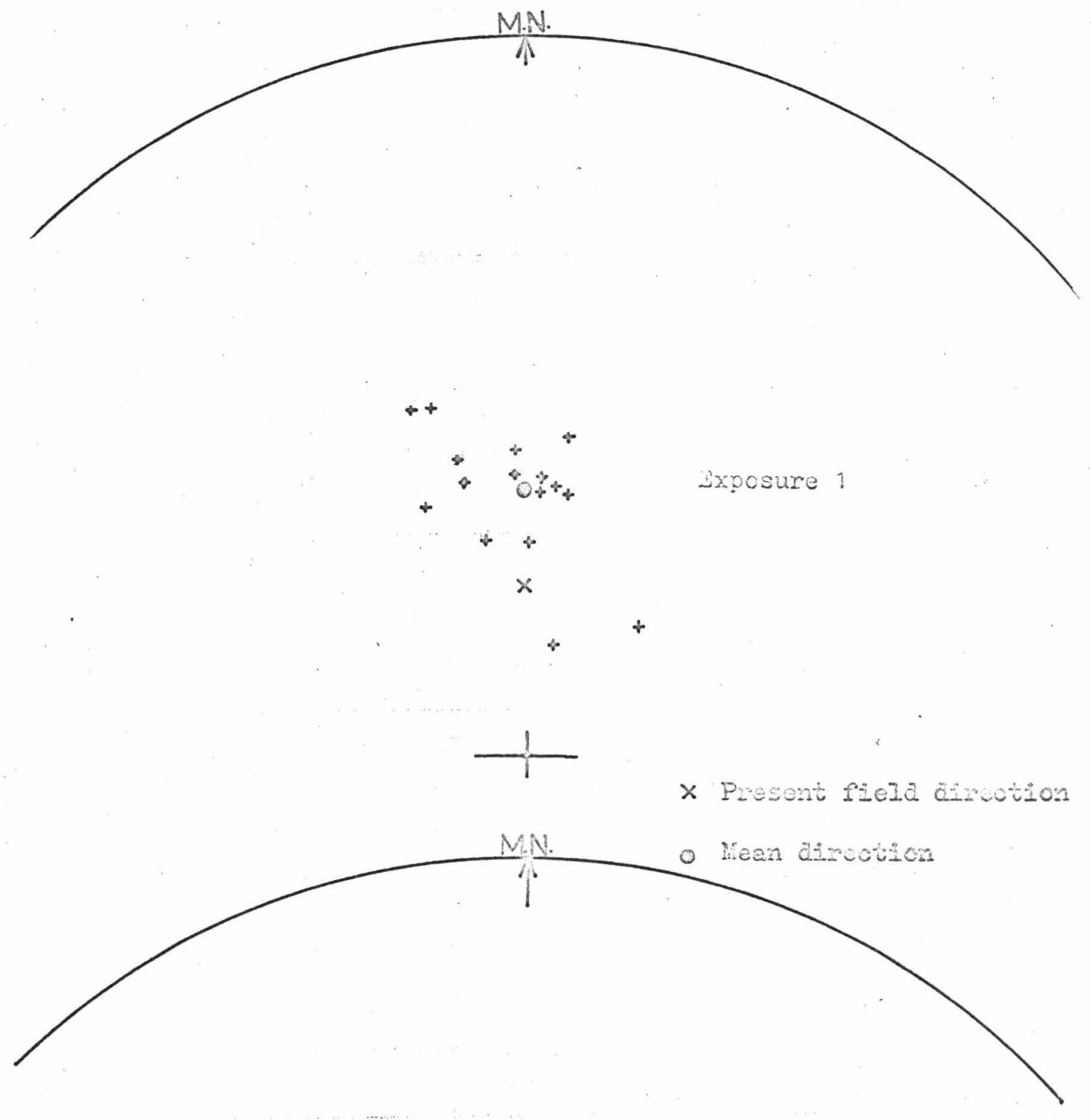

$\diamond$
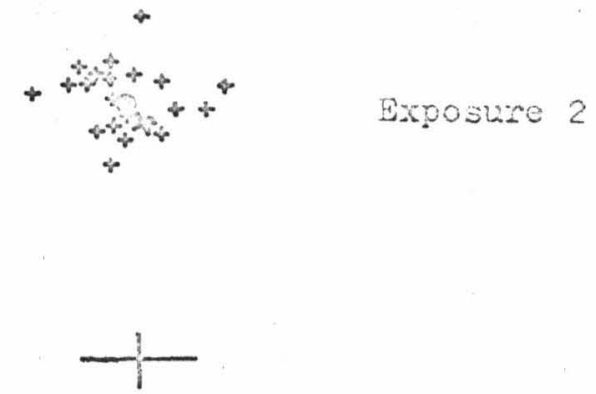

Hig. 10.3 Diregtions of N.R.N. 


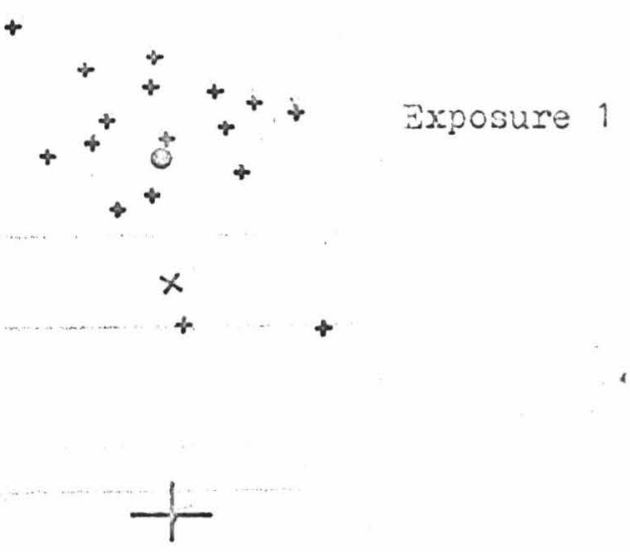

$\times$ Present field direction

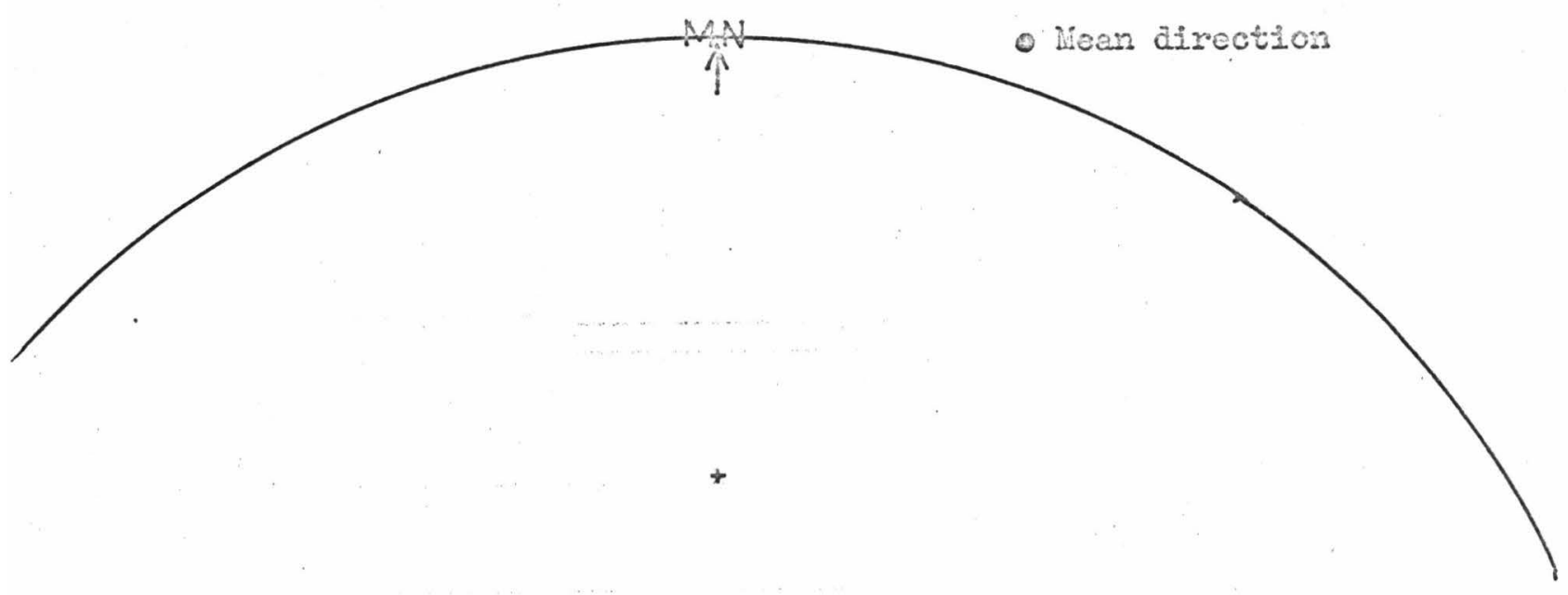

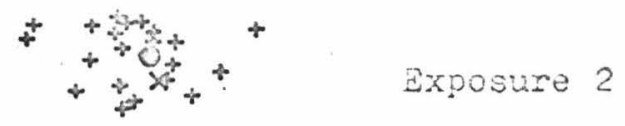




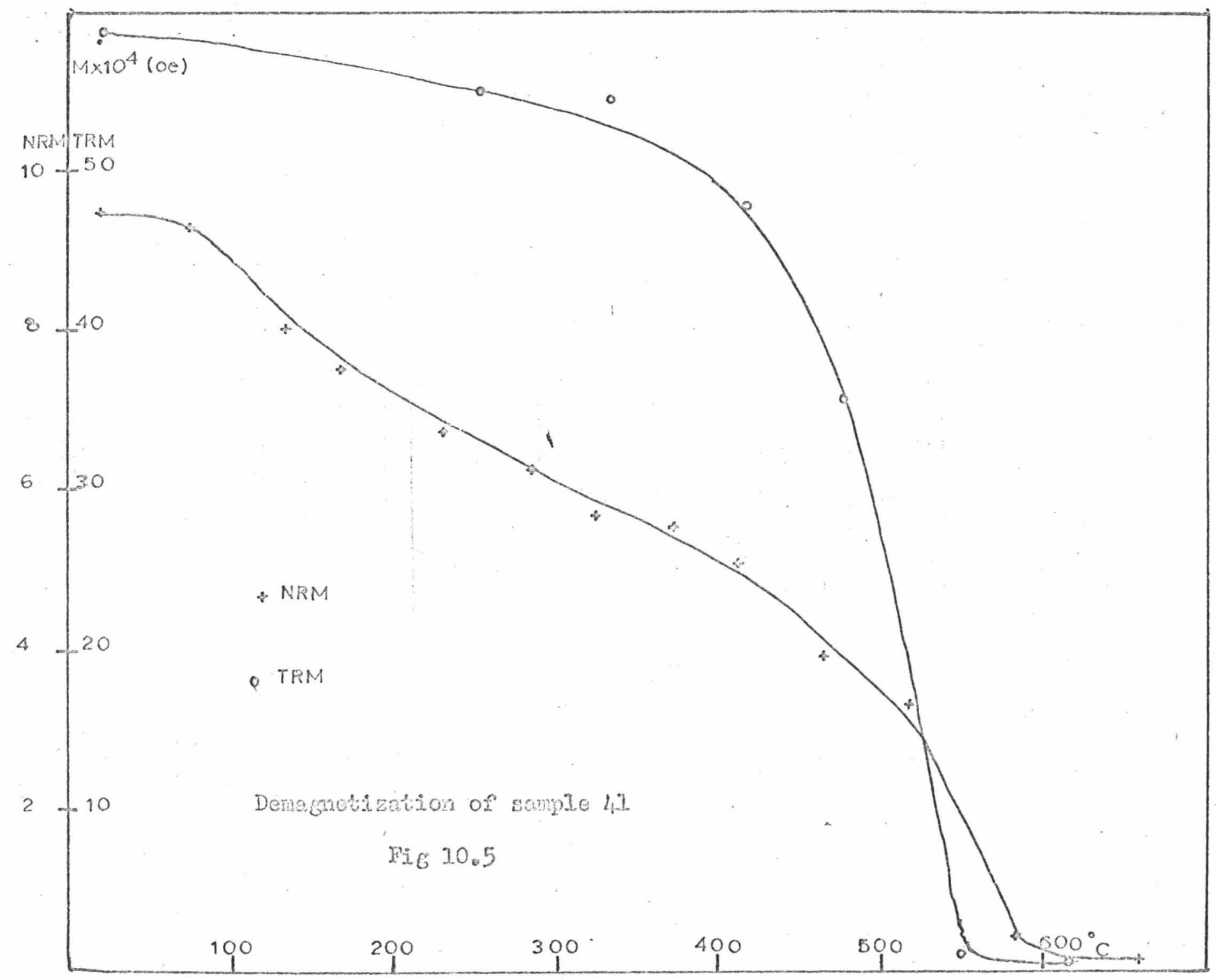

$\vec{\Xi}$ 


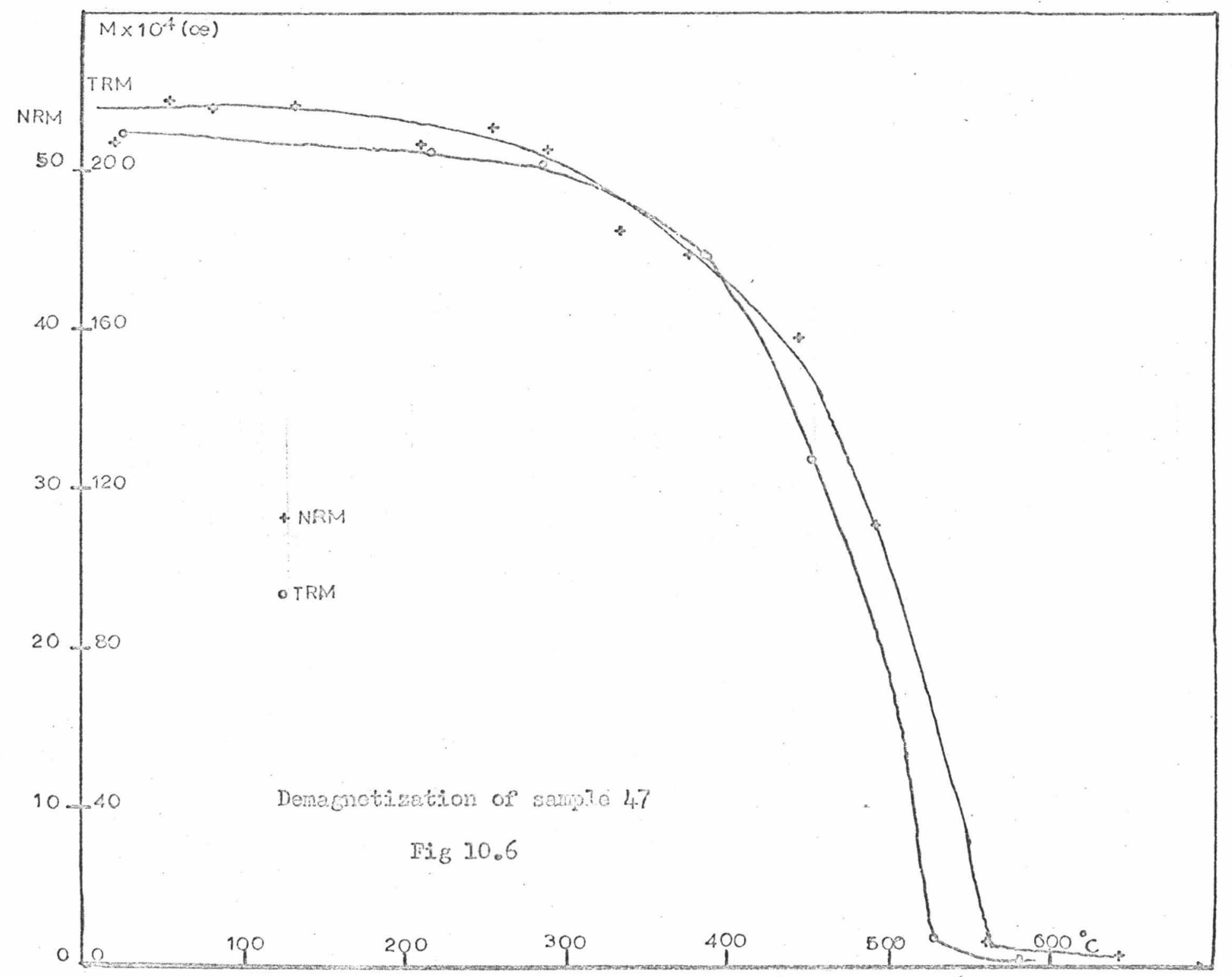

$\overrightarrow{\vec{r}}$ 


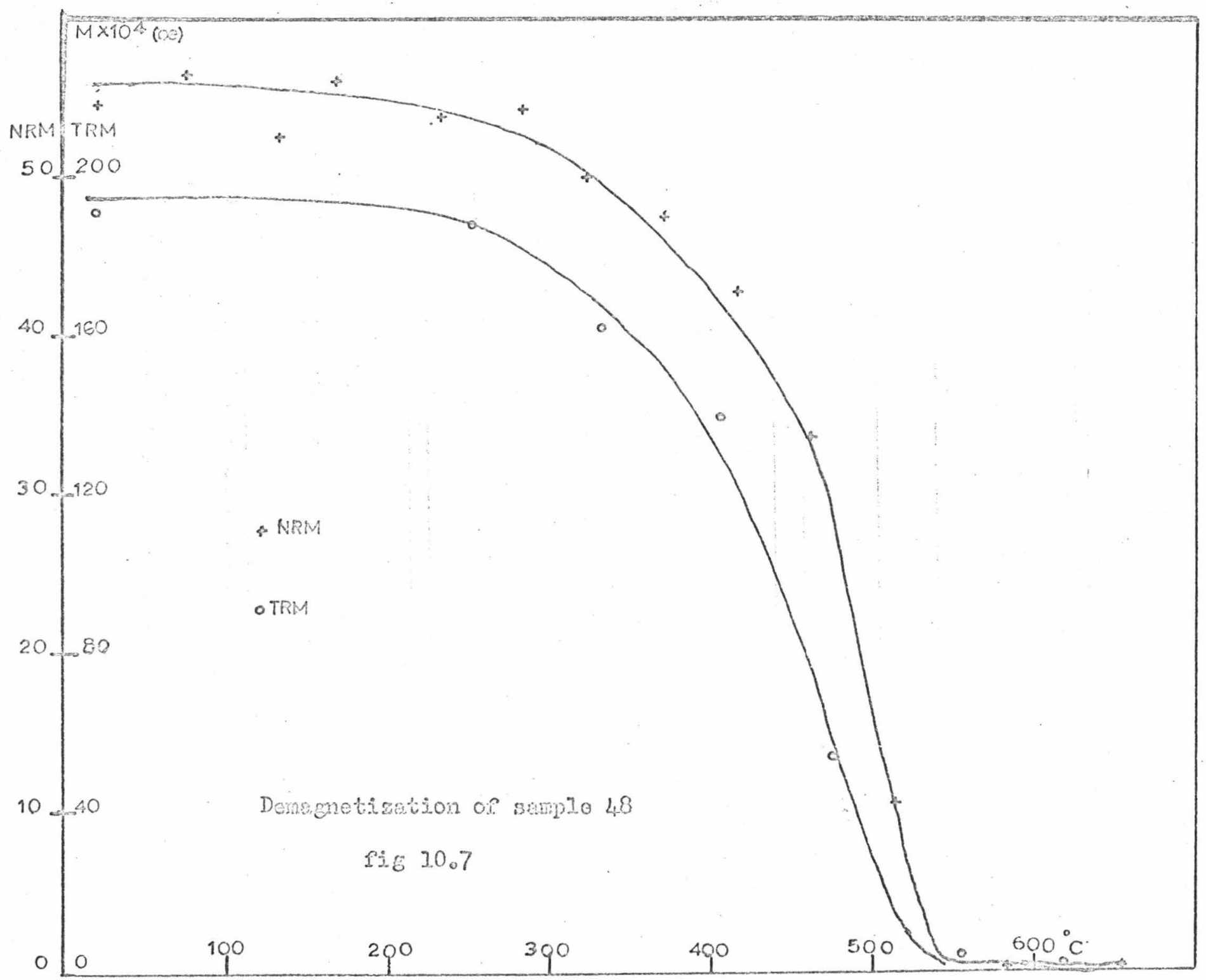

$\vec{D}$ 


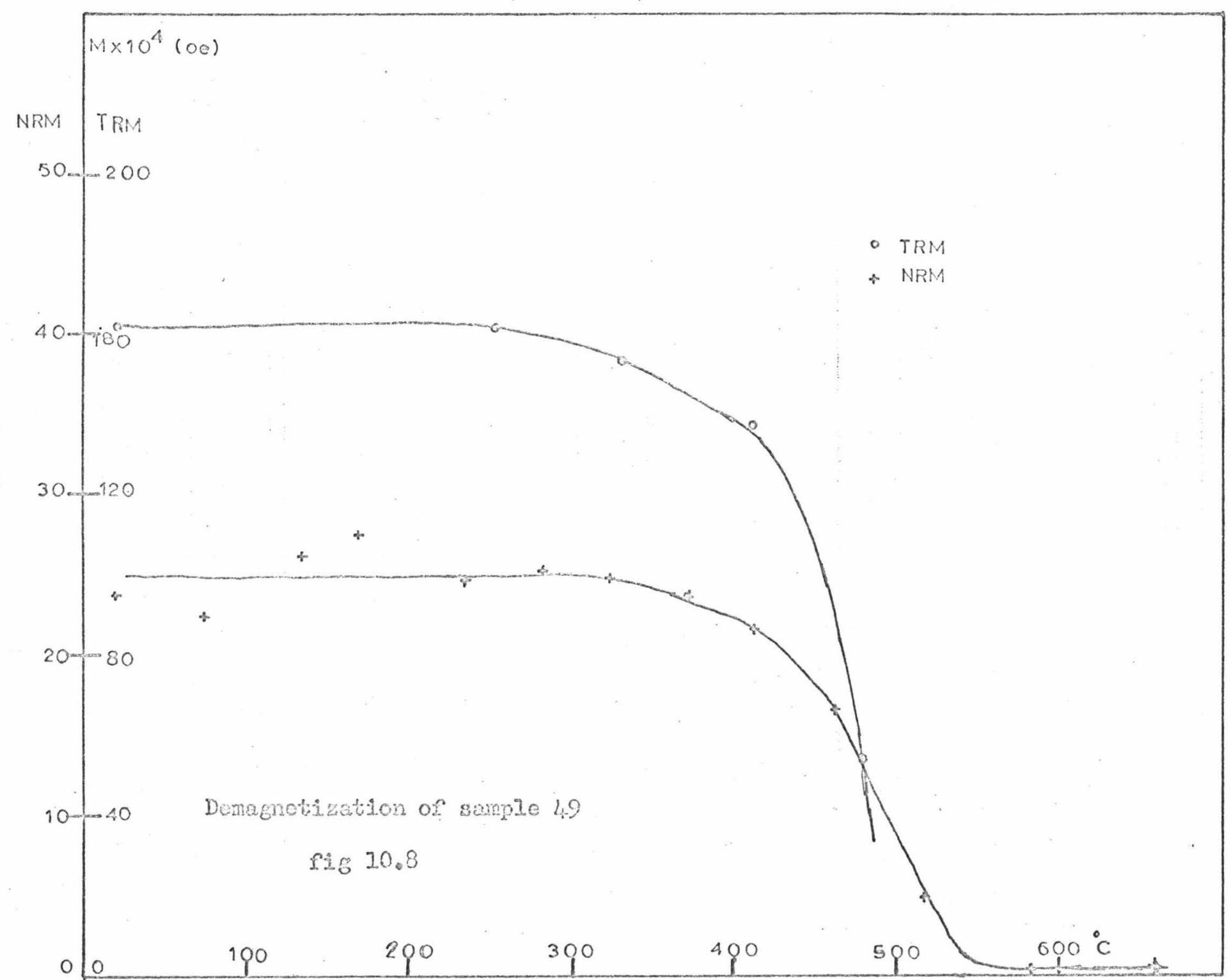

$\underset{-I}{\longrightarrow}$ 


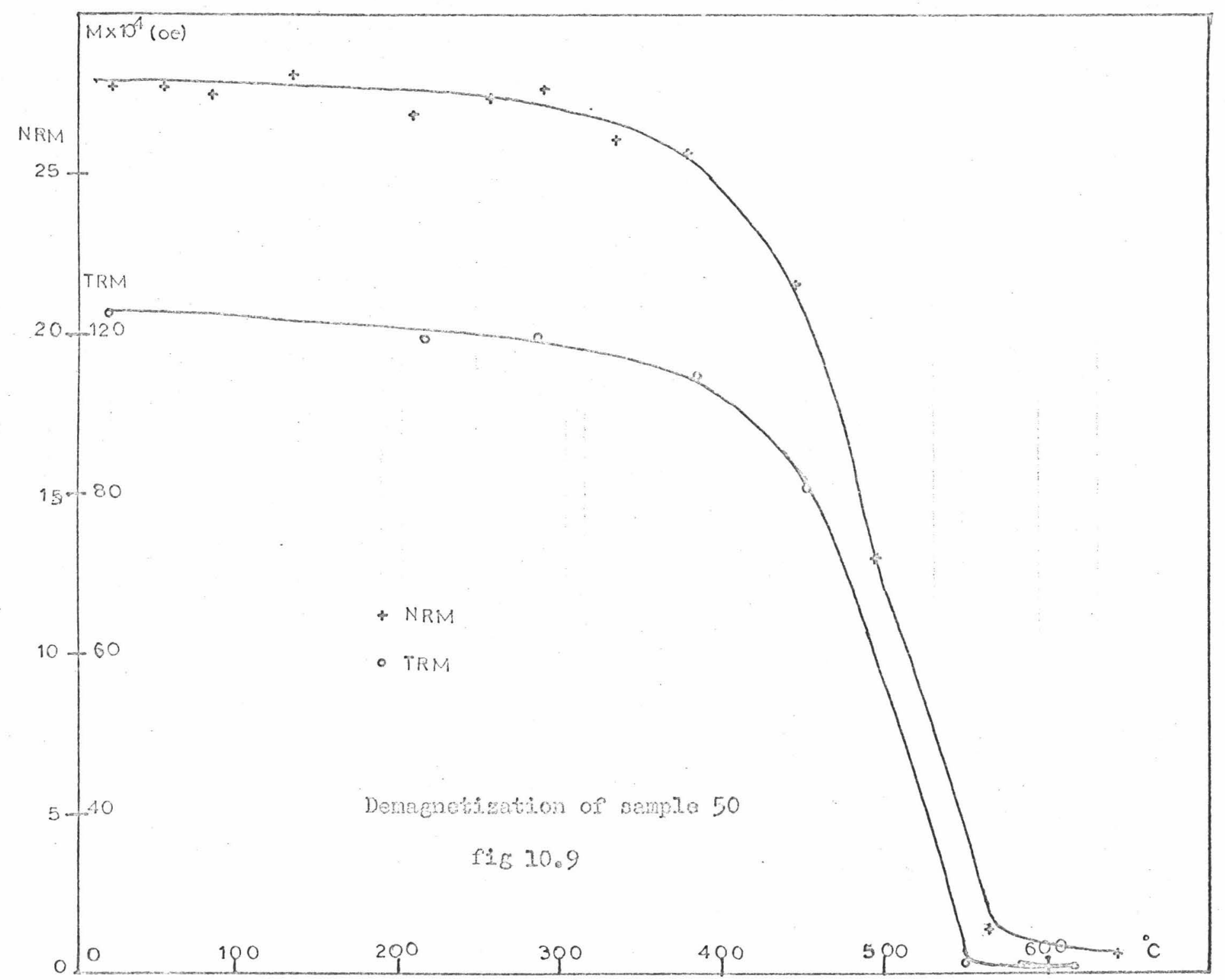

$\vec{\infty}$ 


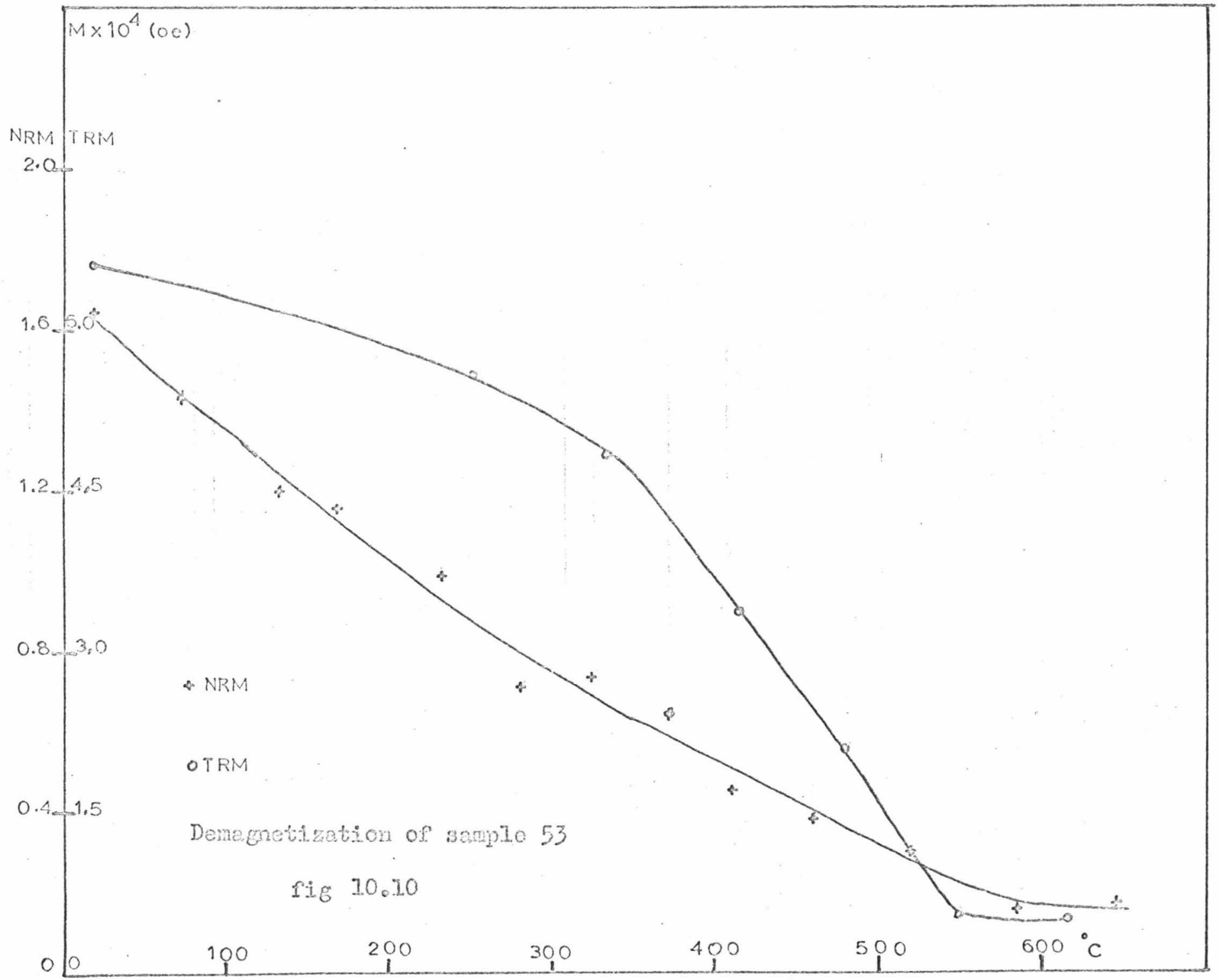

$\vec{b}$ 


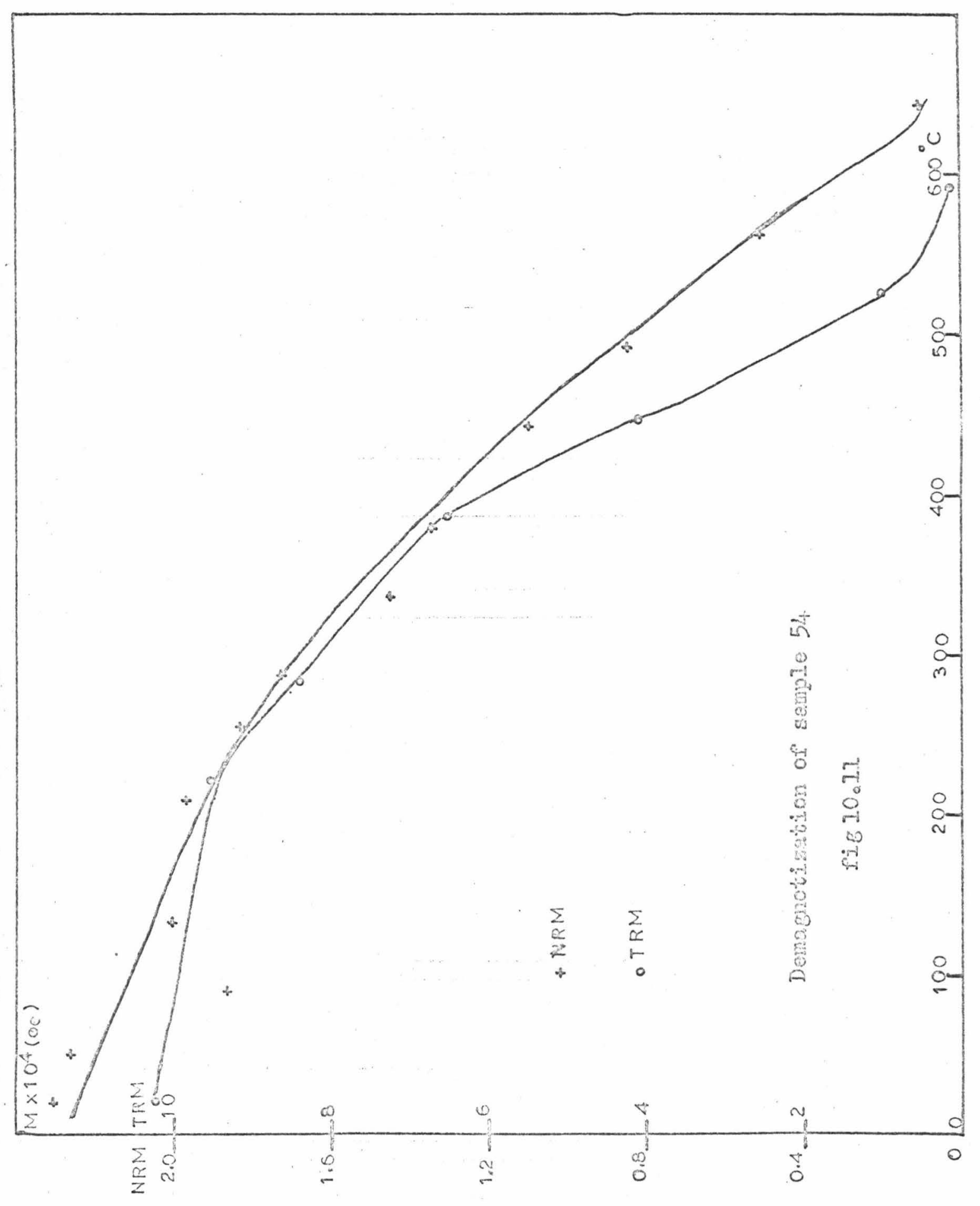




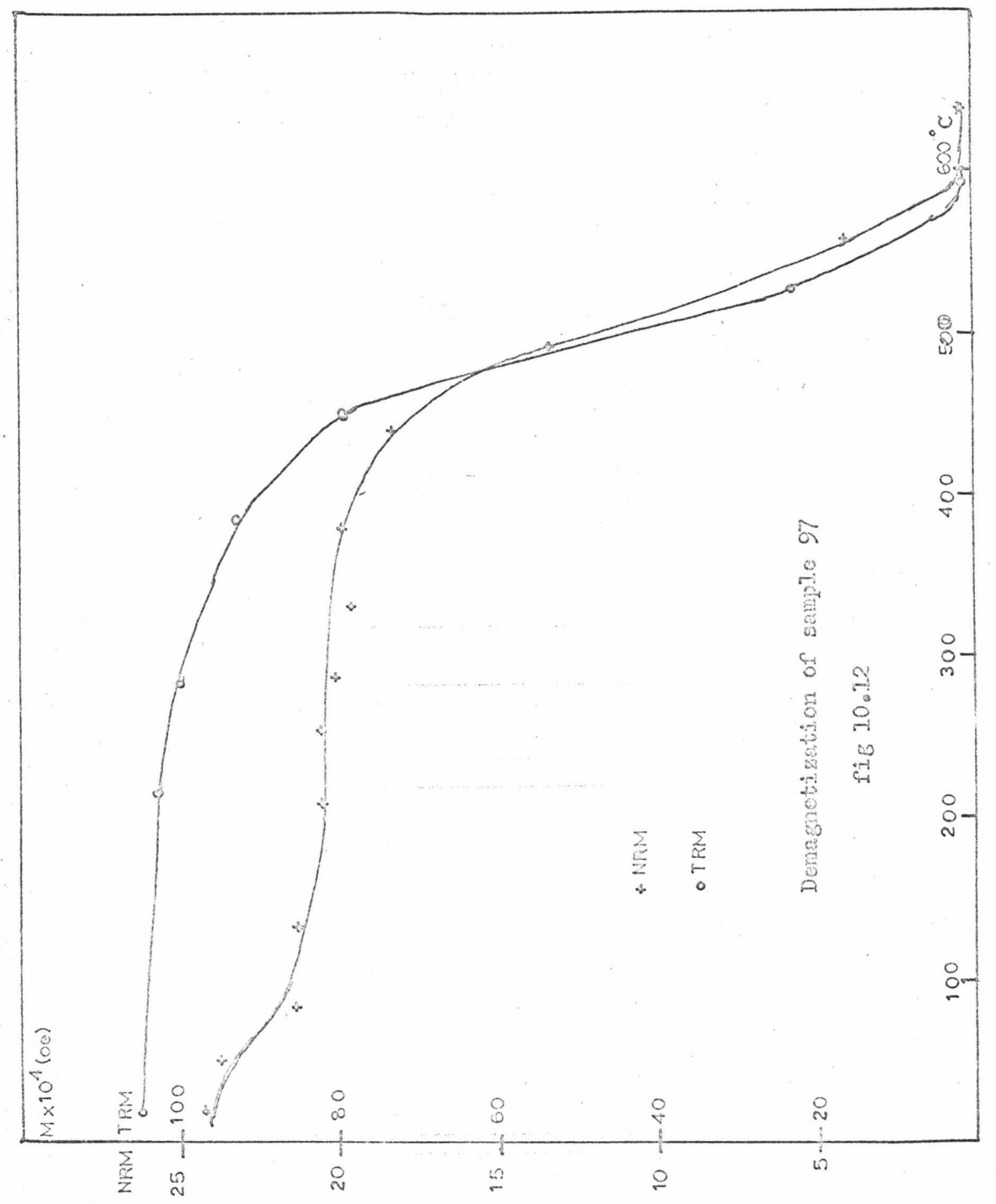




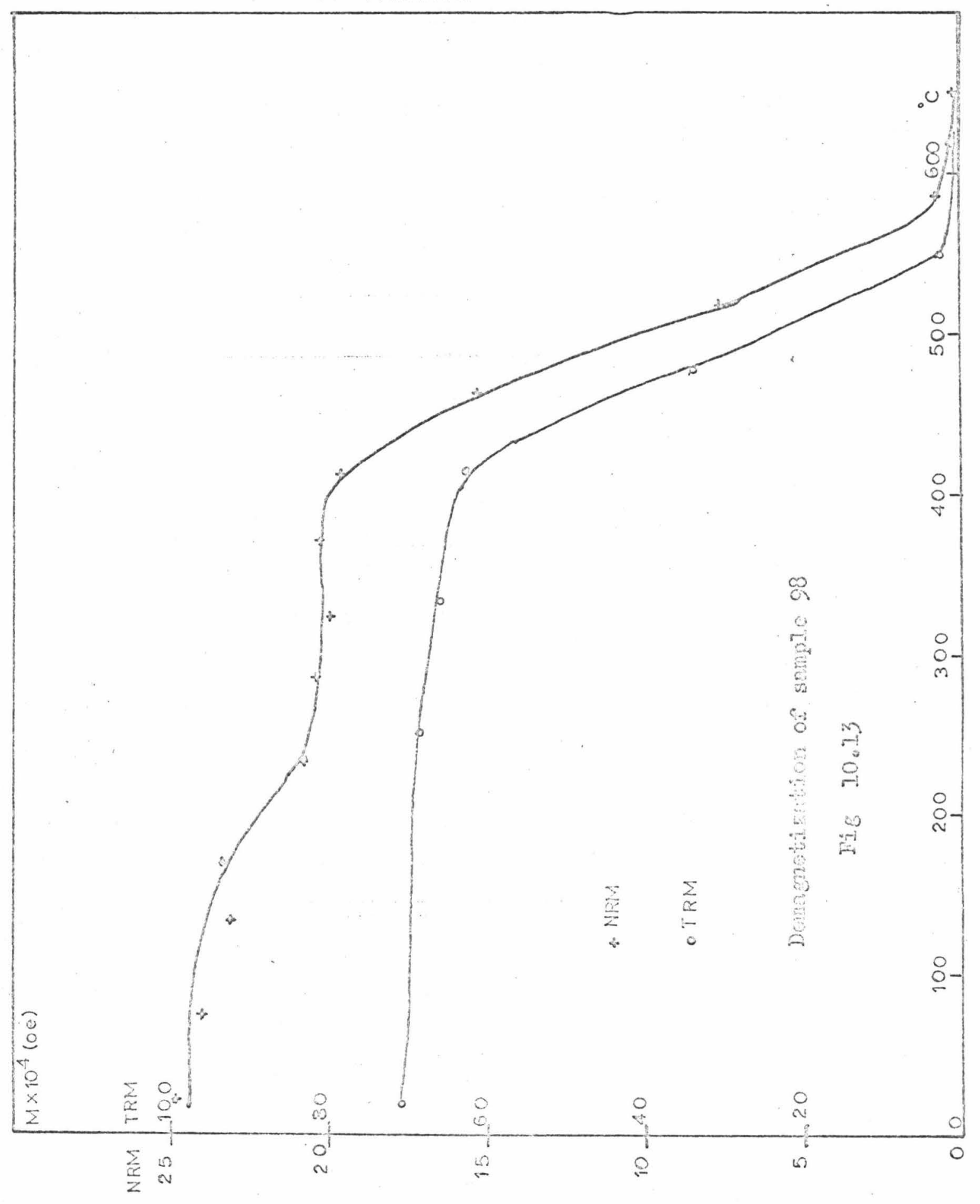




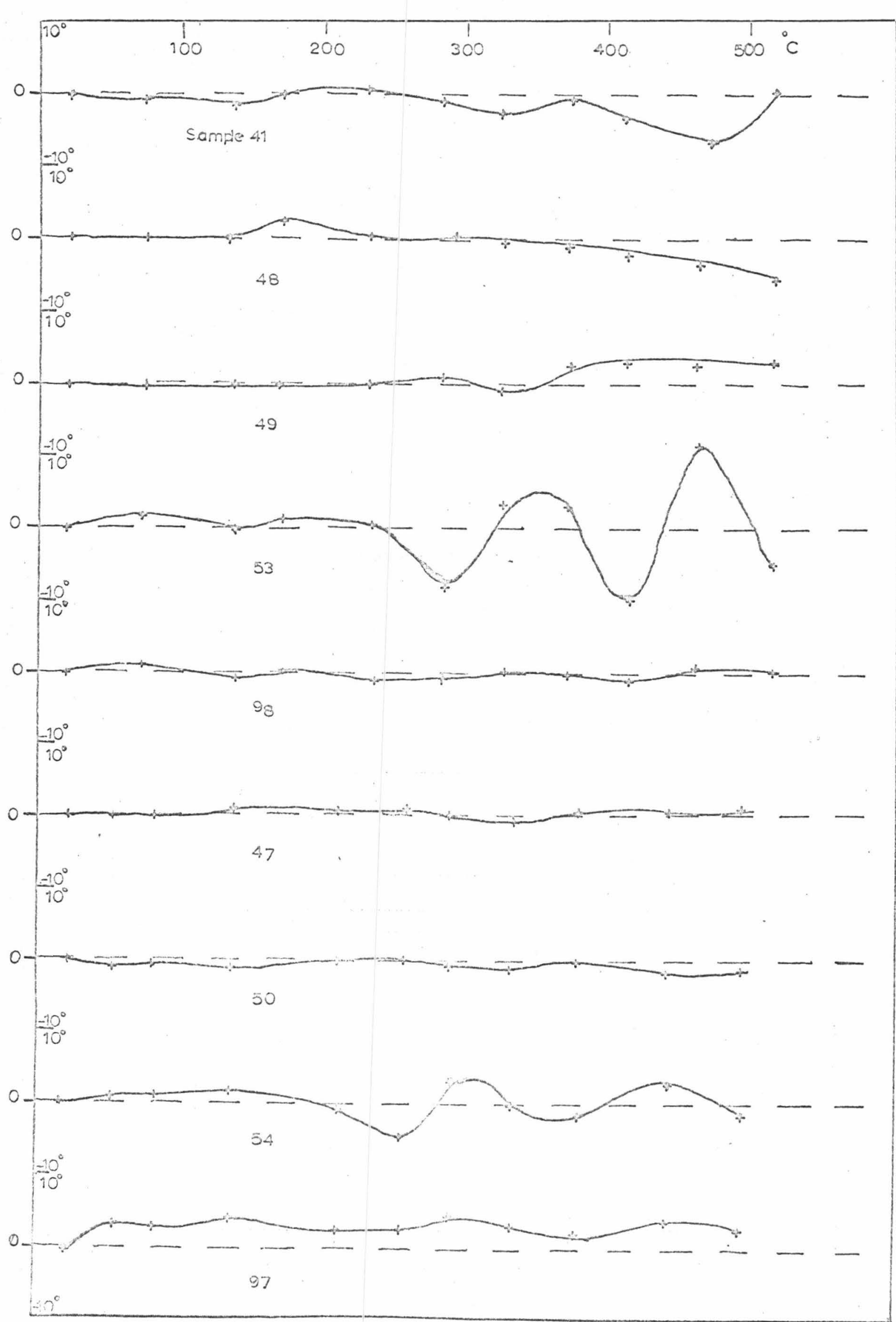




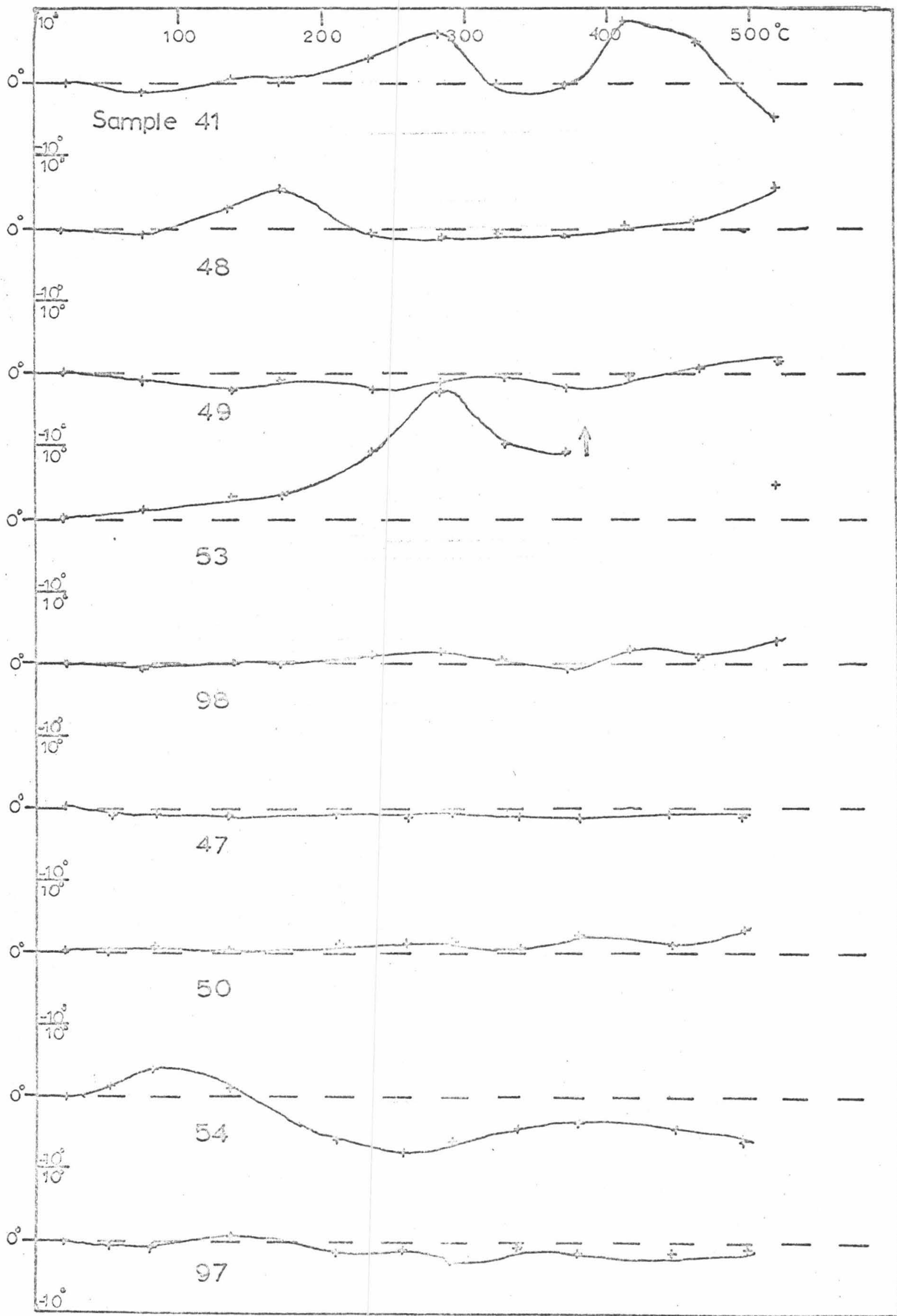




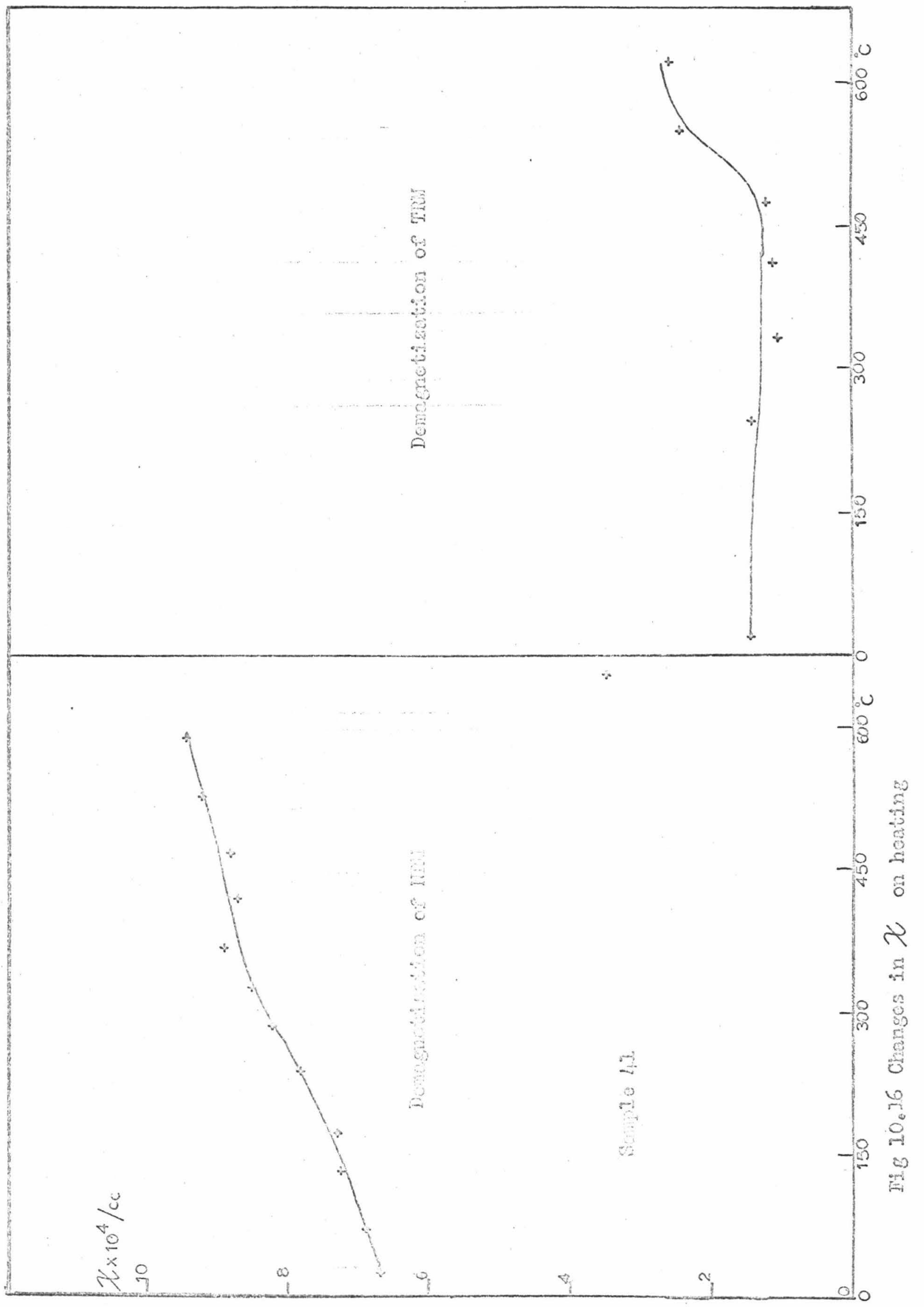




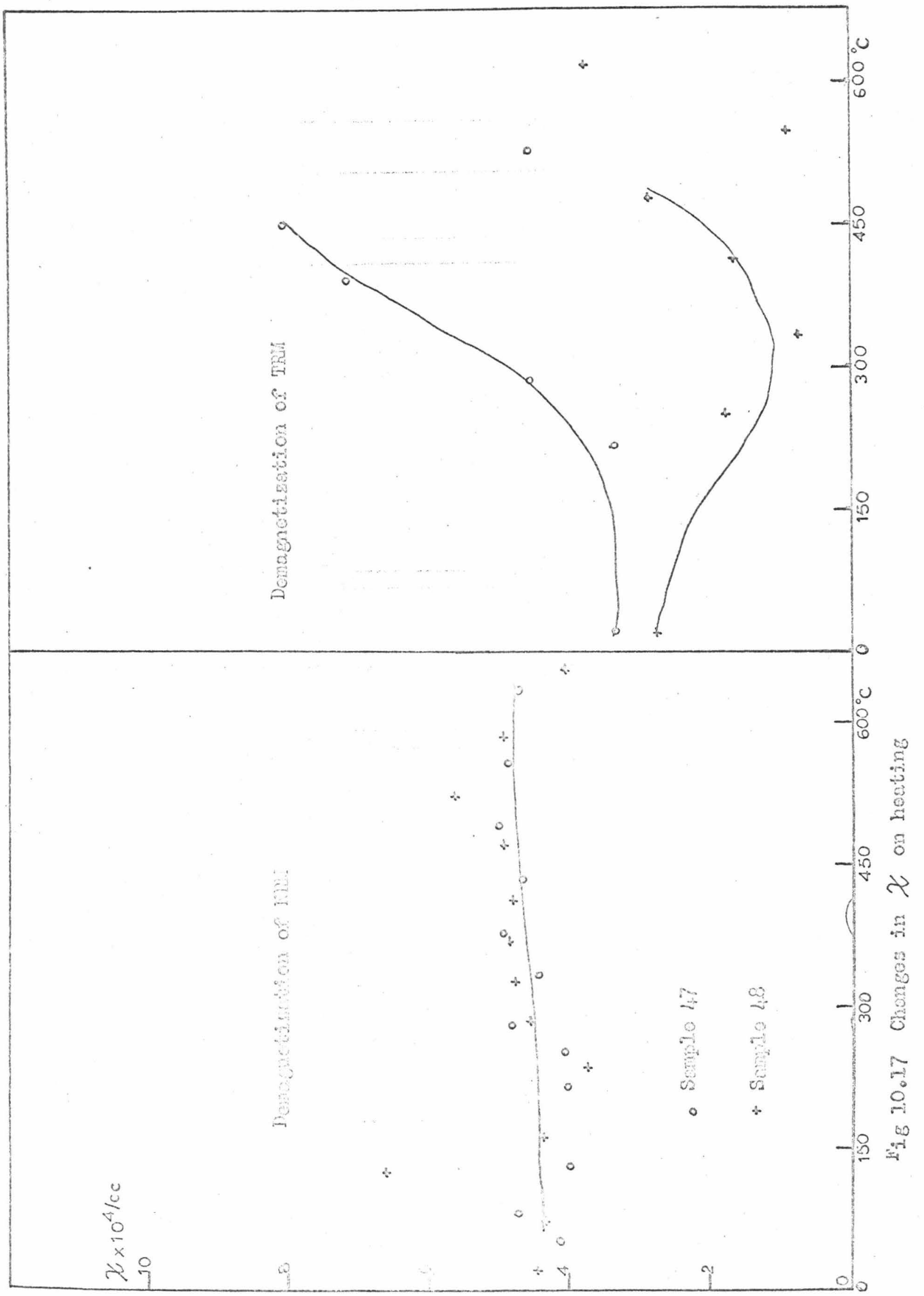




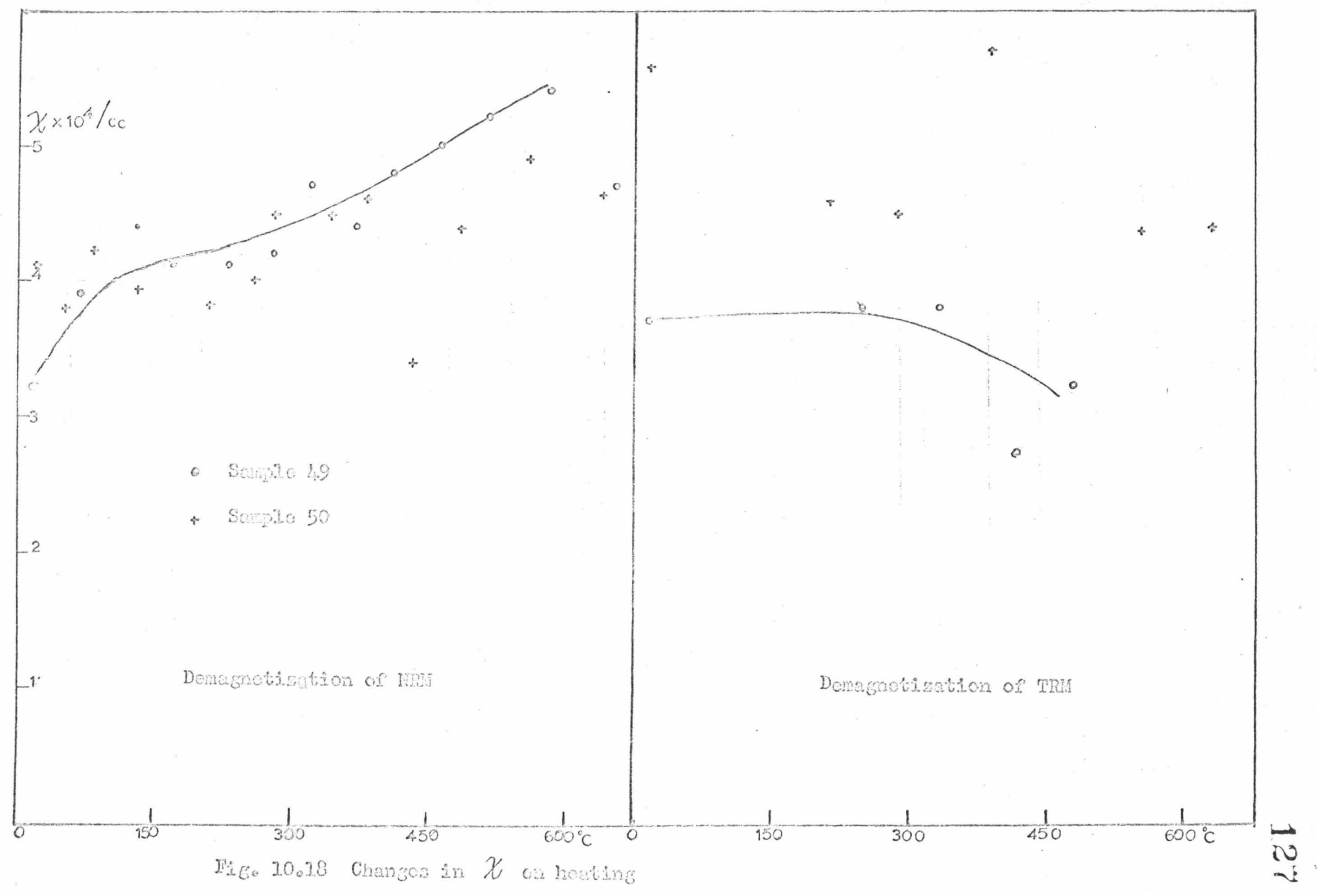




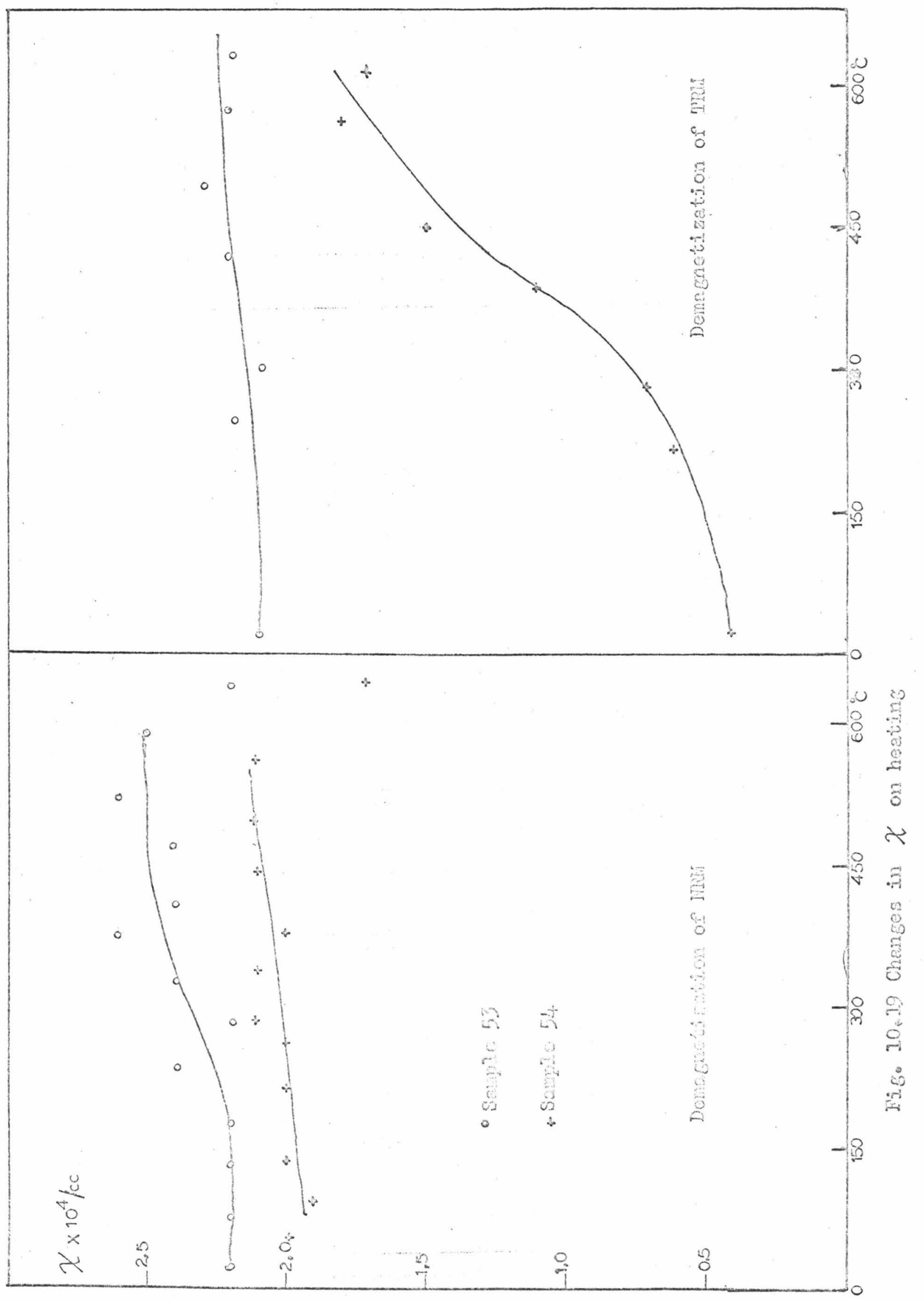




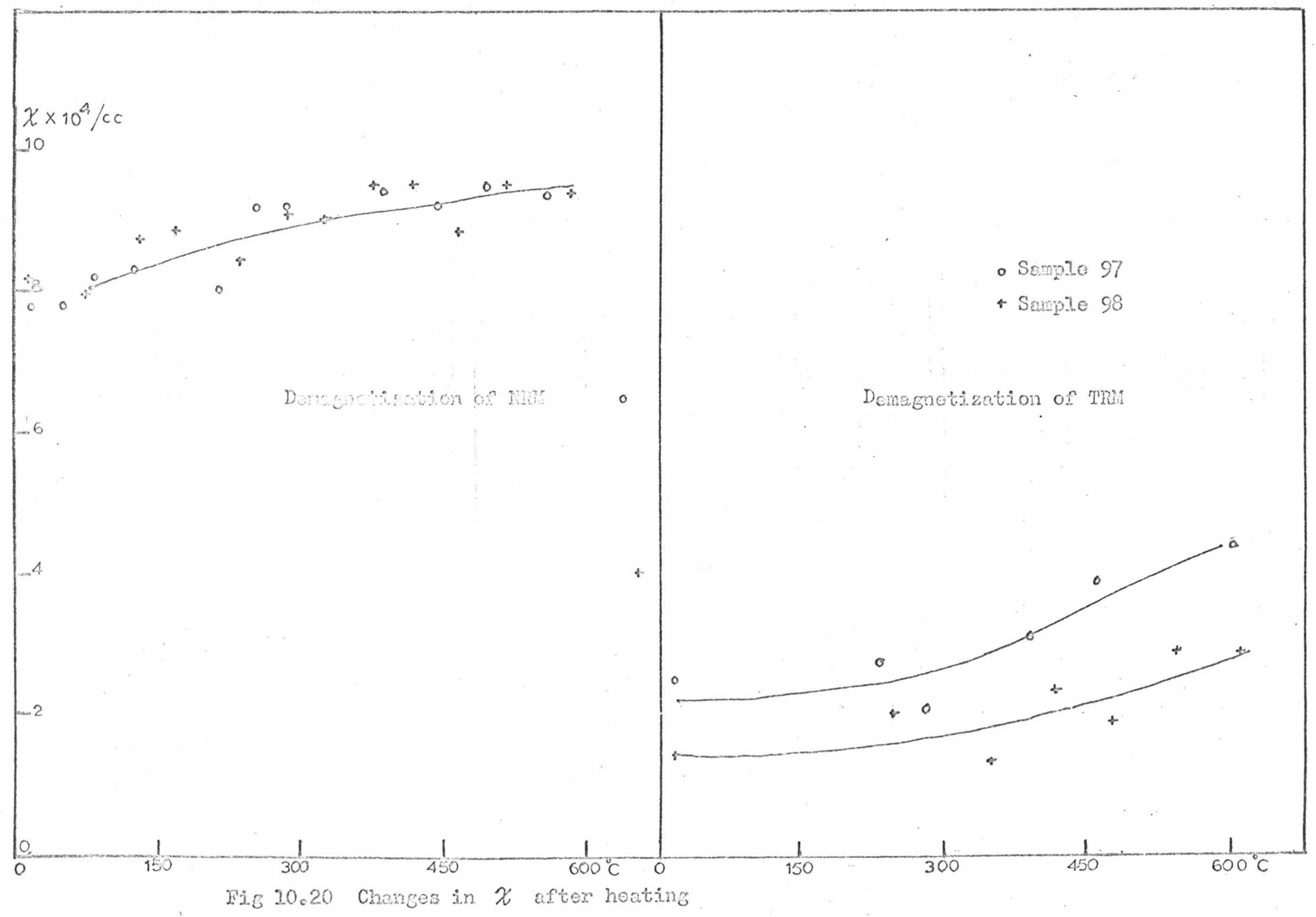

$\overrightarrow{0}$ 


\section{SIGNIFICANCE OF EXPERTMENTAL RESULTS}

11.1 DIRECTION OF N.R.M.

In this chapter the properties of samples are supposed to be the same as those of the specimens examined. The direction of the N.R.M. appears to be different for the two exposures, even after thermal washing, but to settle this point the two sets of results were assumed to be independent Fisher distributions, and the usual methods (Fisher, 1953, Watson, 1956) used to test for equal dispersion and equal mean. The statistical parameters are listed in table 11.1.

TABLE 11.1

Mean

$\frac{\text { Direction }}{\text { D I }}$

Before Washing

Exposure 1

$359^{\circ} \quad 40^{\circ}$

40

22

17

Exposure 2

$355^{\circ} 29^{\circ}$

100

14

22

After Washing

Exposure 1

$000^{\circ} \quad 40^{\circ}$

44

21

17

Exposure 2

$359^{\circ} 31^{\circ}$

116
Number of

Samples 
The significance of the difference between the $\mathrm{k}^{\prime} \mathrm{s}$ may be found (Watson, 1956) by comparing $k_{\max } / k_{\min }$ with the expected maximum values of the ratio

$$
\frac{s_{\max }^{2}}{s_{\min }^{2}} \text {, }
$$

where the s's are mean square deviations in sets with normal distributions. This ratio is tabulated by Pearson \& Hartley (1958), Page 179. For use in this table the $\mathrm{k}^{\prime} \mathrm{s}$ are based on $2(N-1)$ degrees of freedom, where $N$ is the number of samples on which each $k$ estimate is based. In the present case the value of $k_{\max } / k_{\min }$ will, with $95 \%$ probability, be less than some number between 2.1 and 1.7. The actual value is 2.6, so that the difference is significant.

Watson has given a test for whether two statistical samples give estimates of the same mean direction, when the samples have approximately the same dispersion. The quantity

$$
(N-2)\left(\frac{R_{1}+R_{2}-R}{N-R_{1}-R_{2}}\right)
$$

is distributed approximately as the F-ratio with degrees of freedom $\nu_{1}=2$, and $\zeta_{2}=2(N-2)$ (Pearson \& Hartley, 1958, page 159), where $R_{1}$ is the sum of the $N_{1}$ unit vectors with the directions of the first set of samples, $R_{2}$ that corresponding to the second set, and $\mathrm{R}$ is that corresponding to both sets combined, the total number of measurements being N. In this case

$$
\begin{array}{ll}
\mathrm{N}=39 & \mathrm{R}=38.01 \\
\mathrm{~N}_{1}=17 & \mathrm{R}_{1}=16.64 \\
\mathrm{~N}_{2}=22 & \mathrm{R}_{2}=21.82,
\end{array}
$$

which gives $F_{2,74}=31$. The upper $5 \%$ value for $F_{2,74}$ is 3.1, which implies that the sets have significantly different 
mean directions. This probably indicates that the two exposures are separated by a fault (refer Section 10.1.1), which has resulted in a relative change of dip of $10^{\circ}$, in a magnetic north direction. The difference in dispersions may indicate minor slumping on exposure 1. No reliable palaeomagnetic direction could be calculated from such divergent results, but it will obviously be near the present geomagnetic direction, in agreement with previous results on Quaternary rocks.

11.2 VARIATION WITH ALTITUDE OF MAGNETIC PROPERTIES OF THE IGNINBRITE

11.2.1 Changes in Magnetization Intensity After Heating to $300^{\circ} \mathrm{C}$. Table 11.2 shows various properties of samples arranged as well as possible in stratigraphic sequence. The ratio of the intensity of N.R.M. to the intensity after washing in zero field at $300^{\circ} \mathrm{C}\left(\frac{\mathbb{M}_{N R M}}{\mathbb{M}_{300}}\right)$ shows particularly well the variation in the nature of the magnetic properties, which appear to depend on stratigraphic position.

It is tempting but not fully justifiable to suppose that those samples within each group which were fully demagnetized are representative of the group as a whole, and that the information about the group assists the description of the individual samples. Taking this last point, all the samples between 400 and 360 feet (sheet 1 ) show a similar large decrease in magnetization below $300^{\circ} \mathrm{C}$., so removal of a P.T.R.M. (explanation (a) of paragraph 10.4.4) seems unlikely, since it is hard to imagine a mechanism for uniform heating of all the samples. Removel of an I.R.M. (explanation (b)) is unlikely because an I.R.M. requiring $300^{\circ} \mathrm{C}$. to remove it 
would probably be caused by a high field. Such high fields could only be produced by lightning strikes, and then could not be uniform in direction. No changes in direction of N.R.M. were observed so lightning is not likely to be responsible. The low temperature magnetization of sample 41 is evidently unstable to heating.

It seems that the rock in sheet one contains a mineral which is either chemically unstable above $250^{\circ}$, or has a Curie point at $250^{\circ} \mathrm{C}$ and decomposes at some temperature between this and $600^{\circ} \mathrm{C}$. Further experiments could eliminate one alternative, but the point is not worth pressing at the moment. The samples in sheet two (330 360 feet) also show a decrease in intensity below $300^{\circ} \mathrm{C}$ and with the detailed information on samples 97 and 98 , it appears that they contain a lesser amount of the same mineral present above, together with mostly high Curie point magnetite.

The samples from $330^{\prime}$ to $250^{\prime}$ (sheet 3) appear to contain practically pure magnetite.

The nature of the magnetic minerals in sheet 4 is not obvious. The rock might contain magnetite with a continuous blocking temperature distribution.

These regions have been called "sheets" merely for convenience. Hatherton (1954b), in describing the Whakamaru ignimbrite finds horizontal boundaries at which there is a sharp increase in $\frac{M}{\not}$, which he correlates with supposed cooling between separate depositions of several layers of rock. Some of these boundaries had been recognised by geologists, and taken as boundaries between "sheets", the origin of which was left 
undefined. Current opinion is uncertain as to whether these sheets are always due to separate depositionsor whether they are due to surges during continuous deposition of the ignimbrite. Here the term "sheets" refers only to a region of the ignimbrite, with no implications about mode of formation.

11.2.2 Changes in $\frac{M}{X}$ N.R.M.

It may be seen that this ratio takes different and roughly constant values in each sheet. The values obtained are similar to those for most igneous rocks and are about the same as those obtained by Hatherton for the Whakamaru ignimbrite, where $Q=\frac{M}{x H}$ was about 2 to 4 away from boundaries of sheets, and rose at the boundaries to a maximum value, up to 18. H would be about $\frac{1}{2}$ oe. in this expression for Q. The highest values of $\frac{M}{x}$ ) N.R.M. occur near the postulated boundaries of sheet 3 , but in view of the low sampling density at these points, no comparison with Hatherton's work can be made.

11.3 SIGNIFICANCE OF THE VALUES OF $\frac{\mathrm{M}_{\text {TRM }}}{\mathrm{MNRM}_{\mathrm{NR}}}$

This ratio is about 7 in sheet one, about 3 to 4 in sheets two and three, and about 4 to 6 in sheet four. Possible reasons for these generally high values are

a) The N.R.M. is not a T.R.M.

b) The original N.R.M. has decayed with time.

c) When these rocks were formed the earth's field was several times lower than it is at present.

d) Owing to minerological changes, minerals are present in the rock now which were not there originally, and which may now acquire a T.R.M. 
Discussion of these alternatives follows.

a) This may be decided from the shapes of the graphs of demagnetization of N.R.M. and T.R.M. An I.R.M. generally decreases at much lower temperatures than a T.R.M., even when the I.R.M. is acquired in a much higher field. It is seen here that except for samples 41,53 and 54, most of the N.R.M. is destroyed over the same high temperature range as the T.R.M. There is still the possibility of a chemical remanent magnetization (Haigh, 1958, Kobayashi, 1959) for in some circumstances this is almost indistinguishable from T.R.M. However, in view of the known igneous origin of the rocks, and the low likelihood of all the samples from each sheet being subject to the same chemical alteration process, to the same extent,it will be assumed that all the rocks have a T.R.M. as their main magnetic component.

b) At first sight this appears to be consistent with the observation that samples from sheets one and four, which have a low temperature (and therefore magnetically unstable) component also have the highest ratio of T.R.M./N.R.M. However, it has been shown that the low temperature component of magnetization is not present in the T.R.M., so these samples ought to have a lower ratio than the other, thermally stable, rocks. The experiment of paragraph 9.9 was designed to estimate the decay of the magnetization with time after production of a T.R.M. in the laboratory. Suppose the magnetization decays logarithmically with time at all times from, say, several seconds after formation to several million years, i.e. $\quad J=J_{0}(1-\alpha \log t)$. 
The change in $\mathrm{J}$ from $t_{1}=3$ hours to $t_{2}=60$ hours is is given by $\frac{J_{t 1}-J_{t 2}}{J_{t 1}}<1 \%$

$$
\frac{1-\alpha \log t_{1}}{1-\alpha \log t_{2}}=\frac{J_{t_{1}}}{J_{t_{2}}}
$$

so

$$
\frac{\log t_{2} / t_{1}}{1-\alpha \log t_{2}}<0.01
$$

giving $\quad \alpha<0.0076$,

so the maximum rate of decay of magnetization gives

$$
J_{\text {min }}=J_{0}(1-0.008 \log t)
$$

where $t$ is in hours after formation of T.R.M. After $10^{6}$ years $=10^{10}$ hours

so

$$
\begin{aligned}
& J_{\min }=0.92 J_{0} \\
& \frac{J_{\text {TRM }}}{J_{\min }}=1.09 .
\end{aligned}
$$

In other words the magnetization could not have decayed to the observed values if the logarithmic decay law is valid and no changes in minerals occurred when the T.R.M. was given.

c) Some palaeomagnetic evidence has been obtained of past values of the strength of the earth's magnetic field, but work on this aspect is restricted by the great amount of effort required to prove that the intensity of the N.R.M. has been completely stable. E. \& O. Thellier (1959) have performed good work on hematite-bearing baked clays, and have show that the local geomagnetic intensity in Europe has been decreasing for the last 2000 years or so, but their work does not go further back in time, and there is no justification for any extrapolation. Wilson (1961), has used baked hematite-bearing rocks to estimate a field strength in Tertiary times, and found a value comparable with the present field. Some work has been done on magnetite-bearing rocks, by Momose (1963), and van Zijl 
Graham \& Hales, (1962), but little discussion of stability was given. They showed that between reversals the earth's field strength fell to about a quarter of its normal value in the Upper Tertiary.

Although it seems that changes in field strength may occur, it is necessary either to show that no decay or mineralogical changes could have occurred in a particular rock, or to show that several rocks of different types and the same age show the same apparent change in field strength.

d) It has been pointed out that at least some of the minerals present in parts of the ignimbrite are unstable at high temperatures. The observed changes in susceptibility also point towards partial instability.

The changes in susceptibility with temperature are shown in Figs. 10.16 to 10.20 , and the general trend can be seen to be a gradual increase in susceptibility on the first heating, followed by an abrupt decrease above $600^{\circ} \mathrm{C}$., the amount of the decrease depending partly on the length of time the samples were held at that temperature. (The samples were heated three times to more than $600^{\circ} \mathrm{C}$ - once to remove the N.R.M., once to produce the T.R.M., and again to remove the T.R.M.). The changes in susceptibility could be taken to represent simple corresponding changes in the amount of ferromagnetic material. This is hard to reconcile with the values of $\frac{\mathrm{M}_{\text {TRM }}}{\mathrm{M}_{\text {NRM }}}$, which is about twice as large for sample 41 as 98 , which have equal changes in susceptibility, and is the same for samples 97 and 50, which have very different changes in susceptibility.

These variations must derive from a fairly complicated set of changes in minerals. 


\subsection{POSSIBLE CHANGES IN THE MAGNETIC MINERAIS}

The author has not had time to pursue this point to any sort of conclusion, but has acquired some information which may be relevant.

The magnetic fraction was separated by crushing and extracting with a permanent magnet, the minerals in sample 41. An X-Ray powder pattern examination identified only a mineral similar to magnetite or maghemite, but no accurate measurements of unit cell size were possible. An attempt was made to show the presence of maghemite, by heating the powder specimen at successively higher temperatures up to $700^{\circ} \mathrm{C}$. (in air), and taking $\mathrm{X}$-Ray records between each heating. To check against the possibility of oxidation of any magnetite which might be present a specimen of Magnet Cove lodestone, which was identified as magnetite in the Geology Department collection, was prepared and subjected to the same heating processes. The lodestone started changing to hematite at about $400^{\circ} \mathrm{C}$. , the transition being nearly complete at the end of the experiment. On the other hand, the magnetic fraction from sample 41 changed only slightly after about 20 minutes at $700^{\circ} \mathrm{C}$. It was concluded that most of the fraction separated from sample 41 is magnetite, while the lodestone is maghemite.

Weaving (1962), has pointed out that the mineral chlorophaeite, which is an alteration product of olivine, is weakly ferromagnetic, with Curie temperatures $300^{\circ}-400^{\circ} \mathrm{C}$, but alters on heating to $600^{\circ} \mathrm{C}$. to an impure form of hematite which may be 5 times more strongly magnetic. This type of behaviour may be expected to lead to some of the results observed here. This mineral is usually found in basalts, 
but because of its indefinite composition and somewhat variable properties, is not always accepted as a mineral by geologists. It has not been mentioned in any of the literature on ignimbrites read by the author (few petrological studies of N.Z. ignimbrites have been published), but one point arises in an article by steiner, (1960). He reports finding a yellow-green glass of refractive index 1.52 in some "very fresh" samples of some ignimbrites, but the existance of this glass, which is of some importance in Steiner's theory of emplacement of the ignimbrites, is doubted by other workers on the rocks, (R. Martin, pers. comm.). The relevant properties of chlorophaeite are its colour, green; refractive index, $1.50-1.60$; and a tendency to go black rather quickly on exposure to air (Campbell \& Iunn, 1925), (Deer, Howie \& Zussman, 1962). Its tendency to oxidize could well mean that different techniques used in making slides for the petrological examination could lead to differences in opinion as to its presence.

The origin of the observed changes in susceptibility will require further, possibly extensive, investigation. Until this is done it will be impossible to decide whether the apparently low intensity of the N.R.M. compared to the T.R.M. is due to inherent properties of the rock, or changes in intensity of the earth's magnetic field. 
T A B I E 11.2

\begin{tabular}{|c|c|c|c|c|c|}
\hline & Altitude & Sample & $\frac{\mathrm{M}_{\mathrm{NRM}}}{\mathrm{N}_{300}}$ & $\underline{\mathrm{M}}_{\mathrm{NRM}}$ & $\frac{\mathrm{M}_{\mathrm{TRM}}}{\mathrm{M}_{\mathrm{NRM}}}$ \\
\hline \multirow{3}{*}{ Sheet 1} & \multirow{3}{*}{$\begin{array}{r}400 \\
-360\end{array}$} & 43,44 & $1.7,1.4$ & $1.3,1.9$ & $7.5,4.6$ \\
\hline & & 41,42 & $1.7,1.5$ & $1.4,1.5$ & $6.3,6.9$ \\
\hline & & 103,104 & $1.7,1.9$ & $1.5,1.5$ & $7.5,6.1$ \\
\hline \multirow{4}{*}{ Sheet 2} & \multirow{4}{*}{$\begin{array}{r}360 \\
-330\end{array}$} & 39,40 & $1.2,1.2$ & $4.2,3.1$ & $4.4,4.4$ \\
\hline & & 101,102 & $1.2,1.2$ & $3.0,2.2$ & $3.1,3.7$ \\
\hline & & 99,100 & $1.2,1.2$ & $3.3,3.6$ & $3.2,3.3$ \\
\hline & & 97,98 & $1.2,1.2$ & $3.1,3.1$ & $4.3,2.9$ \\
\hline \multirow{10}{*}{ Sheet 3} & \multirow{10}{*}{$\begin{array}{r}330 \\
-\quad 250\end{array}$} & 35,36 & $1.1,1,1$ & $5.3,4.9$ & $3.0,3.8$ \\
\hline & & 45,46 & $1.0,1.0$ & $13.2,11.5$ & $3.9,3.8$ \\
\hline & & 95,96 & $1.0,1.0$ & $3.4,3.0$ & $2.8,4.2$ \\
\hline & & 93,94 & $1.1,1.2$ & $4.4,4.0$ & $3.5,3.8$ \\
\hline & & 91,92 & $1.1,1.1$ & $6.4,6.1$ & $3.1,3.0$ \\
\hline & & 37,38 & $1.1,1.1$ & $5.9,4.6$ & $3.4,3.3$ \\
\hline & & 89,90 & $1.1,1.1$ & $5.0,6.0$ & $3.0,3.1$ \\
\hline & & 87,88 & $1.1,1.1$ & $5.5,5.3$ & $3.2,3.6$ \\
\hline & & 47,48 & $1.0,1.1$ & $12.0,12.5$ & $4.0,3.3$ \\
\hline & & 49,50 & $1.0,1.0$ & $7.5,6.8$ & $6.8,4.5$ \\
\hline \multirow{3}{*}{ Sheet 4} & \multirow{3}{*}{-220} & 51,52 & $1.4,1.2$ & $2.5,3.9$ & $5.5,5.0$ \\
\hline & & 55,56 & $1.2,1.4$ & $3.3,2.5$ & $2.5,6.6$ \\
\hline & & 53,54 & $2.1,1.3$ & $0.7,1.2$ & $5.1,4.4$ \\
\hline
\end{tabular}


APPENDIX I

MAGNETOMETER CORRECTION FACTORS FOR CYLINDRICAL SAMPIES

The field of a cylinder magnetized perpendicular to its axis differs from that of a dipole by a factor

$$
F_{X}=\frac{1}{2 u v^{2}}\left[\frac{1+u}{\left((1+u)^{2}+v^{2}\right)^{\frac{1}{2}}}-\frac{1-u}{\left((1-u)^{2}+v^{2}\right)^{\frac{1}{2}}}\right]
$$

for points close to the axis.

When the magnetization is parallel to the axis, and the point is distant $x$ from the axis, the factor is

$$
F_{z}=\frac{1}{6 u}\left[\frac{1}{\left((1-u)^{2}+v^{2}\right)^{3 / 2}}+\frac{1}{\left((1+u)^{2}+v^{2}\right)^{3 / 2}}\right]
$$

where

$$
u=\frac{h}{2 z} \text {, and } v=\frac{\mathrm{a}}{\mathrm{z}} \text {. }
$$

These two factors are functions of $\frac{h}{a}$ and $\frac{z}{a}$ and so can easily be tabulated for any cylinder and specimen distance.

To get the 1\% accuracy required of the tabulated points, graphs were drawn from the values tabulated by Blackett (1952). It was decided from these to use values of $\mathrm{h} / \mathrm{a}$ ranging from 0.6 to 2.1 in 0.1 increments, and also the values for $\mathrm{h} / \mathrm{a}=0.1$ and 0.4 .

The values of $\mathrm{z} / \mathrm{a}$ started at 2.00 , increased by 0.05 increments till $z / a=3.00$, by 0.10 increments till $\mathrm{z} / \mathrm{a}=5.00$, by 0.20 up to 7.00 , and then by 0.5 steps up to $z / a=10$. These values resulted in differences between successive points on the table of about $1 \%$ in most cases, and $2 \%$ in a few.

The calculation was performed on an I.B.M. 1620 computor at Canterbury University, using a FORTRAN programme written by the author. The printed output of the computor was arranged so that 
by a small amount of cutting and pasting, the tables could be prepared for direct copying by Xerox and Multilith processes. The programme is shown in Fig. I.1.

When allowance is made for the upper magnet, the simple dipole formulae must be multiplied by

$$
G_{X}=F_{X_{1}}\left(1-\frac{F_{X_{2}}}{F_{X_{1}}}\left(\frac{z_{1}}{z_{2}}\right)^{3}\right)
$$

$$
\text { and } G_{z_{2}}=F_{z_{1}}\left(1-\frac{F_{z_{2}}}{F_{z_{1}}}\left(\frac{z_{1}}{z_{2}}\right)^{4}\right)
$$

where $z_{1}$ and $z_{2}$ are distances to the lower and upper magnets. Since $z_{2}=z_{1}+2.51$, the functions cannot be written as functions of $\mathrm{z} / \mathrm{a}$ and $\mathrm{h} / \mathrm{a}$, so the tabulation was performed for $a=1.75 \mathrm{~cm}$. The effects of changes in a are greatest for the factors $F_{X_{1}}$ or $F_{z_{1}}$, and the ratios $F_{z_{1}} / F_{z_{2}}$ and $F_{x_{1}} / F_{X_{2}}$ are little affected, so that multiplication of $G_{x}$ by $\frac{F_{X}\left(a, h, z_{1}\right)}{F_{X}\left(1.75, h, z_{1}\right)}$ will correct for changes in $a$, and similarly for $\mathrm{G}_{\mathrm{z}}$. The functions $G_{X}$ and $G_{Z}$ were tabulated for $h$ increasing from 0.20 to 4.00 by 0.20 increments, and for $\mathrm{z}$ increasing from 3,00 to 20.07 by $2 \%$ increments, and many copies made by multilith. The programme is shown in Fig. I.2.

The results are shown as Tables I.1 and I.2. 
FIG. I.1

C $Z$ FIELD OF CYIINDER

DIMENSION Y(11)

$Z=2.00$

$4 I=0.0$

$\mathrm{V}=1.0 / \mathrm{z}$

$W=1.4$

$3 \mathrm{U}=\mathrm{V}^{*} \mathrm{~W} / 2.0$

$\mathrm{URED}=1.0-\mathrm{U}$

UINC $=1.0+U$

ROOT $1=\operatorname{SQRT}\left(\mathrm{URED}^{* *} 2+\mathrm{V}^{* *} 2\right)$

ROOT2 $=\operatorname{SQRT}\left(\right.$ UINC $\left.^{* *} 2+V^{* *} 2\right)$

$I=I+1$

$5 Y(I)=1.0 /(6 . U) *\left(1.0 / R_{0 O T} * * 3-1.0 / R O O T 2 * * 3\right)$

GO TO $(11,12,13,14,15,16,17,18,19,20,6)$, I

$11 \mathrm{~W}=1.6$

GO TO 3

$12 \mathrm{~W}=1.7$

(up to $W=2.1$ )

21 FORMAT(F7.2, F7.3, 10F6.3)

6 PRINT21Z, Y(1), Y(2),Y(3),Y(4),Y(5),Y(6),Y(7),Y(8),Y(9),Y(10),Y(11) $\operatorname{IF}(\mathrm{z}-3.0) 25,22,22$

$22 \operatorname{IF}(z-5.0) 37,23,23$

$23 \operatorname{IF}(Z-7.0) 38,24,24$

$24 \operatorname{IF}(z-10.0) 39,40,40$

$25 \mathrm{Z}=\mathrm{Z}+0.05$

GO TO 4

$37 \mathrm{Z}=\mathrm{Z}+0.10$

GO TO 4

$38 \mathrm{Z}=\mathrm{Z}+0.20$

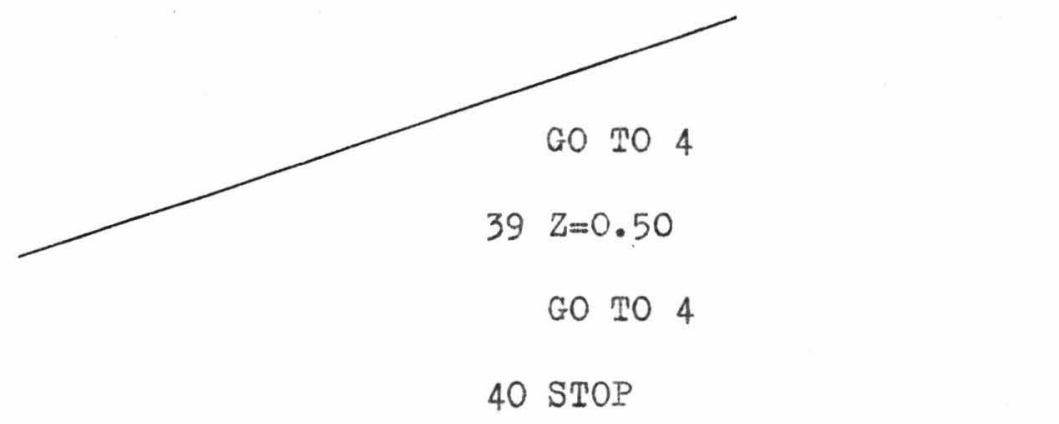

END 


\section{FIG. I.2}

\section{$\mathrm{DO} 22 \mathrm{M}=1,2$}

C VUW MAGNETONETER CORRECTION FACTOR - HORIZONTAL CONPONENT DIMENSION $X(2), G(10)$

5 FORMAT (F7.2, F7.3, 10F6.3)

DO21I $=1,2$

$\mathrm{Z}=3.00$

$\mathrm{DO} 2 \mathrm{~K}=1,200$

IF $(M-2) 31,32,32$

$31 \mathrm{H}=0.20$

GO TO 33

$32 \mathrm{H}=2.20$

$33 \mathrm{D} 031=1,10$

$\mathrm{D} 04 \mathrm{~J}=1,2$

$\mathrm{V}=1.75 / \mathrm{z}$

$\mathrm{U}=\mathrm{H} /(2 . * \mathrm{Z})$

$\operatorname{IF}(\mathrm{I}-2) 11,12,12$

$11 \mathrm{~W}=1 .+\mathrm{U}$

$X(J)=1 \cdot /(2 \cdot * U * V * V) *\left((W) / S Q R(W * V+V * V)-(1,-U) / S Q R\left((1,-U) * * 2+V^{*} V\right)\right)$

GO 204

$12 X(J)=1 . /(6 . * U) *(1 . /((1 .-U) * * 2+V * V) * * 1.5-1 . /((1 .+U) * * 2+V * V) * * 1.5)$

$4 \mathrm{Z}=\mathrm{Z}+2.50$

$z=Z-5.00$

IF(I-2) $13,14,14$

$13 G(1)=X(1) *(1 .-X(2) / X(1) *(z /(z+2.50)) * * 3)$

GO TO 3

$14 G(1)=X(1) *(1 .-X(2) / X(1) *(z /(Z+2.50)) * * 4)$

$3 \mathrm{H}=\mathrm{H}+0.2$

PRINP5 $, Z, G(1), G(2), G(3), G(4), G(5), G(6), G(7), G(8), G(9), G(10)$ $\operatorname{IF}(z-20.0) 2,6,6$

$2 \mathrm{z}=1.02^{*} \mathrm{z}$ 
6 PRINT1

1 FORMAT $(/ / / / / / / / /)$

C VUW MAGNETONETER CORRECTION FACTOR - VERTICAI COMPONENT 21 CONTINUE

22 CONTINUE STOP

END 


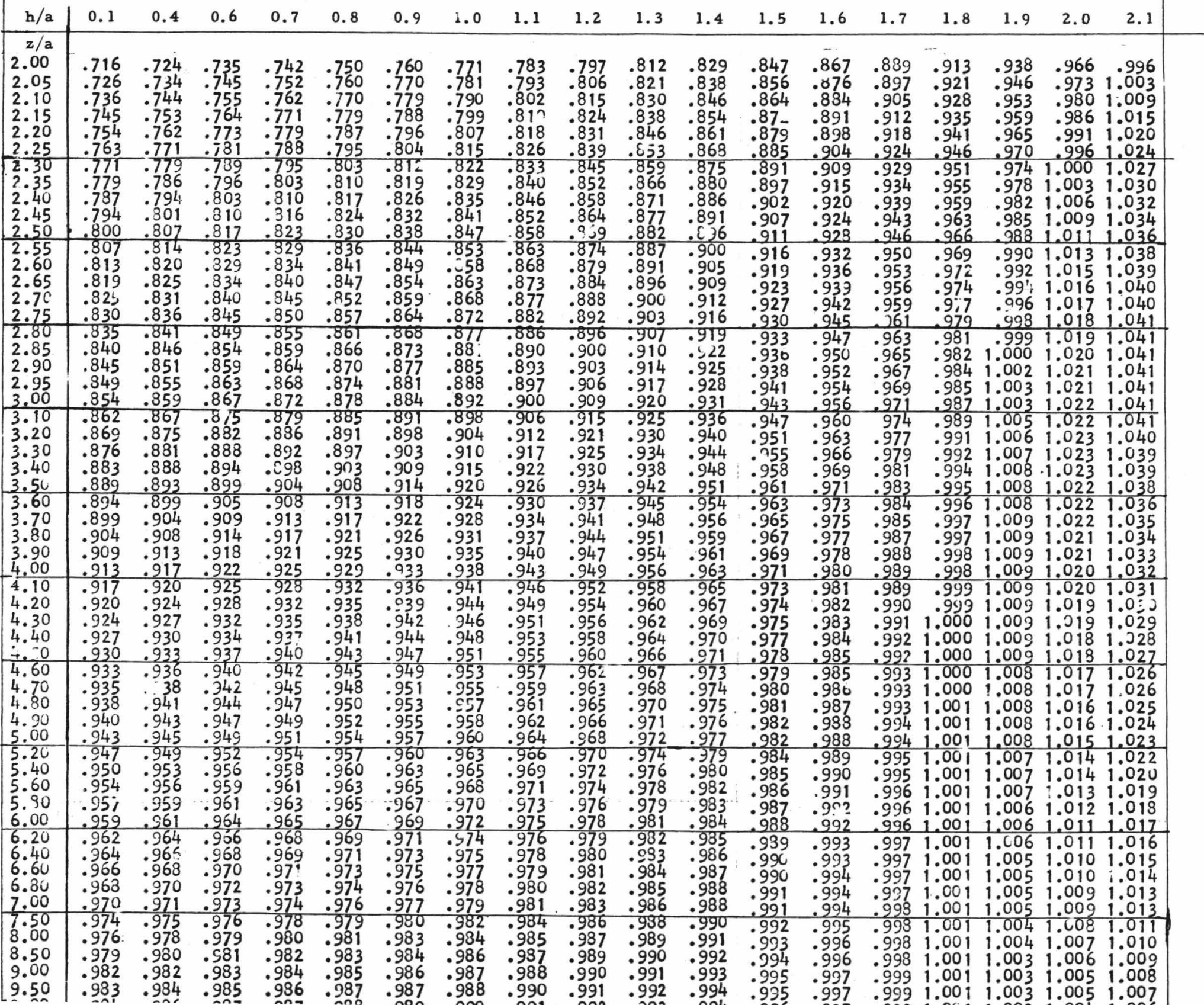




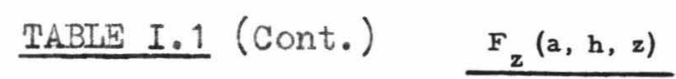

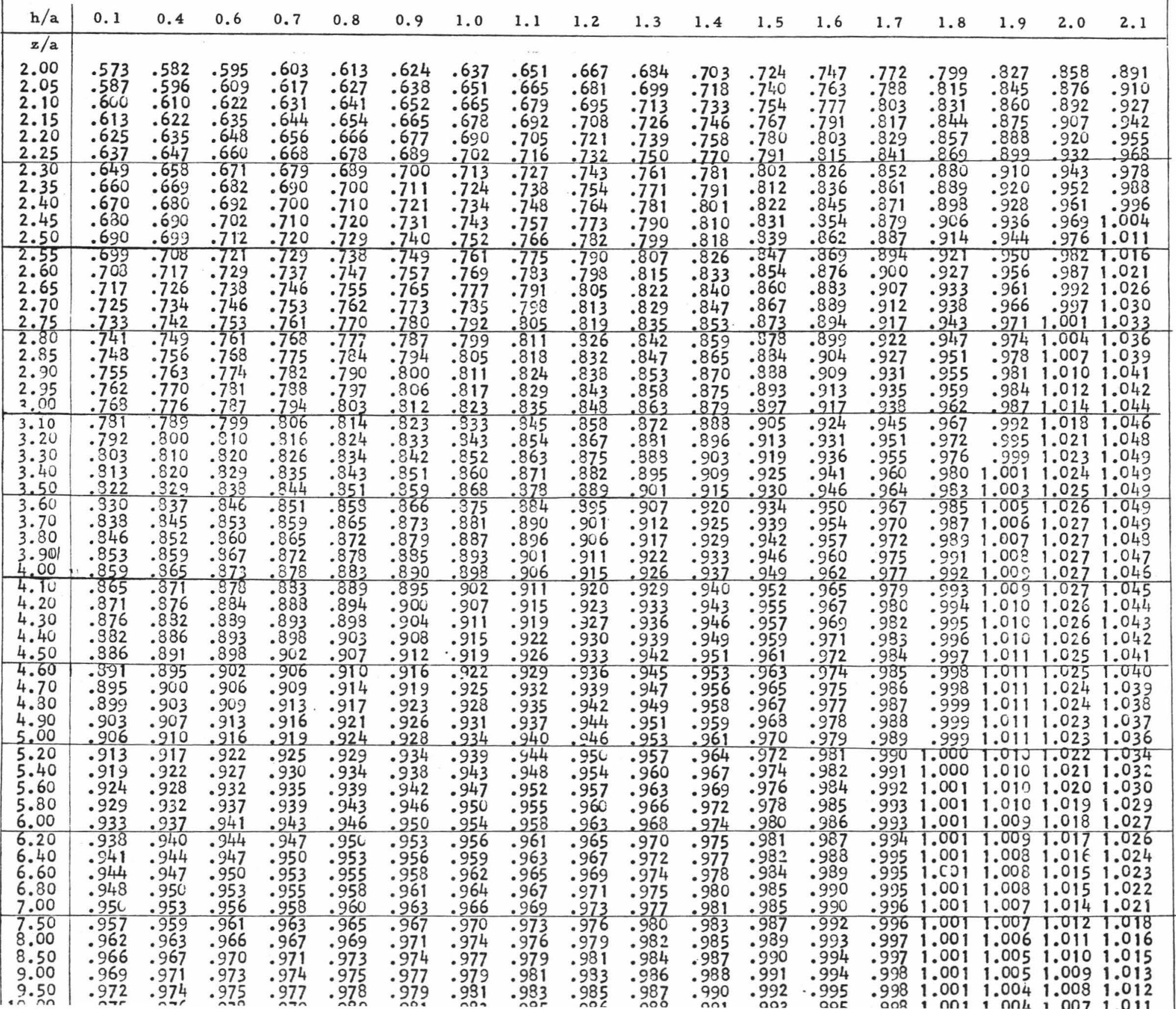




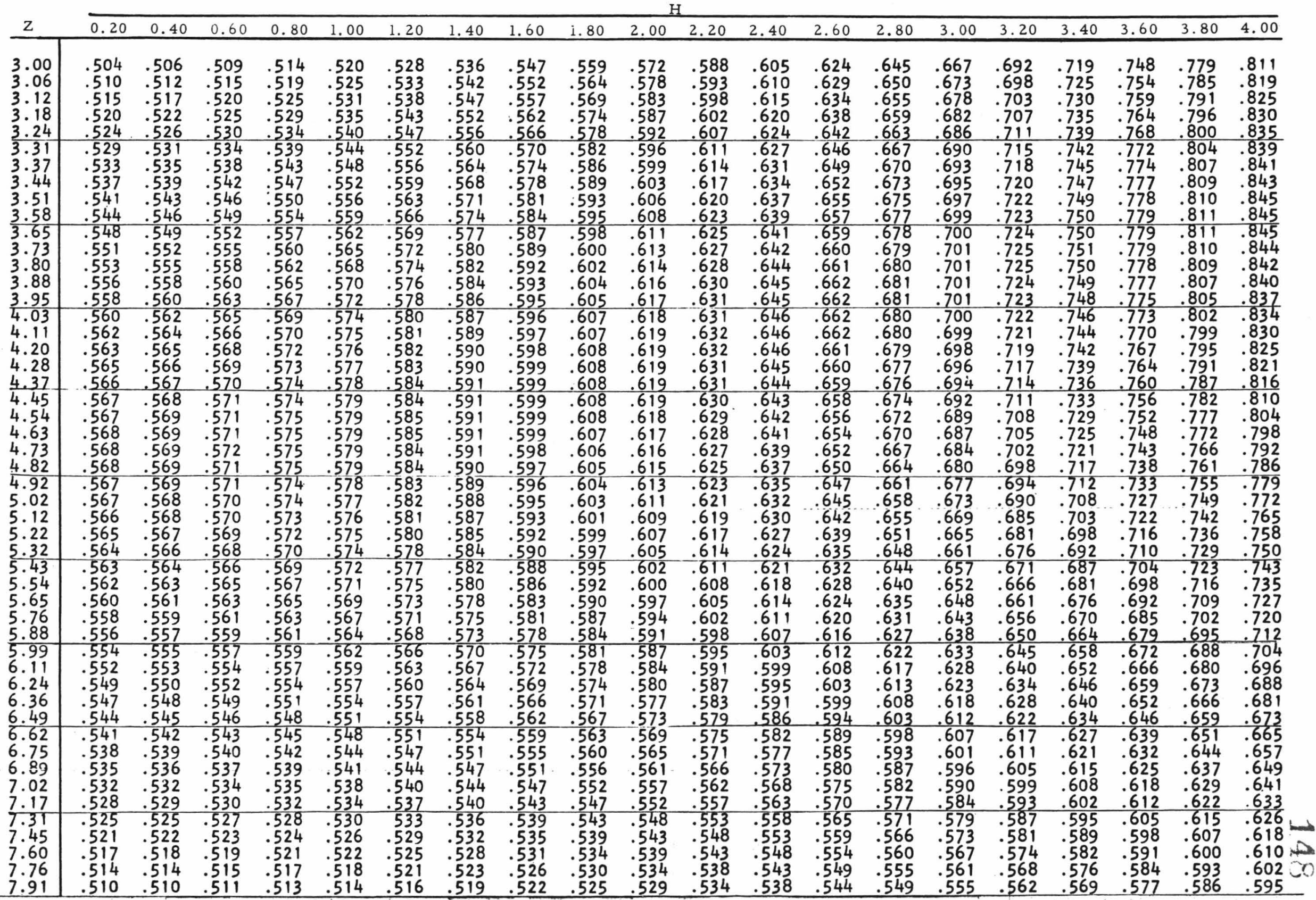


TABLE I.2 (Cont.) V.U.W. MAGNETOMETER CORRECTION FACTOR - HORIZONTAL COMPONENTS (G $\mathbf{x}^{\text {) }}$

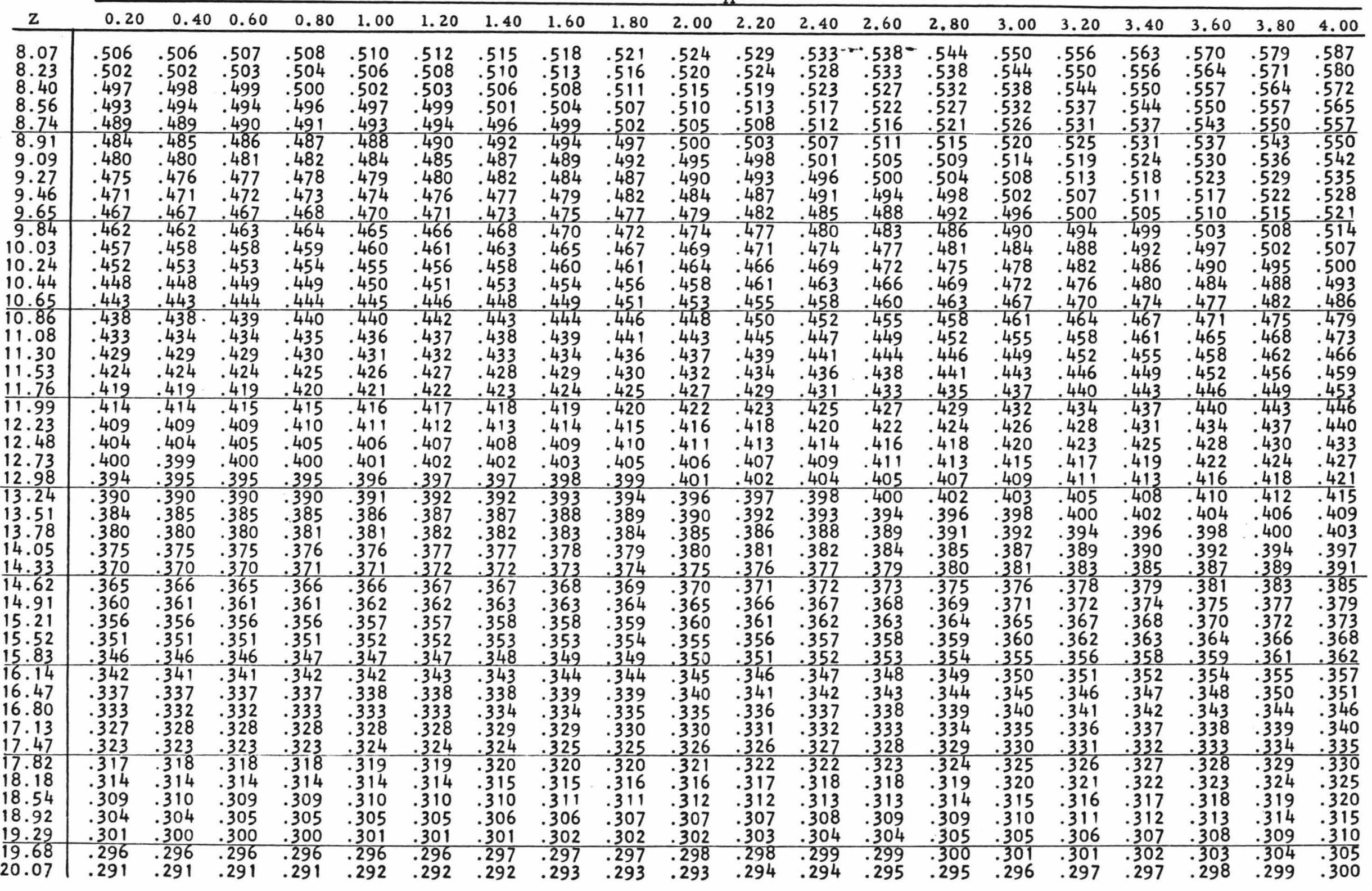


TABIE I.2 (Cont) V.U.W. MAGNETOMETER CORRECTION FACTOR - VERTICAL COMPONENTS (G $\mathbf{z}^{\text {) }}$

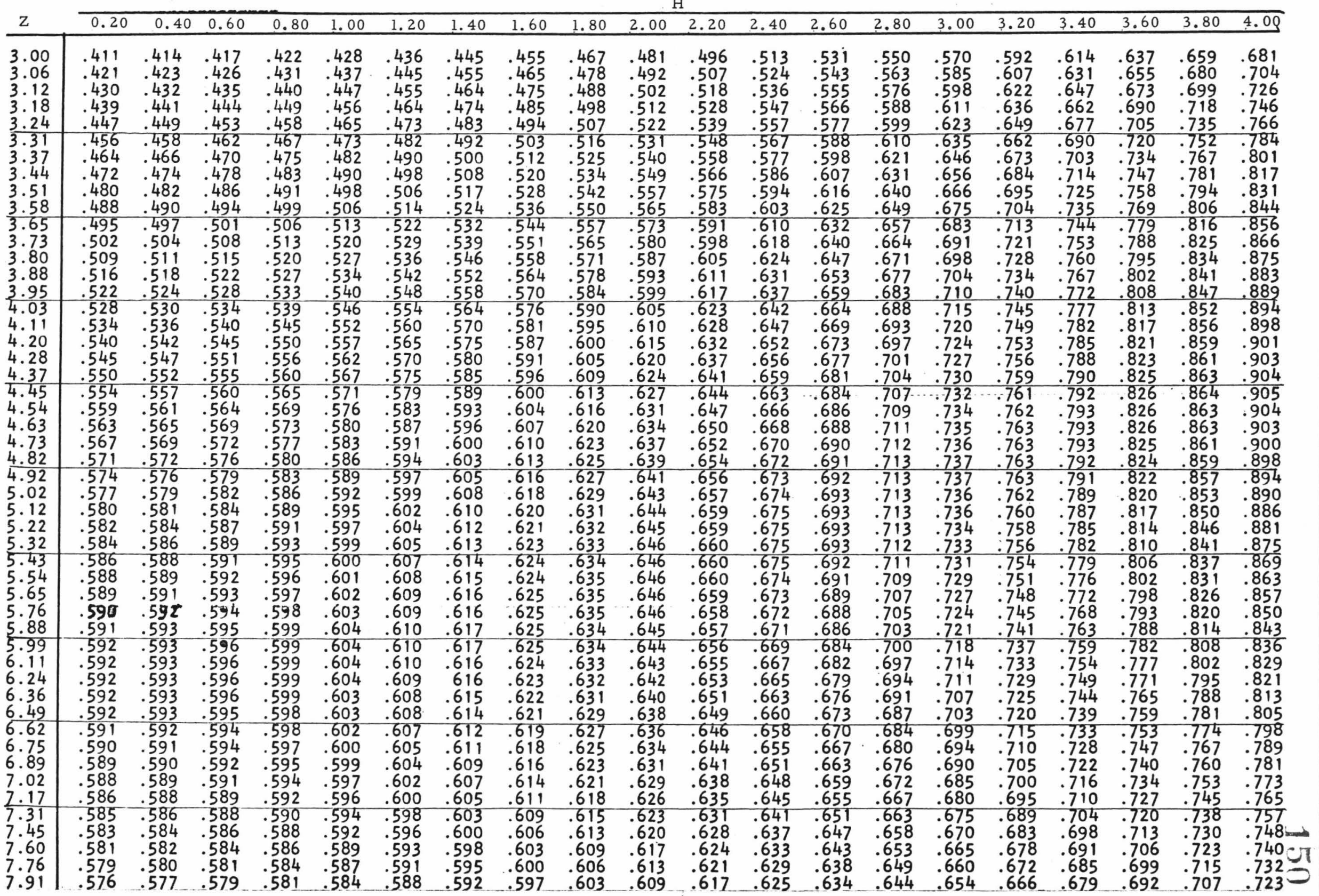


TABIE I.2 (Cont.) V.U.W. MAGNETOMETER CORRECTION FACTOR - VERTICAL COMPONENTS (G

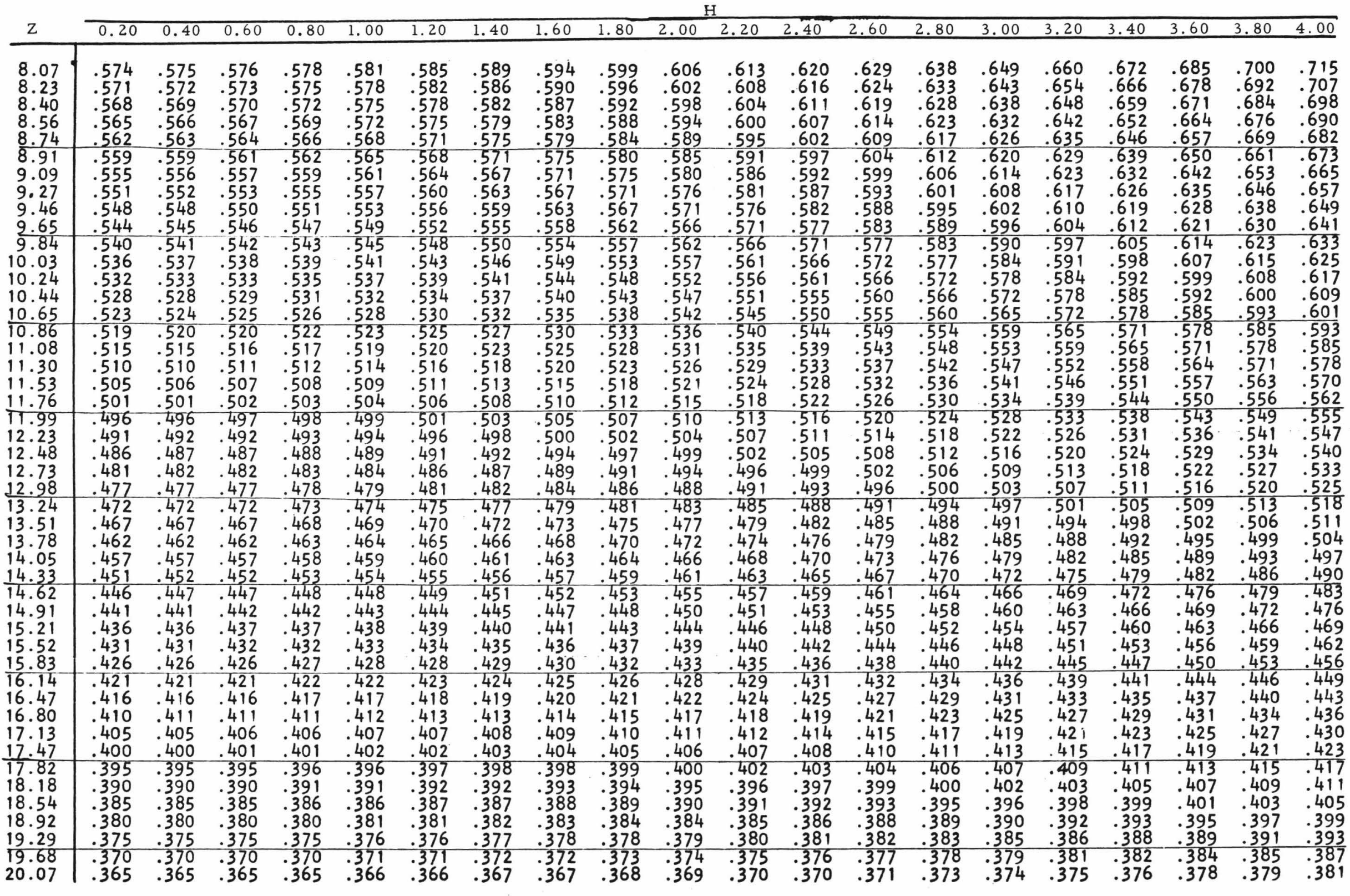




\section{CALCUIATION OF SANPLE MAGNETIZATION}

The laboratory system of coordinates has its $\mathrm{y}$ axis along the direction of the light path from the mirror to the scale at zero deflection, $\mathrm{z}$ axis vertically upwards, and the $\mathrm{x}$ axis for a right handed system.

The specimen coordinates are $X, Y, Z$. For cylindrical specimens the $\mathrm{X}$ axis is parallel to the orientation line on one end, in the direction of the arrow, while the $Z$ axis is parallel to the axis, and outwards from that face containing the $x$ axis (the "top" face).

The magnetometer is affected only by fields parallel to the $x$ axis, so that measurements are taken with the $\mathrm{X}$ and $\mathrm{Y}$ axes in the $\pm x$ direction, and with an $x$ offset, in order to measure all components. A full set of measurements involves starting with the specimen upright and the arrow to the East, measuring the deflection, rotating $90^{\circ}$ and measuring, rotating another $90^{\circ}$ and so on up to $270^{\circ}$, having for all these measurements the $Z$ axis offset to the East of the $z$ axis. The specimen is then inverted and the set repeated. After rotating the sample holder, to give the same offset, but to the West, the complete set of measurements is repeated. By taking sums and differences as show on the measurement sheets, numbers $X, Y, Z_{m}$ and $Z_{\boldsymbol{X}}$ are obtained, which are respectively:

8 times the deflection due to the $X$ component (four measurements of twice the deflection)

8 times the deflection due to the $Y$ component 
16 times the deflection due to the $Z$ component.

16 times the deflection due to the induced magnetization in the $\mathrm{z}$ direction.

The measurement of susceptibility needs some coment. If a field is applied in the $\mathrm{Z}$ direction, the magnetization in this direction will be the component of remanent magnetization plus the induced magnetization. On inverting the specimen, the direction of the remanent magnetization changes sign, while that induced remains the same. However, there is a possibility of miscentring errors giving rise to a non-zero sum on adding the upright and inverted readings, when there is no induced component. Such effects were found to be small, but sufficient to give about $\pm 10 \%$ error in susceptibility measurements. The presence of the field does not appear to affect angle or intensity measurements when the field is about 1 oe.

The field of a cylinder at the distances used is approximately that of a dipole, but a comparison with the values corresponding to a uniformly magnetized cylinder, calculated by Papapetrou (Blackett, 1952), suggested that a more exact expression is needed. Papapetrou's correction factor $F_{X}$ and $F_{z}$ for the $x$ and $z$ components of magnetization has been tabulated by the author (see Appendix I)

Let $X_{1}, z_{1}, X_{2}, z_{2}$ be the horizontal fields at the lower and upper magnets due to the horizontal and vertical components of magnetization of the specimen.

$$
\begin{array}{ll}
\mathrm{x}_{1}=\frac{\mathrm{m}_{\mathrm{x}} \mathrm{V}}{\mathrm{z}_{1}{ }^{3}} \mathrm{~F}_{\mathrm{x}_{1}} & \mathrm{z}_{1}=\frac{3 \mathrm{~m}_{\mathrm{z}} \mathrm{V}_{\mathrm{x}}}{\mathrm{z}_{1}{ }^{4}} \mathrm{~F}_{\mathrm{z}_{1}} \\
\mathrm{X}_{2}=\frac{\mathrm{m}_{\mathrm{x}} \mathrm{V}}{\mathrm{z}_{2}{ }^{3}} \mathrm{~F}_{\mathrm{x}_{2}} & \mathrm{z}_{2}=\frac{3 \mathrm{~m}_{\mathrm{z}} \mathrm{V}_{\mathrm{x}}}{\mathrm{z}_{2}{ }^{4}} \mathrm{~F}_{\mathrm{z}_{2}}
\end{array}
$$

where $z_{1}$ and $z_{2}$ are the distances to the lower and upper magnet 
respectively (see Fig. II.1), $\mathrm{m}_{\mathrm{X}}$ and $\mathrm{m}_{\mathrm{Z}}$ are the volume intensities of magnetization of the specimen, and $V$ is its volume.

Then

$$
\begin{aligned}
& x_{1}-x_{2}=\frac{m_{x} V F_{x_{1}}}{z_{1}{ }^{3}}\left(1-\frac{F_{x_{2}}}{F_{x_{1}}}\left(\frac{z_{1}}{z_{2}}\right)^{3}\right) \\
& z_{1}-z_{2}=\frac{3 m_{z_{2}}{ }^{V V F} z_{1}}{z_{1}{ }^{4}}\left(1-\frac{F_{z_{2}}}{F_{z_{1}}}\left(\frac{z_{1}}{z_{2}}\right)^{4}\right)
\end{aligned}
$$

For convenience,

$$
\begin{aligned}
& G_{\mathrm{X}}=F_{\mathrm{x}_{1}}\left(1-\frac{\mathrm{F}_{\mathrm{x}_{2}}}{\mathrm{~F}_{\mathrm{x}_{1}}}\left(\frac{\mathrm{z}_{1}}{\mathrm{z}_{2}}\right)^{3}\right) \\
& G_{\mathrm{z}}=F_{\mathrm{z}_{1}}\left(1-\frac{\mathrm{F}_{\mathrm{z}_{2}}}{\mathrm{~F}_{\mathrm{z}_{1}}}\left(\frac{\mathrm{z}_{1}}{\mathrm{z}_{2}}\right)^{4}\right)
\end{aligned}
$$

have been tabulated for the present magnetometer. The values given are accurate only for $2 a$ near $3.5 \mathrm{~cm}$, but for other diameters a good approximation to the true value is

$$
\begin{array}{ll}
\text { and } & G_{X} \frac{F_{X}\left(a, z_{1}, h\right)}{F_{X}\left(1.75, z_{1}, h\right)} \\
\text { so } & G_{z} \frac{F_{z}\left(a, z_{1}, h\right)}{F_{z}\left(1.75, z_{1}, h\right)} \\
& x_{1}-X_{2}=\frac{m_{x} V G_{X}}{z_{1}^{3}} \\
& z_{1}-z_{2}=\frac{3 m_{z} V x G_{z}}{z_{1}^{4}}
\end{array}
$$

Any difference in field, $\delta \mathrm{H}$, between the two magnets is measured in terms of the deflection, $N \mathrm{~mm}$, of the light spot, which it produces.

The sensitivity, $\sigma$ oe/mm, is defined from $\delta \mathrm{H}=\sigma \mathrm{N}$.

For the $X$ component of magnetization, $N=\frac{X}{8}$

For the $Z$ component of magnetization, $N=\frac{z_{m}}{16}$

$\sigma$ is determined for each measurement by measuring the deflection, $\mathrm{n} \mathrm{mm}$, produced by reversing a current, i $\mathrm{mA}$, in the calibration coil, which produces a field difference of $\mathrm{S}$ oe/mA between the 
magnets. $S$ is calculated from the dimensions of the coil.

$$
\text { so } \quad \begin{aligned}
\sigma & =\frac{2 S i}{n} \\
M_{X} & =\frac{\mathrm{Xz}_{1}{ }^{3} \mathrm{Si}}{4 n V G_{\mathrm{X}}} \\
\mathrm{M}_{\mathrm{z}} & =\frac{\mathrm{Zmz}_{1}{ }^{4} \mathrm{Si}}{24 \mathrm{xG} \mathrm{G}_{\mathrm{Z}} \mathrm{nV}}
\end{aligned} \quad \mathrm{M}_{\mathrm{y}}=\frac{\mathrm{Yz}_{1}{ }^{3} \mathrm{Si}}{4 \mathrm{nVG} \mathrm{G}_{\mathrm{X}}}
$$

The directions of magnetization are as shown in the diagram. $\tan \theta=\frac{\left|\frac{m_{y}}{\mid m_{x}}\right|}{\mid}=\frac{\mid \underline{Y}}{\mid \bar{X}_{1}}$

$\tan \phi=\frac{\left(m_{y}^{2}+m_{x}^{2}\right)^{\frac{1}{2}}}{\left|m_{z}\right|}$

$$
\begin{aligned}
& =\frac{6 x}{z_{1}} \frac{G_{Z}}{G_{X}} \frac{\left(Y^{2}+X^{2}\right)^{\frac{3}{2}}}{|Z|} \\
& =\frac{6 x G_{Z}}{z_{1} G_{X}} \frac{|Y|}{|Z| \sin \theta}
\end{aligned}
$$

Let

$$
\begin{aligned}
& p=\frac{|Y|}{G_{x} \sin \theta} \\
& q=\frac{\mid Z / z_{1}}{6 x G_{z}}
\end{aligned}
$$

so $\quad \tan \phi=\frac{p}{q}$

The required quantities are the angles

$$
\Theta=\operatorname{Tan}^{-1} \frac{m_{y}}{m_{x}} \quad \Phi=\operatorname{Tan}^{-1} \frac{\left(m_{x}^{2}+m_{y}{ }^{2}\right)^{\frac{1}{2}}}{m_{z}}
$$

The relation between $\Theta, \Phi, \theta$ and $\phi$ is

$$
\begin{array}{cccc}
X>0 & X>0 & X<0 & X<0 \\
Y>0 & Y<0 & Y<0 & Y>0 \\
\Theta=\theta & 360-\theta & 180+\theta & 180-\theta \\
\Phi=\phi \text { if } Z>0 & & \Phi=180-\phi \text { if } Z<0
\end{array}
$$


The intensity of magnetization, $M$, is

$$
\begin{aligned}
M & =\left(m_{x}^{2}+m_{y}^{2}+m_{z}^{2}\right)^{\frac{1}{2}} \\
& =\frac{\operatorname{siz}_{1}{ }^{2}}{4 n V}\left(p^{2}+q^{2}\right)^{\frac{1}{2}}
\end{aligned}
$$

If the value of $\theta<15^{\circ}$, the expression

$$
\mathrm{p}=\frac{\mathrm{y}}{\mathrm{G}_{\mathrm{x}} \sin \theta}
$$

is not sufficiently accurate to use when calculating $\phi$ and $\mathbb{M}$. Instead, the expression

$$
p=\frac{X}{G_{x} \cos \theta}
$$

should be used.

Measurement of Susceptibility

The vertical field $\mathrm{H}_{a p p}$, induces a vertical magnetization proportional to $2 x$

$$
\chi=\frac{\mathrm{Si}}{4 n \nabla} \times \frac{z_{1}^{4} z_{x}}{6 \times \mathrm{G}_{\mathrm{z}} \mathrm{H}_{\mathrm{app}}}
$$

The earth's field at Moore's Valley is 0.53200 , so if the vertical. cancellation current is reversed, $\mathrm{H}_{\text {app }}=1.0640 \mathrm{e}$.

\section{Definitions of Distances (Refer Fig. II.1)}

$z_{1}$ and $z_{2}$ are measured from the centre of the specimen.

$\mathrm{h}$ is the height of the specimen,

d is the diameter of the specimen,

$a=\frac{1}{2} d$ is the radius of the specimen,

b is the "datum", which is the distance from the bottom magnet to the bottom of the sample in its lowest position.

$c$ is the elevation of the sample, and is the length of the perspex rods inserted in the sample holder. In the lowest position $c=0$.

$$
z_{1}=b-c-\frac{1}{2} h \quad z_{2}=z+2.5 \text {. }
$$




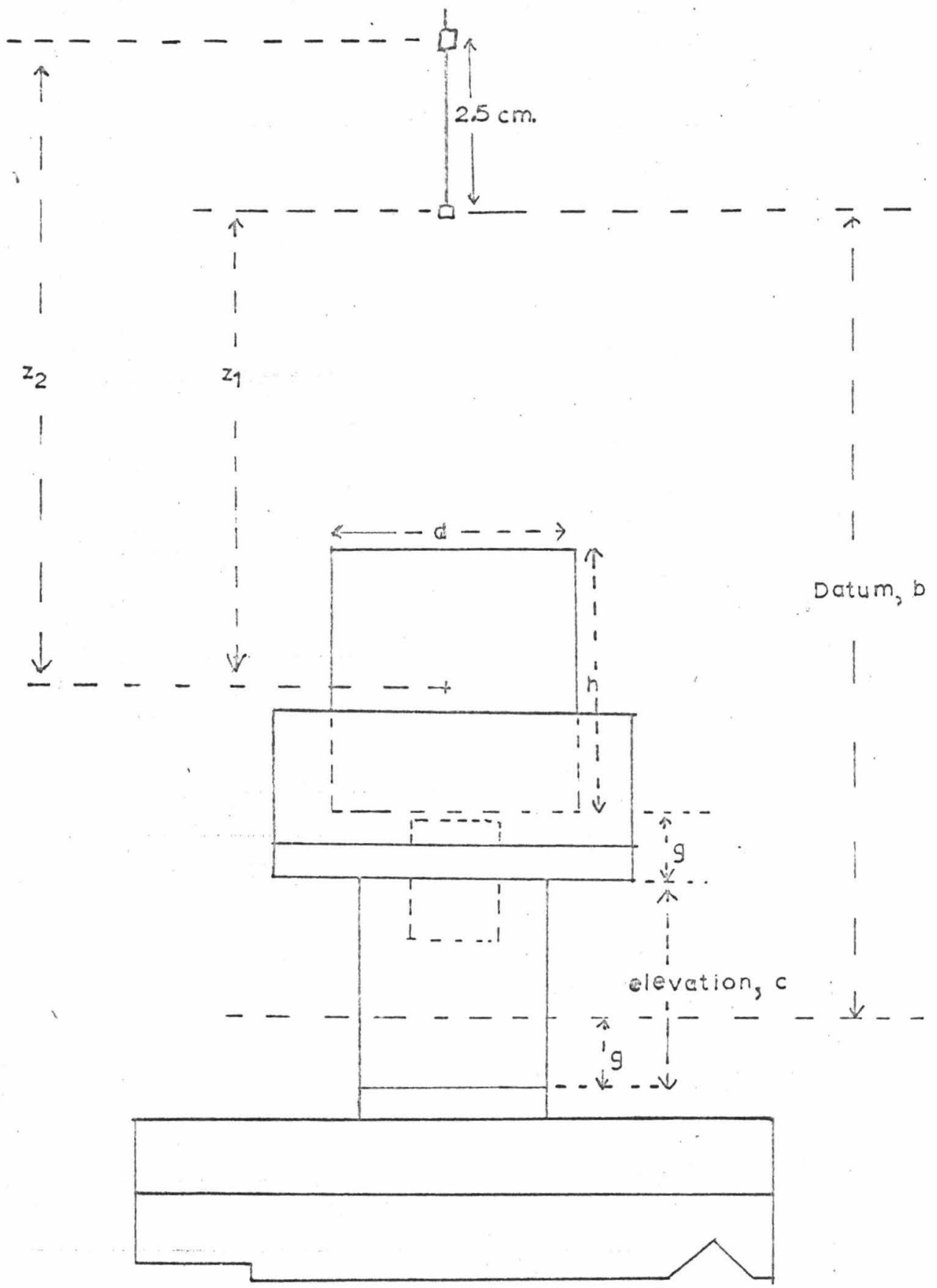

FIG. I.1 
It is assumed that the direction of magnetization of the specimen in its own coordinate system has been measured, with the angles $\theta$ and $\phi$ defined as shown in Fig. III.1.

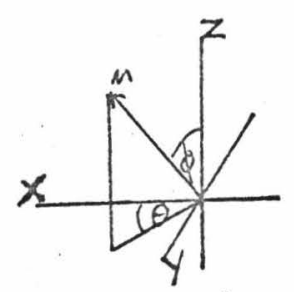

Fig III.1

The geographic coordinate system has axes $N, E$, and $V$, representing north, east and vertical directions. The relation between the two coordinate systems is shown in Fig. III.2. The $\mathrm{X}$ axis was originally horizontal, i.e., in the $\mathrm{N}-\mathrm{E}$ plane.

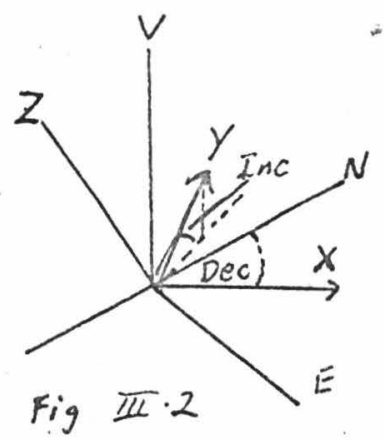

The required transformation is to rotate the specimen coordinate system about its $X$ axis until its $Y$ axis is in the $N-E$ plane, and then rotate it about its $Z$ axis, until the $X, Y$ and $Z$ axes are parallel to the $N, E$ and $V$ directions. This can conveniently be done on a stereogram, thus:

1. Make the centre and zero azimuth on the transparent paper.

2. Put a mark on the paper at the point on the edge of the stereogram, corresponding to the declination of the $\mathrm{X}$ axis, as recorded in the field book, this angle being measured clockwise. This is now used to define the sample coordinate system on the paper. 
3. Rotate the paper until the $X$ axis lies on the $0-180^{\circ}$ line of the stereogram.

4. Mark the position of the magnetization vector in sample coordinates on the paper, measuring $\theta$ anti-clockwise and $\phi$ downwards from vertical. To do this, a mark is put $\theta^{\circ}$ anti-clockwise from $X$, then the paper is rotated until this mark lies on the $90^{\circ}$ or $270^{\circ}$ mark of the stereogram. The required point is then $\phi^{\circ}$ from the centre.

5. Return the paper so the $\mathrm{X}$ direction is on the $0^{\circ}-180^{\circ} \mathrm{line}$.

6. The rotation of the magnetic vector about the $\mathrm{X}$ direction is performed by following the small circle lines the number of degrees equal to the dip of the planeas recorded in the field book, the rotation being performed in a clockwise direction, when looking in the $+\mathrm{X}$ direction (i.e., the vector goes from pointing left, to upwards, to pointing right, with the $+\mathrm{X}$ direction to the top of the paper). This sense is required because the previously horizontal X - Y plane is now being made to dip in the positive direction.

The point obtained by this rotation is the magnetization direction, since the rotation about a vertical axis was in effect performed in steps 2 and 3 .

7. The coordinates of this point are found by rotating the paper until the point lies on the $0-180^{\circ}$ axis. The dip can be read directly, off the $0-180^{\circ}$ line, and the declination is found from the position of the zero mark, reading clockwise. 
Akimoto, S., 1955

As, J.A., Zijderveld, J. D. A., 1958

Blackett, P. M. S., 1952

Brynjolfsson, A., 1957

Cave, I. D., 1961

Campbell, R., \& Iunn, J.

Chevallier, R., 1925

Cox, A. 1957

Cox, A., \& Doell, R., 1960

Creer, K. M., 1959

Deer, W. A., Howie, R. A., \&

Zussman, J., 1962

Doell, R., \& Cox, A., 1961

Everitt, C.W.F., 1961

Everitt, C.W.F., 1962

Fisher, R. A., 1953

Gellen, J. W., 1959

Graham, J., 1949

Graham, J., 1953

Grange, I. I., 1937

Haigh, G., 1958

Hatherton, T., 1954 a

Hatherton, T., 1954b

Irving, E., Robertson, W. A., Stott, P. M., Tarling, D. H., \& Ward, M. A. (Irving \& others), 1961

Irving, E., Stott, P.M., \& Ward, M. A., 1961
Jap. J. of Geophys. 1

Geophys. J. 1 308-19

Phil. Trans. A245 p. 309

Adv. Phys. 6 247-254

M.Sc. Thesis, V.U.W.

Min. Mag. (Iondon) 20 p. 435

Ann. Phys. (Ser. 10) 4 5-162

Nature $179 \quad 685-686$

Bull. Geol. Soc. Am. 71 645-768

Geophys. J. 2 p. 261

"Rock Forming Minerals" Vol. I

(Longmans, London)

Adv. in Geophys. 8 221-313

Phil. Mag. 6 713-726

Phil. Mag. 7 583-616

Proc. Royal Soc. A217 p. 295

M.Sc. Thesis, V.U.W.

J. Geophys. Res. $\underline{54}$ 131-67

J. Geophys. Res. 58 243-260

Bull. N.Z.G.S. n.s. 37

Phil. Mag. 3 p.267

J. Geophys. Res., 59 p. 223-232

N.Z.J.Sci.\& Tech., 35 421-432

J. Geophys. Res. 66 1927-1933

Phil. Mag. 6 p. 225 


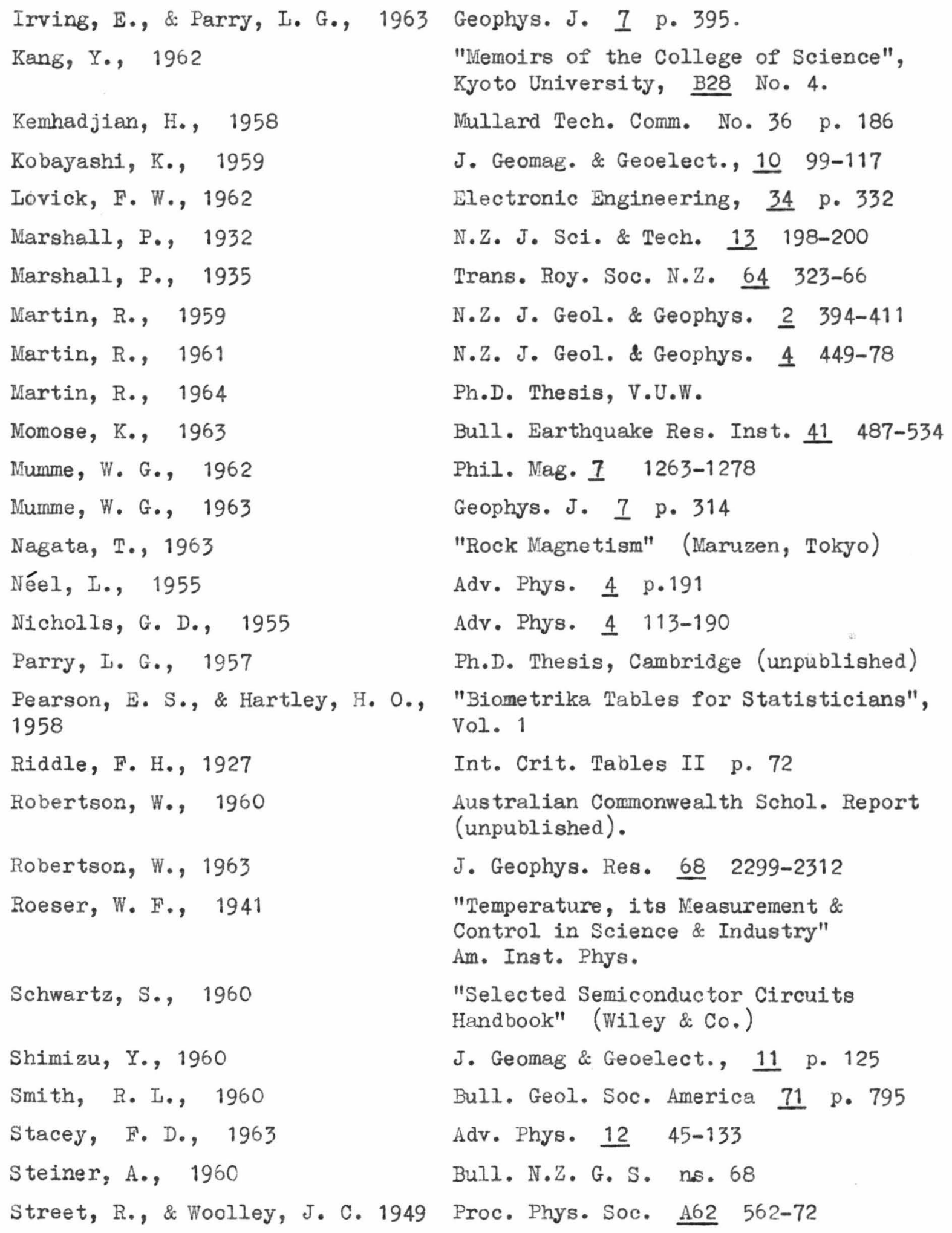


Thellier, E., \& Thellier, 0., 1959 Ann. de Geophys. 15 285-376 Thellier, E., \& Rimbert, F., 1954 Comptes Rendu 239 p. 1399 Thellier, E., \& Rimbert, F., 1955 Comptes Rendu $\underline{240}$ p. 1404 Thorpe, J. F., 1937 "Thorpe's Dictionary of Applied Chemistry" 4 th Ed.

Torreson, O. W., et al., 1949 J. Geophys. Res. 54 111-129

Walker, D. E., 1962

Electronic Engineering, 34 p. 406

Wa.tson, G. S., 1956

Roy. Ast. Soc. Geophys. Supp. 7 p. 153

Weaving, B., 1962

Proc. Phys. Soc. 80 p.1149

Wilson, R. L., 1961

Geophys. J. 5 p. 45

Wilson, R. L., $1962 a$

Geophys. J. 6 o p. 397

Wilson, R. L., 1962b

Geophys. J. 7 p. 125

van Zijl, J., Graham, K.W.T., \& Hales, 1962

Geophys. J. $I$ p. 169 
ACKNOWTEDGNENTS

The author wishes to thank sincerely the many people who assisted him in this work, in particular

Mr J.W. Gellen for many helpful discussions, and for criticism of the first draft,

Dr R. M. McFarlane, for operating the Canterbury University IBM 1620 Computor, and advice on programming,

Mr R. Cowan, for construction of the sample holder, Dr R. Martin, for advice on geological problems,

The Physics Department technical staff, for their patience and helpfulness,

Mr M. King, the University photographer,

Staff members and fellow-students for their interest and advice, and

Miss M. J. McKay, for typing the thesis. 